Portland State University

PDXScholar

Summer 8-19-2019

\title{
Avian Dispersal Networks, Metacommunity \\ Structure, and Bryophyte Community Assemblages
}

Matthew Wojciech Chmielewski

Portland State University

Follow this and additional works at: https://pdxscholar.library.pdx.edu/open_access_etds

Part of the Biology Commons

Let us know how access to this document benefits you.

\section{Recommended Citation}

Chmielewski, Matthew Wojciech, "Avian Dispersal Networks, Metacommunity Structure, and Bryophyte Community Assemblages" (2019). Dissertations and Theses. Paper 5096.

https://doi.org/10.15760/etd.6972

This Dissertation is brought to you for free and open access. It has been accepted for inclusion in Dissertations and Theses by an authorized administrator of PDXScholar. Please contact us if we can make this document more accessible: pdxscholar@pdx.edu. 
Avian Dispersal Networks, Metacommunity Structure, and Bryophyte Community Assemblages

by

Matthew Wojciech Chmielewski

A dissertation submitted in partial fulfillment of the requirements for the degree of

\author{
Doctor of Philosophy \\ in \\ Biology
}

\author{
Dissertation Committee: \\ Sarah Eppley, Chair \\ Todd Rosenstiel \\ Michael T. Murphy \\ Daniel Ballhorn \\ Catherine de Rivera
}

Portland State University

2019 
(C) 2019 Matthew Wojciech Chmielewski 


\begin{abstract}
Spatial processes have a profound influence on the structure and function of community assemblages. The dispersal of organisms from their place of origin to the location in which they live out their reproductive life is particularly important for plant communities, which generally cannot adjust their location post-germination. Connection between communities at a landscape scale can also influence species persistence, local and regional diversity, and functional turnover at the metacommunity scale. Animals have been shown to disproportionately deposit propagules in particular microsites in many plant species, facilitating the arrival of plants to appropriate niche-space. Birds are particularly notable seed dispersers, given their ability to fly long distances and their behavioral inclination toward using specific microsites within their habitat for foraging and nest building. Despite the known influence of animal behavior on plant dispersal outcomes, little work has been done to investigate the role of animals in dispersing bryophyte (moss, hornwort, liverwort) propagules. In order to examine how birds may affect bryophyte dispersal, I conducted two studies focused on understanding how bird species identity and behavior influence the bryophyte propagules they carry. In addition, I conducted a study to understand how metacommunity structure across a landscape can be influenced by focal spatial scale.
\end{abstract}

In the first study I examined how bird species and foraging behavior impact the topical load of bryophyte spores found on bird surfaces. In order to determine this, I captured passerine birds in mist nets and swabbed them for spores. I found that spores were more abundant on passerine tails than legs, and that overall spore load was higher 
on larger birds. Thrushes in particular carried more spores than other groups overall. Bark and foliage foraging birds had more spores on their tails than ground foraging birds. From these samples I was able to germinate 242 individual bryophytes, demonstrating that carried spores were readily viable.

In the second study, I examined species-specific relationships between bryophytes and the birds carrying them. Swabs from captured birds were grown in the lab and bryophyte species were determined genetically. I used a bipartite network approach to determine the level of specialization of associations within the overall network, as well as how specialized the avian associations of individual bryophyte species were. I then used the phylogenetic distance of bryophytes found on individual bird species in order to assess how specialized the assemblages on a given bird species were compared with a null, random model. I found that bryophyte associations with birds were nonrandom, and that the extent to which those associations were specialized differed by bird foraging behavior. In addition, I found that the diversity of propagules on bird surfaces was significantly nonrandom, with the exception of those bryophytes found on Spotted Towhees.

In the final study, I examined the metacommunity structure of bryophytes at both patch and landscape scales across a relict landscape of Valdivian forest in North-Central Chile. This landscape consists of distinct natural patches of forest maintained by coastal fog deposition, surrounding by a dry matrix inhospitable to patch-resident bryophytes. I used quadrats to sample bryophyte species abundance at the base and at breast height of ten trees in each patch, in 20 patches across the landscape. I found that when considering 
the whole park as one metacommunity, the bryophyte community exhibited a Gleasonian structure, in which individual species turnover was idiosyncratic. Considering assemblages from both heights separately, a Clemenstian pattern was observed, suggesting that within each height compartment, turnover of species tended to happen together. Treating each patch as a metacommunity of individual community trees resulted in a wide variety of metacommunity structures across the park that did not reflect either longitude or latitude. Low canopy cover and small DBH resulted in structures reflecting random species loss. Underlying Shannon diversity did not explain differences in the observed structures.

This dissertation provides the first evidence that passerine birds carry bryophyte propagules, and that their individual species use of habitat and foraging behaviors are likely to influence the number and diversity of the bryophytes they are dispersing. This has implications for understanding disjunct species and genetic distributions observed in bryophytes that to date have lacked an explanatory mechanism for long distance directed dispersal. In addition, understanding how avian behavior may disperse propagules at a local to regional scale may provide better insight into the trajectory of bryophyte recruitment on impacted landscapes. I also found that assignation of metacommunity structure is sensitive to spatial scale in bryophytes. Together, these findings increase our understanding of the role that spatial processes play in forming bryophyte communities. 


\section{Acknowledgements}

This body of work wouldn't have been possible without the support of a myriad of people in both my academic and personal life. First and foremost, I would like to thank my mother for all of her support over the years, and for her constant enthusiasm for promoting my education. I'd also like to thank my maternal grandparents for taking a risk and moving to a foreign land with their children in tow in order to pursue an existence with greater possibilities for their family.

I would like to thank my advisor Sarah Eppley for the support, advice, and opportunity she has provided. Her editing, statistical, and presentation advice has all contributed to marked improvements in my work, and her assistance in navigating the publication and funding arms of academic life have provided me with the skills necessary to function fully as an independent academic. Of equal importance, she allowed me to take risks in developing my own work that other advisors would not have had the patience for, and it has made my development as a scientist that much richer. Todd Rosenstiel has provided much advice regarding developing and promoting the ideas within this work, and has consistently demonstrated an infectious enthusiasm for the scientific process that helped when motivation was flagging. Michael Murphy's expert knowledge of all things avian helped me take on a project bridging two traditionally separate areas of ecology, and his willingness to support my permitting made this work possible. Both Daniel Ballhorn and Catherine de Rivera provided critical advice and challenged me throughout the development of this work. Their input helped shape this dissertation from a variety of potential ideas into the final product before you. 
I'm grateful for the many years of teaching assistantships that the Portland State University Department of Biology provided to support my degree. I also thank the Fulbright U.S. Student Program for the opportunity to work internationally in Chile, and for the assistance that Javi Malebrán Muñoz, Natalia Jordan, Javier Alejandro, Simon Castillo, Jaime Jimenez, and Ricardo Rozzi provided for navigating the scientific community within their country. I also thank the National Science Foundation's Doctoral Dissertation Improvement Grant program for funding the latter end of my research and improving the scope of my dissertation. The Botanical Society of America and American Bryological and Lichenological association, as well as PSU Biology's Forbes Lea scholarship together provided the funding the get these projects off the ground.

I thank my fellow graduate students, especially my Eppley and Rosenstiel labmates for the years of discussion, support, and assistance in both the field and lab. I'd like to particularly thank Mehmet Balkan, Hannah Prather, Amie Romney, Erin Shortlidge, Jason Maxfield, Andrea Melnychenko, Caitlin Marist, Andrew Clements, and Amy Seufert. Hannah was particularly instrumental in my planning and orientation to Antarctica work, for which I am forever grateful. Lab and field assistance from Jess Shamek, Ariadna Covarrubias-Ornelas, Sara Herrejon-Chavez, and Cammille Mitchell made sample collection and processing a tractable endeavor.

I would like to thank all of my students over the years for giving me the opportunity to discover my love of teaching and for helping me develop that craft. Tom Hancock provided pedagogical support for many years, and his commitment to teaching has made my life as a teaching assistant gratifying. I also thank Jaime Wood and the 
Certificate of Innovation in College Teaching program for developing a platform for self improvement in teaching.

I'm indebted to Cody Woll, Jake Hyman, Pat Stenger, and Sara Schoettler for their consistent fellowship throughout these years. Our collective adventures have been instrumental in the life portion of work-life balance and have given me the respite needed to come back to the work refreshed. To Ethan Linck I owe thanks for a camaraderie through parallel stages of our respective dissertations. Finally, I owe innumerable thanks to the myriad of supportive roles that both Claudia Candia and Anna Levy have filled over the years. Without their practical, intellectual, and emotional support as well as their patience and encouragement, this dissertation may never have been realized. 


\section{Table of Contents}

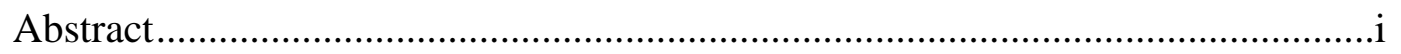

Acknowledgements ................................................................................

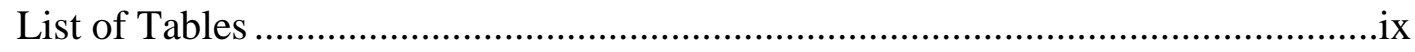

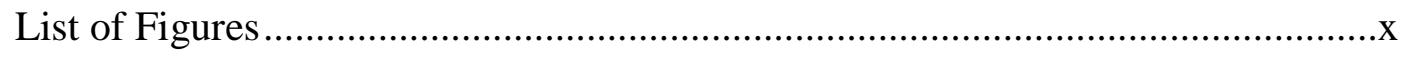

\section{Chapter 1}

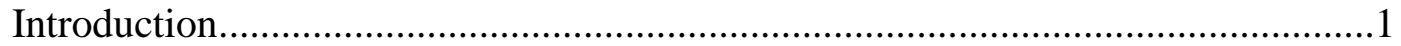

\section{Chapter 2}

Forest passerines as a novel dispersal vector of viable bryophyte

propagules

\section{Chapter 3}

Species-specific interactions in avian-bryophyte dispersal networks

\section{Chapter 4}

Metacommunity structure of epiphytic bryophytes in fog-maintained patches of relict Valdivian forest of north-central Chile

\section{Chapter 5}

Conclusions.

\section{Appendix A}

Appendices List of Tables and Figures.

\section{Appendix B}

Supplemental Materials to Chapter 2: Forest passerines as a novel dispersal vector of viable bryophyte propagules

\section{Appendix C}

Supplemental Materials to Chapter 3: Species-specific interactions in avianbryophyte dispersal networks 


\section{Appendix D}

Supplemental Materials to Chapter 4: Metacommunity structure of epiphytic bryophytes in fog-maintained patches of relict Valdivian forest of north-central Chile... 


\section{List of Tables}

Table 4.1 Metacommunity structure of epiphytic bryophytes across Parque Nacional Bosque Fray Jorge as well as by sampling height and patch ..........................................8 
List of Figures

Figure 2.1 Scatterplot of number of bryophyte spores found on birds by bird tarsus length

Figure 2.2 Boxplots showing the number of bryophyte spores found on the legs and rectrices

of birds, by bird behavioral group

Figure 2.3 Boxplots showing the number of bryophyte spores found on the legs and rectrices of birds, by bird species

Figure 2.4 Boxplots showing the number of bryophyte spores found on the legs and rectrices of birds, by bird family..... .35

Figure 3.1 Visualization of bipartite avian-bryophyte dispersal network relationships.

Figure 3.2 Boxplots showing the network-level specialization of the overall network, and subset networks by avian behavioral guild

Figure 3.3 Boxplots showing the species-level specialization of bryophytes within the overall network, and subset networks by avian behavioral guild .61

Figure 3.4 Faith's Phylogenetic Distance of bryophytes found on individual bird species and families compared with iteratively generated null distributions .63

Figure 4.1 Map of metacommunity structures of epiphytic bryophytes found in Parque Nacional Bosque Fray Jorge, Chile .90

Figure 4.2 Boxplots showing the relationship between canopy cover and metacommunity structure 
Figure 4.3 Boxplots showing the relationship between diameter at breast

height (DBH) and metacommunity structure

Figure 4.4 Map of Shannon's Diversity Index of high samples across the park

Figure 4.5 Map of Shannon's Diversity Index of low samples across the park. .94

Figure 4.6 Boxplots showing the relationship between Shannon's Diversity Index and metacommunity structure .95 


\section{Chapter 1}

\section{Introduction}

While traditionally overlooked as minor components of terrestrial ecosystems, it is becoming increasingly apparent that bryophytes (mosses, liverworts, and hornworts) play a significant role in global ecology. In particular, they are important in high latitude locations as the predominant plant cover $[1,2]$, and in wet forests, a large part of canopy photosynthetic biomass exists as epiphytes [3]. Mosses provide refuge for a complex food web, providing the structural and environmental conditions to host a large variety of microorganisms [4] and fungi [5], which in turn support a detrital food web of animal biota including tardigrades, collembola, and both detrital and predatory mites [6-8]. These animals provide food for higher trophic level taxa, such as birds [9]. In addition, bryophytes provide further resources as nesting material for both mammals and birds [10-14]. These associations influence habitat and ecosystem flux of carbon and nitrogen, playing a role in determining their relative rates of sequestration and release [15-18].

Despite these important roles that bryophytes play, debate remains surrounding the role of spatial processing is structuring bryophyte communities. Dispersal via windgenerated movement of spores is generally considered the dominant form of dispersal in bryophytes, and has historically been considered to be ubiquitous. Empirically, however, there is conflicting evidence regarding spore dispersal distances, and the ability of spore to survive in long-distance dispersal scenarios [19-23]. Epiphytic forest species further suffer from tree-generated wind buffering, which reduces the rate of wind flow and may 
lead to dispersal limitation in the understory, even at a local scale [24].

A full understanding of how dispersal impacts bryophyte communities will require both a mechanistic and phenomenological approach [25]. Identifying mechanisms that may ameliorate dispersal limitation and alter dispersal outcomes is likely to provide a better understanding of how bryophyte community diversity is assembled and maintained over time. Animal dispersal is known to be a particularly impactful mechanism in seed plant dispersal, but has only received sporadic attention with regards to bryophytes [2632]. Birds are of particular interest as potential dispersers of bryophytes due to their highly vagile nature, and there is some preliminary evidence that they may be a vector of bryophyte propagules $[33,34]$. Despite this, no work has been done to determine whether passerines (the largest group of birds) have dispersal associations with bryophytes.

Drivers of community assembly can also be assessed from a phenomenological point of view, in which distribution patterns are related to spatial and environmental factors to infer causal relationships. Depending on the spatial extent and level of connectivity of = habitat areas, community ecology can be extended to include metacommunity theory. Under this framework, each community at a given locality is part of a larger metacommunity, and these communities are linked by dispersal $[35,36]$. Various viewpoints within this framework have been developed, with the dialogue focusing on differences in their emphasis of the importance of deterministic abiotic influence and biotic interactions, structured spatial processes (dispersal, connectivity, patch size and shape), and stochastic neutral processes in shaping communities [37-39]. By applying these frameworks to bryophyte communities, it will be possible to 
disentangle the drivers of bryological diversity at local, regional, and landscape scales. In this dissertation, I provide the groundwork for understanding passerine birdmediated dispersal of bryophytes by assessing topical residence of bryophyte propagules on a variety of passerines. I also relate individual species of bryophytes to the birds that vector them. I consider these associations within the context of avian behavior, and describe specific relationships that provide avenues for further research. In addition, I examine the structure of a patchy metacommunity of bryophytes to assess how delineations of scale impact structural assignation. I address these questions more specifically in the following manner:

- In Chapter 2 I examine the topical bryophyte spore load of a variety of passerine birds to determine whether particular bird species or behavioral groups are more likely to disperse bryophyte spores, and whether this varies by location on the bird.

- In Chapter 3 I describe species-specific relationships in a bipartite avianbryophyte dispersal network to better understand the level of specificity of these associations.

- In Chapter 4 I investigate the metacommunity structure of bryophyte communities in a naturally patchy fog-deposition dependent forest landscape to assess how focal habitat compartments and underlying diversity impact structure at both the patch and landscape scale.

- In Chapter 5 I provide conclusions regarding chapters 2-4 as well as suggestions for future work. 


\section{References}

1. Beringer J, Lynch AH, Stuart F, Mack M, Bonan GB. 2001 The Representation of Arctic Soils in the Land Surface Model: The Importance of Mosses. J. Clim. 14, $3324-3335$.

2. Gornall JL, Jónsdóttir IS, Woodin SJ, Van der Wal R. 2007 Arctic mosses govern below-ground environment and ecosystem processes. Oecologia 153, 931-941. (doi:10.1007/s00442-007-0785-0)

3. Nadkarni N. 1984 Epiphyte Biomass and Nutrient Capital of a Neotropical Elfin Forest. Biotropica 16, 249-256.

4. Anderson OR. 2006 The Density and Diversity of Gymnamoebae Associated with Terrestrial Moss Communities (Bryophyta: Bryopsida) in a Northeastern U.S.

Forest. 53, 275-279. (doi:10.1111/j.1550-7408.2006.00103.x)

5. Dobbeler P. 1997 Biodiversity of bryophilous ascomycetes. Biodivers. Conserv. 6, $721-738$.

6. Ingemar Jonsson K. 2003 Population density and species composition of mossliving tardigrades in a boreo-nemoral forest. Ecography (Cop.). 26, 356-364.

7. Gerson URI. 1969 Moss-Arthropod Associations. Bryologist 72, 495-500.

8. Lindo Z, Winchester NN. 2007 Local-regional boundary shifts in oribatid mite 
(Acari: Oribatida) communities: species-area relationships in arboreal habitat islands of a coastal temperate rain forest, Vancouver Island, Canada. J. Biogeogr. 34, 1611-1621. (doi:10.1111/j.1365-2699.2007.01710.x)

9. Sillett TS. 1994 Foraging ecology of epiphyte-searching insectivorous birds in Costa Rica. Condor 96, 863-877.

10. Blem CR, Blem LB. 1994 Composition and Microclimate of Prothonotary Warbler Nests. Auk 111, 197-200.

11. Honorato MT, Altamirano TA, Ibarra JT, de la Maza M, Bonacic C. 2016 Composición de nidos de vertebrados nidificadores de cavidades en el bosque templado andino de Chile. Bosque 37, 485-492. (doi:10.4067/S071792002016000300005)

12. Parnikoza I, Dykyy I, Ivanets V, Kozeretska I, Kunakh V, Rozhok A, Ochyra R, Convey P. 2012 Use of Deschampsia antarctica for nest building by the kelp gull in the Argentine Islands area (maritime Antarctica) and its possible role in plant dispersal. Polar Biol. 35, 1753-1758. (doi:10.1007/s00300-012-1212-5)

13. Kim J-U, Lee W, Lee E-J. 2018 The use of artificial nest boxes by Siberian flying squirrels (Pteromys volans) in South Korea. J. For. Res. (doi:10.1007/s11676-0180787-2)

14. Minato S, Doei H. 1995 Arboreal Activity of Glirulus japonicus (Rodentia: Myoxidae) confirmed by use of bryophytes as nesting material. Acta Theriol. 
(Warsz). 40, 309-313.

15. Turetsky MR. 2003 The Role of Bryophytes in Carbon and Nitrogen Cycling. Bryologist 106, 395-409. (doi:10.1639/05)

16. Bisbee KE, Gower ST, Norman JM, Nordheim E V. 2001 Environmental controls on ground cover species composition and productivity in a boreal black spruce forest. , 261-270. (doi:10.1007/s004420100719)

17. Swanson R V, Flanagan LB. 2001 Environmental regulation of carbon dioxide exchange at the forest floor in a boreal black spruce ecosystem. 108, 165-181.

18. Rousk K, Jones DL, Deluca TH. 2013 Moss-cyanobacteria associations as biogenic sources of nitrogen in boreal forest ecosystems. 4, 1-10. (doi:10.3389/fmicb.2013.00150)

19. van Zanten BO. 1978 Experimental studies on trans oceanic long-range dispersal of moss spores in the southern hemisphere. J. Hattori Bot. Lab. 44, 455-482.

20. Lönnell N, Hylander K, Jonsson BG, Sundberg S. 2012 The fate of the missing spores--patterns of realized dispersal beyond the closest vicinity of a sporulating moss. PLoS One 7, e41987. (doi:10.1371/journal.pone.0041987)

21. Sundberg S. 2013 Spore rain in relation to regional sources and beyond. Ecography (Cop.). 36, 364-373. (doi:10.1111/j.1600-0587.2012.07664.x)

22. Ross-Davis AL, Frego KA. 2004 Propagule Sources of Forest Floor Bryophytes : Spatiotemporal Compositional Patterns. Bryologist 107, 88-97. 
23. Miles CJ, Longton RE. 1992 Deposition of moss spores in relation to distance from gametophyte. J. Bryol. 17, 355-368.

24. Kimmerer RW. 2005 Patterns of Dispersal and Establishment of Bryophytes Colonizing Natural and Experimental Treefall Mounds in Northern Hardwood Forests. Bryologist 108, 391-401. (doi:10.1639/00072745(2005)108[0391:PODAEO]2.0.CO;2)

25. Levin SA, Muller-Landau HC, Nathan R, Chave J. 2003 The ecology and evolution of seed dispersal: A theoretical perspective. Annu. Rev. Ecol. Evol. Syst. 34, 575-604. (doi:10.1146/annurev.ecolsys.34.011802.132428)

26. Heinken T. 2001 Epizoochorous dispersal of bryophyte stem fragments by roe deer (Capreolus capreolus) and wild boar (Sus scrofta). J. Bryol. 23, 293-300.

27. Pauliuk F, Müller J, Heinken T. 2011 Bryophyte dispersal by sheep on dry grassland. Nov. Hedwigia 92, 327-341. (doi:10.1127/0029-5035/2011/0092-0327)

28. Parsons JG, Cairns A, Johnson CN, Robson SKA, Shilton LA, Westcott DA. 2007 Bryophyte dispersal by flying foxes: a novel discovery. Oecologia 152, 112-4. (doi:10.1007/s00442-006-0639-1)

29. Boch S, Berlinger M, Fischer M, Knop E, Nentwig W, Türke M, Prati D. 2013 Fern and bryophyte endozoochory by slugs. Oecologia 172, 817-822. (doi:10.1007/s00442-012-2536-0)

30. Kimmerer RW, Young CC. 1995 The role of slugs in dispersal of the asexual 
propagules of Dicranum flagellare. Bryologist 98, 149-153.

31. Marino P, Raguso R, Goffinet B. 2009 The ecology and evolution of fly dispersed dung mosses ( Family Splachnaceae ): Manipulating insect behaviour through odour and visual cues. Symbiosis 47, 61-76.

32. Rudolphi J. 2009 Ant-mediated dispersal of asexual moss propagules Antmediated dispersal of asexual moss propagules. Bryologist 112, 73-79.

33. Lewis LR, Rozzi R, Goffinet B. 2014 Direct long-distance dispersal shapes a New World amphitropical disjunction in the dispersal-limited dung moss Tetraplodon (Bryopsida: Splachnaceae). J. Biogeogr. 41, 2385-2395. (doi:10.1111/jbi.12385)

34. Lewis LR et al. 2014 First evidence of bryophyte diaspores in the plumage of transequatorial migrant birds. PeerJ 2, e424. (doi:10.7717/peerj.424)

35. Hanski I, Gilpin M. 1991 Metapopulation dynamics: brief history and conceptual domain. Biol. J. Linn. Soc. 42, 3-16.

36. Holyoak M, Leibold MA, Holt RD. 2005 Metacommunities: spatial dynamics and ecological communities. Chicago, IL: University of Chicago Press.

37. Yu DW, Wilson HB. 2001 The competition-colonization trade-off is dead; long live the competition-colonization trade-off. Am. Nat. 158, 49-63. (doi:10.1086/320865)

38. Calcagno V, Mouquet N, Jarne P, David P. 2006 Coexistence in a metacommunity: the competition-colonization trade-off is not dead. Ecol. Lett. 9, 
897-907. (doi:10.1111/j.1461-0248.2006.00930.x)

39. Rosindell J, Hubbell SP, He F, Harmon LJ, Etienne RS. 2012 The case for ecological neutral theory. Trends Ecol. Evol. 27, 203-8.

(doi:10.1016/j.tree.2012.01.004) 


\title{
Chapter 2
}

\section{Forest passerines as a novel dispersal vector of viable bryophyte propagules}

*This chapter has been previously published:

Chmielewski MW, Eppley SM. 2019 Forest passerines as a novel dispersal vector of viable bryophyte propagules. Proc. R. Soc. B Biol. Sci. 286. doi:10.1098/rspb.2018.2253)

\begin{abstract}
Animal dispersal influences the community structure and diversity of a wide variety of plant taxa, yet the potential effects of animal dispersal in bryophytes (hornworts, liverworts, and mosses) is poorly understood. In many communities, birds use bryophyte-abundant niche space for foraging and gathering nest material, suggesting that birds may play a role in bryophyte dispersal. As highly motile animals with long migratory routes, birds potentially provide a means for both local and long-distance bryophyte dispersal in a manner that differs greatly from passive, aerial spore dispersal. To examine this phenomenon, we collected and germinated bryophyte propagules from the legs, feet and tails of 224 birds from 34 species within a temperate forest community. In total we found 1,512 spores, and were able to germinate 242 bryophyte propagules. In addition, we provide evidence that topical (externally carried) spore load varies by bird species and behavior. Tail feather spore abundance is highest in bark and foliage gleaning species and is positively correlated with tarsus length. Together, these data suggest that a variety of forest birds exhibit the potential to act as dispersal vectors for bryophyte propagules, including an abundance of spores, and that understanding the effects of
\end{abstract}


animal behavior on bryophyte dispersal will be key to further understanding this interaction.

\section{Background}

The ability of a species to disperse is one of the fundamental forces shaping the assembly of ecological communities [1,2]. Dispersal distance, timing, and pattern of propagule arrival also influence the dynamics among communities, and are central to our understanding of large-scale community dynamics, including in metacommunities [3,4]. Efficiency of dispersal [5] and the rate of dispersal-influenced species turnover [6] are predicted requirements in maintaining diversity in patchy landscapes and creating observed metacommunity structures. Even metacommunities that appear to be structured in a manner consistent with strong environmental filtering have been shown to be influenced by dispersal effects when examined across spatial scales [7].

Dispersal plays a particularly important role in plant communities, as plants are non-mobile, and the location in which they germinate determines the community context in which they must grow and reproduce. Yet, while much work has gone into elucidating how dispersal phenomena shape propagule distribution probabilities [8,9], determining the extent to which these propagules arrive in suitable microsites has proven considerably less tractable [10]. One promising approach involves quantifying the mechanistic influence of behaviorally mediated dispersal via associations with animal vectors, as 
evidence suggests animals can strongly influence recruitment success in a variety of vascular plant taxa $[11,12]$.

Animal-mediated plant dispersal research has primarily focused on seed dispersal in angiosperms $[13,14]$, with little attention being given to animals as potential vectors for spore dispersal in bryophytes (hornworts, liverworts, and mosses). As extant bryophytes are thought to resemble the morphology and physiology of the first terrestrial plants [15-17], understanding more about their dispersal strategies may be insightful in understanding the evolution of initial spore-based plant dispersal strategies. Furthermore, bryophytes provide essential ecosystem services, including nutrient cycling [18-20], and are dominant plant species in Arctic and Antarctic systems. Understanding dispersal mechanisms in bryophytes is necessary for determining the drivers of community biodiversity in these systems, and understanding how climate change may alter species composition, distribution, and associated ecological interactions.

Historically, bryophyte spores have been assumed to be ubiquitously dispersed by air, with dispersal limitation being only relevant in situations with limited airflow conditions, such as the forest understory [21]. Despite this, some studies have shown that even in conditions with open-air circulation, spore dispersal by air can be extremely limited [22,23]. Importantly, animal dispersal may lead to an increased probability of dispersal against or across dominant wind flow patterns [24,25], resulting in dispersal distributions and resultant metacommunity structuring that differ from those expected via wind dispersal alone. Thus, animal dispersal of bryophyte spores may explain patterns of strong genetic structure within taxa consistent with historical long-distance dispersal 
events that have previously lacked an explanatory dispersal mechanism [26-28]. Animal vectoring may also provide clarity regarding bryophyte species exhibiting disjunct northsouth distributions $[25,29,30]$, in which analyses of population structure indicate direct long-distance dispersal as the drivers of such distributions $[28,30]$.

To date, studies addressing animal dispersal of bryophytes have mainly focused on mammals dispersing fragments of leaf and stem tissue (the cells of which are totipotent) at the local level (boar and deer: [31], sheep: [32], flying foxes: [33], squirrels and voles [34]) and invertebrates (slugs: [35,36], ants: [37]). A few experiments have demonstrated that waterfowl may be able to vector bryophyte material internally $[38,39]$. Additionally, one study of the bryophyte component of hummingbird nests concluded that incorporated bryophyte leaves and stems (gametophytes, the haploid life-history phase which is dominant in bryophytes) established and grew, suggesting that nesting behavior can disperse bryophytes locally [40]. Studies examining spore dispersal by animals are limited to flies distributing specialized dung mosses [41], spores found as part of the propagule load of small terrestrial forest mammals[34], and a few spores found on shorebirds [42].

Widespread long-distance dispersal of bryophyte spores by birds has been proposed [43], but the occurrence and rate of topical (externally carried) dispersal of bryophyte spores across a variety of avian species has not been explicitly addressed. Dispersal of bryophyte spores by birds is potentially significant given both their movement among local sites during regular activities such as foraging and gathering of nest material, as well as their ability to fly between more distant sites during migration. 
Additionally, birds have close association with bryophytes as nesting material $[40,44-46]$ and as a reservoir of invertebrate food items $[47,48]$, and thus birds may frequently come into contact with sporophytes (the diploid life-history stage of bryophytes) that are actively releasing spores, many of which may adhere to the surface of bird feet and feathers. Birds are known to disperse fungi and slime mold propagules in this way $[49,50]$, and a similar association with bryophytes may occur. A recent study has tested for the association between bryophyte material and bird external surfaces; two bryophyte leaf fragments were found on the feathers of seven individual wading birds on their breeding grounds, which are bryophyte abundant [42]. This work suggests that topical retention and dispersal of bryophyte fragments is theoretically possible.

To characterize the extent of avian dispersal of bryophytes spores, we examined forest passerines in Gifford Pinchot National Forest, WA, Pacific Northwest USA for bryophyte spores. We collected spores from the birds' legs and feet as well as tails, and we tested spores for viability. As a variety of birds use forest habitat that overlaps with bryophyte distributions, we predicted that we would find spores on multiple bird species. We additionally predicted that spore abundance would differ among the bird species due to their different foraging modes. We specifically expected that foliage and bark gleaning species would exhibit larger topical spore loads than those in other foraging guilds (ground foragers, aerial salliers, nectivores) due to their use of bryophyte mats and bryophyte-abundant habitat when looking for food. 


\section{Methods}

\section{(a) Study site and bird capture}

Our field site is located in the Wind River Experimental Forest in Gifford Pinchot National Forest, WA (centered at 54 48’40” N, 12156 '35” W). We captured birds via mist nets during the spring and summer of 2014 along a transect running through seasonally inundated Oregon Ash (Fraxinus latifolia Bentham) forest. Our site abuts both reforested and old growth Douglas-Fir (Pseudotsuga menziesii (Mirbel)) and Western Hemlock (Tsuga heterophylla Sargent) dominated patches, as well as a small anthropogenically maintained meadow. Together, these features contribute to a relatively diverse avifauna, with abundant bryophyte cover (mean of $15.8 \%$ on ground plots and $29.5 \%$ on trees). The conditions at this location during our study period is typically consistently dry. We set an array of ten 12 x $3 \mathrm{~m}, 30 \mathrm{~mm}$ mesh mist nets set along a set of pre-existing recreational pathways. We opened nets at dawn and closed them midafternoon, checking for captured birds at least every 30 minutes. Birds were then brought to a central banding location for banding, sampling, and release.

\section{(b) Bird sampling}

Our study included 192 birds representing 34 different western North American species (ranging from 1-47 captures, mean $=7.1, \mathrm{~B} 1$ ). We used cotton swabs to topically sample the 1) legs and feet and 2) rectrices (tail feathers) of each bird for bryophyte spores and tissue. To dislodge topically resident bryophyte propagules, we pulled swabs laterally 
along scale edges. We took advantage of the grip response passerines often exhibit in hand to sample their feet, allowing individuals to clasp the swab tip while we rotated the cotton applicator to pick up material lodged in foot pads. We used a different swab end for each foot, for a total of two leg swabs per bird. Similarly, we used duplicate rectrix (tail feather) swabs, and sampled by pulling them proximally to distally across feathers. We placed feather and leg swabs into individual, sterile $1.5 \mathrm{~mL}$ microcentrifuge tubes for laboratory analysis. We additionally pulled one rectrix from each bird and placed it immediately into a microcentrifuge tube as a second measure of spores trapped on tail feathers. To avoid potential cross contamination, we cleaned our hands repeatedly with wet wipes between handling and sampling each bird, and we used hand swabs as contamination controls. After swabbing, we fitted each bird with a numbered USGS leg band to permit identification upon recapture. Whenever possible, we aged and sexed birds using secondary sex characteristics and plumage [51]. Additionally, we collected data on wing chord, mass, and tarsus length, width, and height, to assess whether topical spore load scales with typical body size metrics. We submitted all avian data to the USGS Bird Banding Laboratory.

\section{(c) Sample processing}

We dislodged sample material from cotton swabs and rectrices by individually vortexing them twice for one minute each time in filtered tap water. After each round of vortexing, 
we vacuum filtered the resultant solution across a gridded $0.45 \mu \mathrm{m}$ mixed cellulose ester membrane (EMD Millipore). We individually counted all spores and any chlorophyllcontaining fragments of tissue via compound light microscopy. We applied filters with captured samples face-down to BCD nutrient agar in [52] petri plates, and sealed them with parafilm to allow for gas exchange while preventing plate contamination. While we originally set out to link spore abundance with germination rate, logistical constraints prevented our ability to separate spores from plant fragments. Thus, whole samples were plated to determine whether bryophyte propagules, including both spores and fragments, on bird surfaces were viable. While all plant fragments containing chlorophyll were counted, a fraction were likely not bryophyte fragments. To assess germination rates, we grew samples in $60 \times 15 \mathrm{~mm}$ plates under an approximately 500 lux, 12:12 L:D light cycle at room temperature $\left(22-25^{\circ} \mathrm{C}\right)$ until positive identification of protonemal or gametophytic growth was possible.

\section{(d) Data categorization and processing}

To address our research questions, individual birds were assigned behavioral designations based on foraging strategy as defined by the Cornell Laboratory of Ornithology [53], and binned by taxonomic family. As we found wing chord and tarsus length were correlated

$\left(\mathrm{F}=154.6, \mathrm{p}<0.01, \mathrm{R}^{2}=0.61\right.$, Figure $\mathrm{B} 2$ ), and because we expected tarsi to be exposed to bryophyte-covered surfaces during perching, we used tarsus length as the sole body size metric to relate to topical spore abundance. Date of capture did not appear to have an 
impact on spore load, and was not thus not further considered as an explanatory variable (Figure B4). Tarsus length was not available for all birds, as we did not measure hummingbird tarsi and there were a number of other missing values due to various restraints of avian field work. Tarsus length was therefore available for 106 individuals. In addition, as hummingbirds were the only floral feeding group, and leg swabs were difficult to obtain, hummingbirds were removed from statistical analyses $(\mathrm{N}=171$ for analyses not requiring tarsus length). As the only continuous explanatory variable, tarsus length was centered on the mean before being included in models to ease interpretation. Total spore counts were summed from tarsus and rectrix swabs, as well as rectrix pull samples. When examining species-level differences in spore load, species with fewer than three captures were excluded from models $(\mathrm{N}=20)$, as estimations based one or two data points would be uninformative.

\section{e) Statistical analysis}

We fit a series of generalized linear models and generalized linear mixed models to determine how bird 1) size, 2) behavior, and 3) identity influenced topical spore load. We examined bird identity both at the individual species and family level in our models. To address these objectives, we first fit a series of models (summarized in B3) with summed total spore count (from both swabs and the feather pull) as the dependent variable, considering tarsus length, behavior, species identity, and family affiliation as explanatory variables. Tarsus length and behavior were modeled together as fixed variables with species identity as a random variable. Separate total spore count models 
were fit with family and species as fixed variables in order to determine pairwise differences between species and families. As we were also interested in understanding how the abundance of spores on different surfaces varied by these explanatory variables, we fit an additional set of models with either only spores swabbed from legs, or spores swabbed from tails as dependent variables. Our interest in comparing feather and leg resident spores lead us to avoid separately fit models with rectrix pulls as the response variable, due to this method being incomparable to leg swabs. Rather, we chose to relegate them to inclusion in the aforementioned total spore values (which are therefore comparable across all species samples). All models were fit with a negative binomial loglink function to account for overdispersion of spore count residuals using the MASS and [54] lmer [55] packages in the R statistical computing software (version 3.3.3) platform [56]. Residual vs. fitted value plots validated a marked improvement of negative binomial models over either linear model or Poisson distribution approaches. Influential point leverages were examined via Cook's distance. When potentially influential points were excluded from a comparison model, model outcomes did not change drastically, and all points were included in final models. Additionally, we examined spore number by the number of captures of each species to determine whether sampling efforts in relation to particular species may have driven our outcomes, and found no particular pattern with number of captures and number of spores (Figure B5). Factor contributions to models were evaluated by comparing to reduced models via likelihood ratio tests. Pairwise comparisons of levels within model factors were generated under a least squares means 
approach adjusted by Tukey's HSD with the lsmeans package [57]. All visualizations of data were generated using ggplot2 [58].

\section{Results}

\section{(a) Avian topical spore load and variation}

In total, we found 1,512 chlorophyllic bryophyte spores on the feet and feathers of a wide variety of passerine birds. While most individuals carried few spores, individual topical load was highly variable (Figure B1). We found that tarsus length was associated with an increased spore load at a rate of 7.4\%/cm $\left(\chi^{2}=9.16, \mathrm{p}<0.01\right.$, Figure 2.1). Both bark and foliage foragers carried more total spores than aerial foragers $\left(\chi^{2}=9.16, \mathrm{p}<\right.$ 0.01, Figure 2.2). Differences in overall spore load by bird identity were observed at both the species $\left(\chi^{2}=49, \mathrm{p}<0.01\right.$, Figure 2.3$)$ and family levels $\left(\chi^{2}=63.66, \mathrm{p}<0.01\right.$, Figure 2.4). In particular, Lazuli Buntings carried few spores compared to other species, while American Robins and Swainson's Thrushes had more than other species.

When examining those spores found on bird legs, tarsus length unsurprisingly positively predicted spore load $(\chi 2=20.88, \mathrm{p}<0.01)$ while foraging behavior had no significant impact $(\chi 2=2.02, \mathrm{p}=0.11$, Figure 2.2$)$. While models indicated that family and species identities both predicted leg spore load $(\mathrm{F}=2.41, \mathrm{p}<0.01 ; \mathrm{F}=2.55, \mathrm{p}<0.01$ respectively), pairwise comparisons failed to find any difference between any levels within these two factors (Figures 2.3,2.4). Rectrix spore load differed by bird behavior (F $=4.152, \mathrm{p}<0.01$, Figure 2.2) but not by tarsus length $(\mathrm{F}=1.84, \mathrm{p}=0.17)$. Specifically, 
aerial foragers carried fewer spores on their rectrices than either bark or foliage gleaners. Unlike leg spores, family $(\mathrm{F}=3.24, \mathrm{p}<0.01)$ and species $(\mathrm{F}=3.26, \mathrm{p}<0.01)$ differences in spores load exhibited pairwise differences. In particular, Swainson's Thrushes carried more spores on their tails compared with Lazuli Buntings (Figure 2.3), and the thrushes generally had more tail spores than some other families (Figure 2.4).

\section{(b) Germination}

In total, we successfully germinated 242 individual bryophytes from avian swabs, with $0.95 \pm 0.17$ (mean $\pm \mathrm{SE}$ ) germination events per bird capture (Figure B1). While we focused on quantifying the abundance of spores on bird surfaces, our germination trials include gametophytic fragments as well as spores. Germination varied among species, ranging from zero to three germination events per capture. While some protonema developed into gametophytes, the artificial growth conditions limited our ability to grow all samples to a visually identifiable stage, putting species-specific interactions beyond the scope of this paper. Anecdotally, however, we observed bryophytes of various genera (Ceratodon, Aulacomnium, Marchantia, and at least one free-branching growth form).

\section{Discussion}

Our results demonstrate that 1) bryophyte spores are widely prevalent on bird feathers and feet (Figures 2.2-24), 2) topical spore abundance patterns are partially driven by bird behavior (Figures 2.2-2.4), and 3) passerine birds carry propagules on their surfaces that 
are at least somewhat viable (Figure B1). Indeed, germination in our study likely underrepresented the number of viable propagules found on birds, as artificial growth conditions were unlikely to be suitable for all species present. Together, these findings provide the first evidence that topical retention of spores and gametophyte fragments is widespread across many species of passerines, an avian group composing over half of extant bird species. Future work aimed at better understanding this dispersal mode may provide an explanatory mechanism for addressing observed bryophyte distributions that have remained a mystery despite much research attention.

We expect that the dispersal of bryophyte spores by birds is likely to be driven by either direct use of bryophytes for nesting and foraging by birds, overlapping spatial use by both groups, or a combination of these factors. We therefore propose that topical dispersal of spores by birds is a byproduct of avian-bryophyte association, rather than a tightly coevolved syndrome in which the propagule being dispersed has been selected to exhibit properties that facilitate being moved by the disperser. While tight coevolution has historically been considered to be integral to dispersal interactions between plants and vertebrate vectors, a body of evidence suggests that diffuse mutualistic interactions can play important roles in seed dispersal outcomes [59]. Long term empirical evidence has demonstrated that tight coupling is not a necessary requirement of ecologically relevant dispersal networks, and that the strength of dispersal links can shift through time via annual changes to ecological context [60]. A review of the evolution of plant-disperser interactions throughout the fossil record additionally supports the importance of diffuse coevolution of dispersal syndromes, with diffuse mutualistic interactions forming the 
basis for further, more specialized syndromes as species-specific relationships develop [13]. Differences in species-specific animal behavior and associated dispersal phenomena are therefore relevant to our system, despite bryophytes lacking the typical specialized structures for attracting and attaching to animal vectors more familiar in tracheophyte dispersal syndromes.

The variability we report in the topical load of spores by species and foraging guild (Figures 2.2-2.4) supports the existence of species-specific interactions between birds and bryophytes that are driven by avian behavior. Bird size also affects spore load, and we hypothesize that the observed positive relationship between tarsus size and spore number (Figure 2.1) likely reflects an increase in the total surface area available for spore adhesion on larger birds. As tarsus length is often used as a single measure proxy for overall body size in birds $[61,62]$ we expect our approach to be the most useful single size-based metric for within species or behavioral group comparisons of topical spore load in birds. Together, behavior and size of a given species provide the ecological and mechanistic context that determine the probability of spore load in our study system.

We hypothesize that across foraging guilds, a greater spore abundance on bark foragers (Figure 2.2) likely reflects the high bryophyte cover on tree trunks within our study site. These birds, as well as foliage foragers, additionally held significantly more spores on their rectrices (Figure 2.3), suggesting that tail feathers may be an important point of attachment for tree-resident bryophytes. Brown Creepers and Hairy Woodpeckers also carried many tail spores (Figure 2.3, B1), but were poorly represented in our dataset. As these species spend a substantial amount of time on vertical bark 
surfaces [63-65], the woodpeckers using their rectrices as struts to help prop them in place, [66], these birds may plausibly come in contact with bryophytes regularly. Future work should consider targeting treecreepers and woodpeckers to better determine whether their spore loads reflect bark abundant bryophytes in our region such as Neckera douglasii Hook., Hypnum circinale Hook., and Isothecium myosuroides Brid. [67,68]. Interestingly, there is some evidence that in areas with higher moss abundance, woodcreepers have consistently different bill shapes and longer tarsus lengths, suggesting that moss cover may itself exert selection on bird morphology [69]. As both bill shape and leg length may be associated with foraging ability on vertical tree trunk surfaces, the authors of that work suggest that the presence of moss itself may be influencing these traits in woodcreepers.

Thrushes also contained many spores on tail feathers (Figure 2.3), which we attribute to either large total area or because their length promotes contact with sporophytes during ground foraging [70,71]. Finally, the large number of spores reported on Corvid legs (Figure 2.4) may reflect leg size or the amount of time spent ground foraging [71], suggesting that future work should consider examining their propensity for dispersing propagules of ground-dwelling bryophytes such as Kindbergia oregana (Sull.), Rhytidiadelphus triquetrus (Hedw.), and Ceratodon purpureus (Hedw.) that are common in our region $[67,68]$. Together, our findings support the existence of a previously unexplored association between passerines and topically-carried bryophytes that may enhance our understanding of the role of spatial processes in shaping bryophyte 
ecology. Additionally, we suggest that this relationship may be of use in asking questions about the dispersal ecology of plants more generally.

The high abundance of bryophyte spores and gametophytic fragments we found on passerine surfaces add to our understanding of the mechanisms by which animals could potentially disperse bryophytes. While avian dispersal may prove to be a fractional component of the overall dispersal outcomes of a given bryophyte species, we hypothesize that this mode of transport could play a role in explaining the growing evidence that direct, long-distance dispersal is a the causal factor of disjunct amphitropical distributions in bryophytes [26-30]. To date bryologists have lagged vascular plant ecologists in considering the specific impacts that a combination of multiple and varied dispersal mechanisms may have on bryophyte populations. Compared with aerial dispersal, zoochorous dispersal may specifically increase dispersal to appropriate niche-space, as animal dispersers are likely to be drawn to specific localities within a patch of habitat $[10,12,59,72]$. The dispersal kernels of bryophytes carried by birds may differ in both distance and timing compared with abiotic dispersal. By increasing the deposition of propagules at particular localities within the available niche space that reflect areas already visited by birds, dispersal volume, rate, and timing may have impacts on the structure exhibited by the bryophyte component both in the local community as well as the metacommunity. Bryophytes also play a role in ecosystem function via both nutrient cycling and water retention [18,19,73-75], and thus bird dispersal of bryophytes may influence ecosystem function via structuring of bryophyte communities. 
The role of dispersal in shaping bryophyte communities and their associated ecosystem functions is as yet an undeveloped field relative to what we understand about seed-bearing plants. Our results provide the first insight into how differences in avian behavior might provide a mechanism for altering bryophyte community assembly at various scales. While we have not demonstrated dispersal between sites, the presence of propagules across a wide variety of bird species provides a basis for directing future work aimed at understanding the potential for this mode of transport. We speculate that birds could facilitate directed dispersal of bryophytes, impacting the bryophyte community structure. We propose that this could occur both at a local level, and over larger scales via long-distance dispersal during migration. Future work should aim to quantify the diversity of bryophytes carried by different bird species, as this may improve our understanding of the species of bryophytes most likely to have their population dynamics and distributions impacted by bird-associated dispersal. Furthermore, future work should attempt to quantify how long spores reside on bird surfaces to better understand the potential magnitude of avian dispersal of bryophytes. Thus, our finding that a large variety of avian species are carrying spores topically on both feet and feathers provides the first step in a series of questions that ultimately will provide a larger understanding of how bryophyte community diversity is assembled and maintained.

\section{Ethics}


All birds were captured under U.S. Geological Survey Bird Banding permit number 22230 - S, and were also overseen by the Portland State University Institute Animal Care and Use Committee (IACUC protocol \#52).

\section{Data accessibility}

Data will made available in the Dryad Digital Repository upon manuscript acceptance. The code and data to reproduce the analysis are freely available at https://github.com/mwchmiel/birdspores. Additionally, all bird capture data have been submitted to the U.S. Geological Survey's Bird Banding Laboratory.

\section{Competing Interests}

The authors have no competing interests to declare.

\section{Authors' Contributions.}

MWC designed the study with input from SME. MWC carried out the study and analyzed the data. MWC and SME wrote the manuscript.

\section{Acknowledgements}

The authors would like to thank Ariadna Covarrubias-Ornelas, Sara Herrejon Chavez and Samantha Martin for assistance in the laboratory. We thank the United States Forest Service, especially Ken Bible for logistical support in the field, and the Portland State 
University Institute Animal Care and Use Committee, Washington State Department of Fish and Wildlife, and the United States Geological Survey Bird Banding Laboratory for permitting and animal research oversight. We also thank four anonymous reviewers for their assistance in improving the manuscript.

Funding. The Portland State Biology Department, American Bryological and Lichenological Society, and National Science Foundation (DEB-1701756) provided financial support. 


\section{Figures:}

Figure 2.1: Topical spore count by bird lower leg (tarsometatarsus) length for all individuals for which tarsus length was measured $(\mathrm{N}=106)$. Total spore load reflects the sum of rectrix (tail feather) and leg swabs as well as feather pulls. Spore load is positively

correlated with tarsus length $(\mathrm{F}=9.16, \mathrm{p}<0.01)$, exhibiting a fitted $7.4 \%$ increase per $\mathrm{cm}$. Line indicates computed averages by applying a negative binomial generalized linear model to total spore count by tarsus length. 


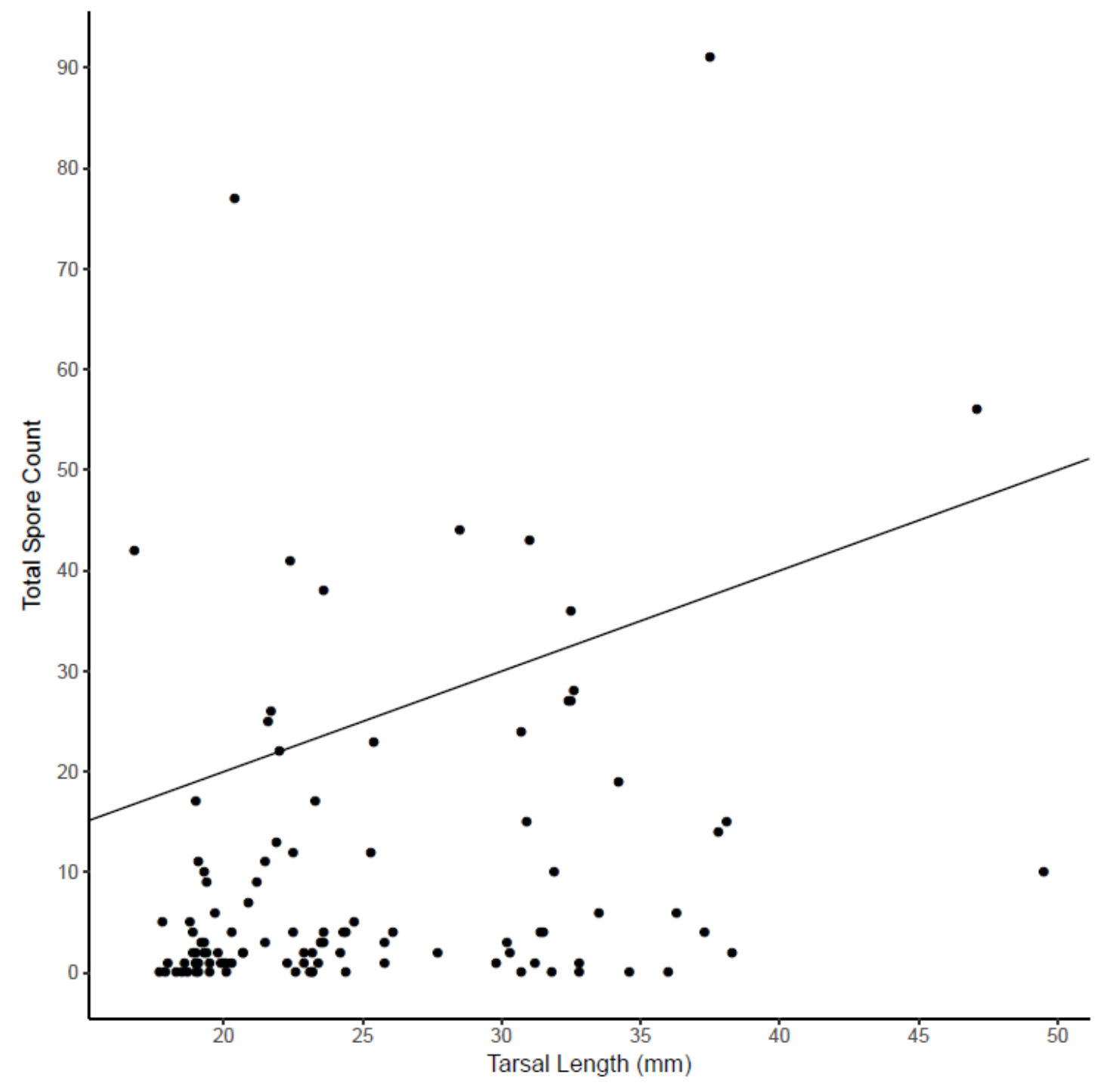


Figure 2.2: Leg, rectrix, and total number of chlorophyllic bryophyte spores found on different passerine foraging guilds species in a Pacific Northwest forest $(\mathrm{N}=171)$.

Behavioral groups are plotted by average tarsus length, increasing from left to right.

Pairwise contrasts did not reveal any differences in number of spores on legs between foraging guilds. Groups marked with a Roman numeral differed significantly $(\mathrm{p}<0.05)$ from each other in retrix spore numbers, while those with different letter designations differed in total spore load. Groups without numeral or letter designations were not significantly different from any other group. 


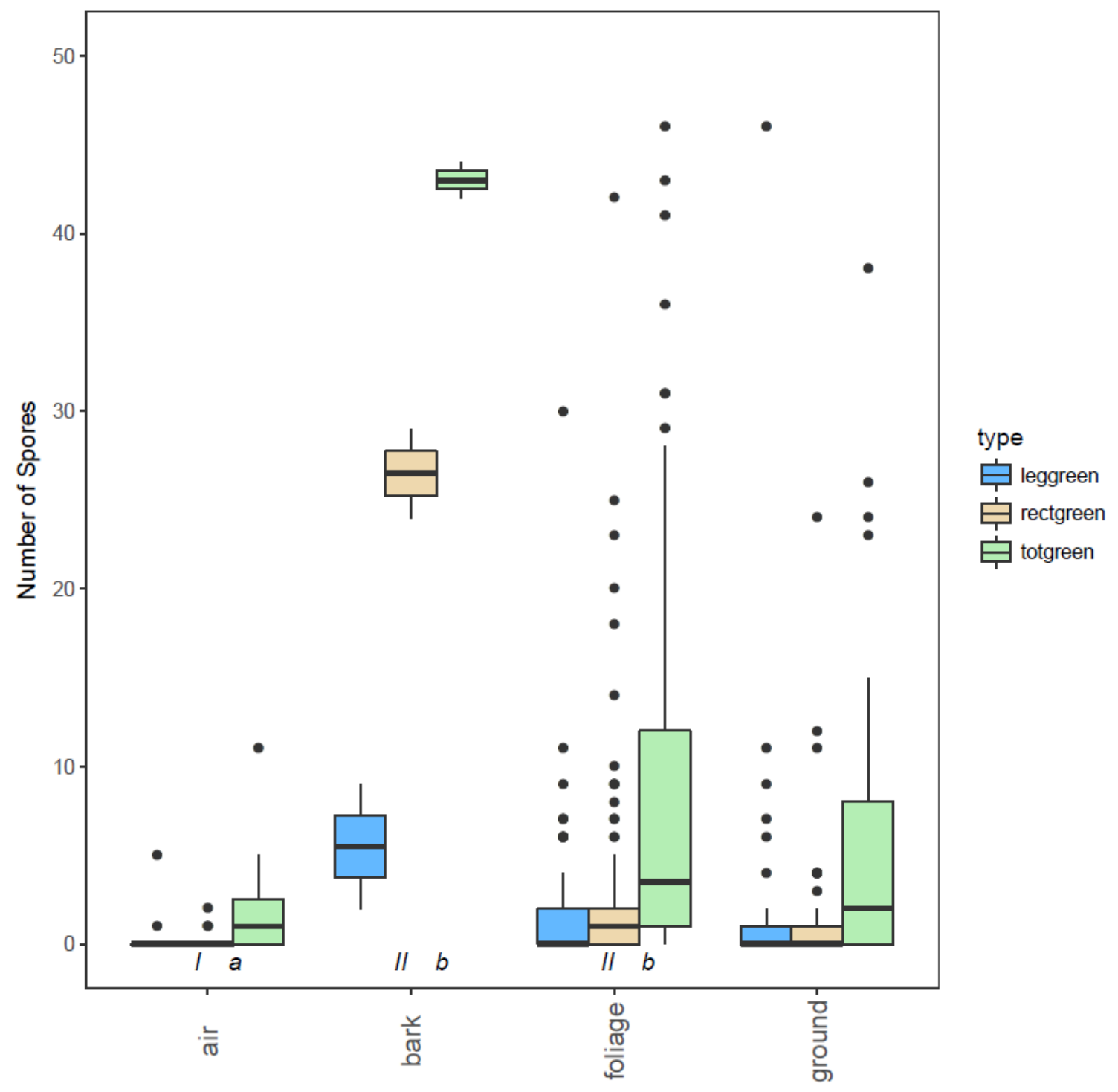


Figure 2.3: Leg, rectrix, and total number of chlorophyllic bryophyte spores found on various passerine species in a Pacific Northwest, USA forest. Species are plotted by average tarsus length, increasing from left to right. Pairwise contrasts did not reveal any differences in number of spores on legs between species. Species marked with a Roman numeral differed significantly $(\mathrm{p}<0.05)$ from each other in retrix spore numbers, while those with different letter designations differed in total spore load. Groups without numeral or letter designations were not significantly different from any other group. Species are identified via their Bird Banding Laboratory four-letter identification code as follows: American Robin (AMRO), Brown Creeper (BRCR), Black-throated Gray Warbler (BTYW), Chestnut-backed Chickadee (CBCH), Cedar Waxwing (CEDW), Chipping Sparrow (CHSP), Dusky Flycatcher (DUFL), Gray Jay (GRAJ), Hammond's Flycatcher (HAFL), Lazuli Bunting (LAZB), MacGillivray's Warbler (MGWA), Oregon Junco (ORJU), Pacific Wren (PAWR), Pacific Slope Flycatcher (PSFL), Song Sparrow (SOSP), Spotted Towhee (SPTO), Swainson's Thrush (SWTH), Warbling Vireo (WAVI), Western Tanager (WETA), and Wilson's Warbler (WIWA). 


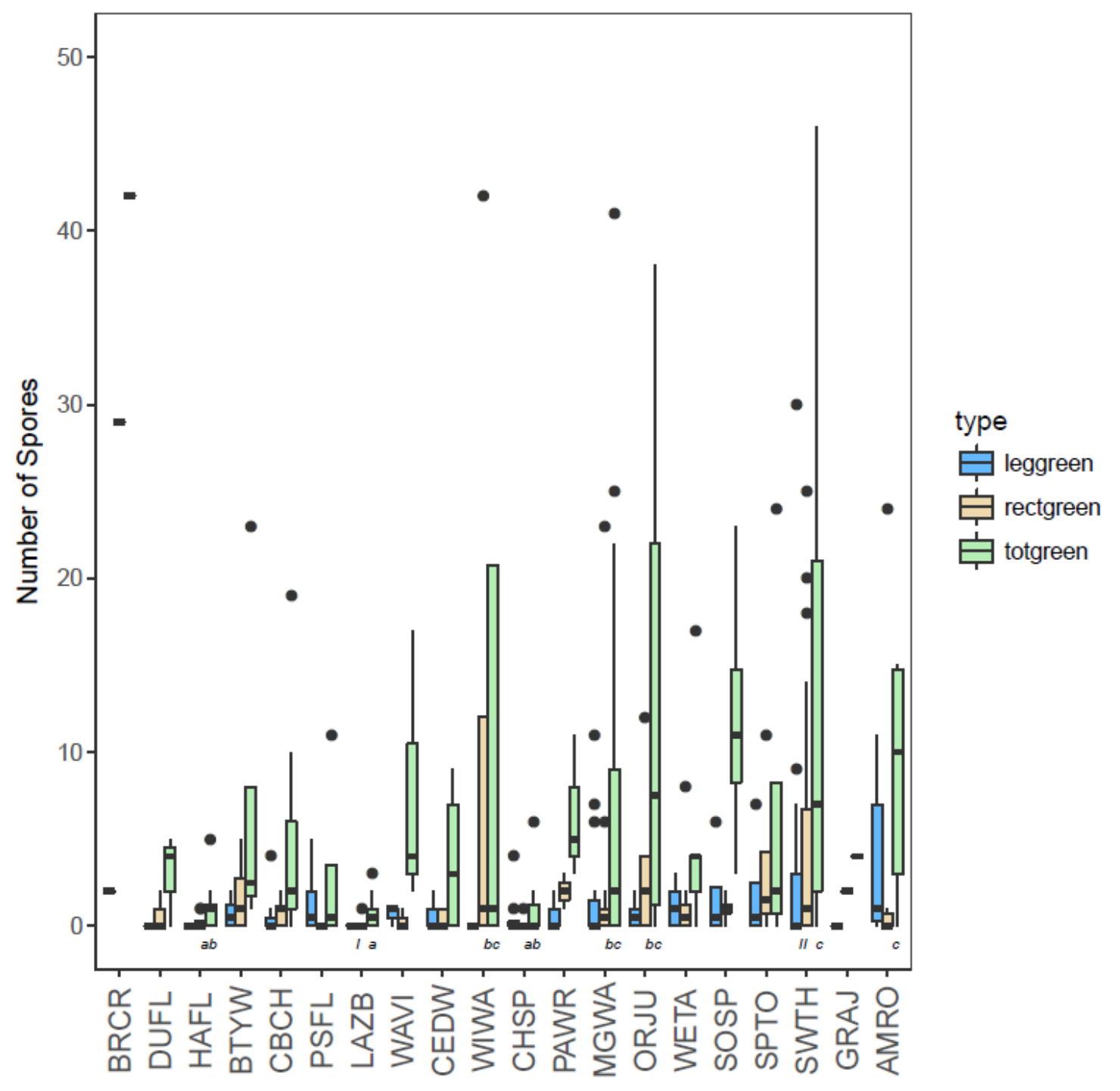


Figure 2.4: Leg, rectrix, and total number of chlorophyllic bryophyte spores found on different families of passerines in a Pacific Northwest, USA forest $(\mathrm{N}=171)$. Species are plotted by average tarsus length, increasing from left to right. Pairwise contrasts did not reveal any differences in number of spores on legs between species. Species marked with a Roman numeral differed significantly $(\mathrm{p}<0.05)$ from each other in retrix spore numbers, while those with different letter designations differed in total spore load. Groups without numeral or letter designations were not significantly different from any other group.

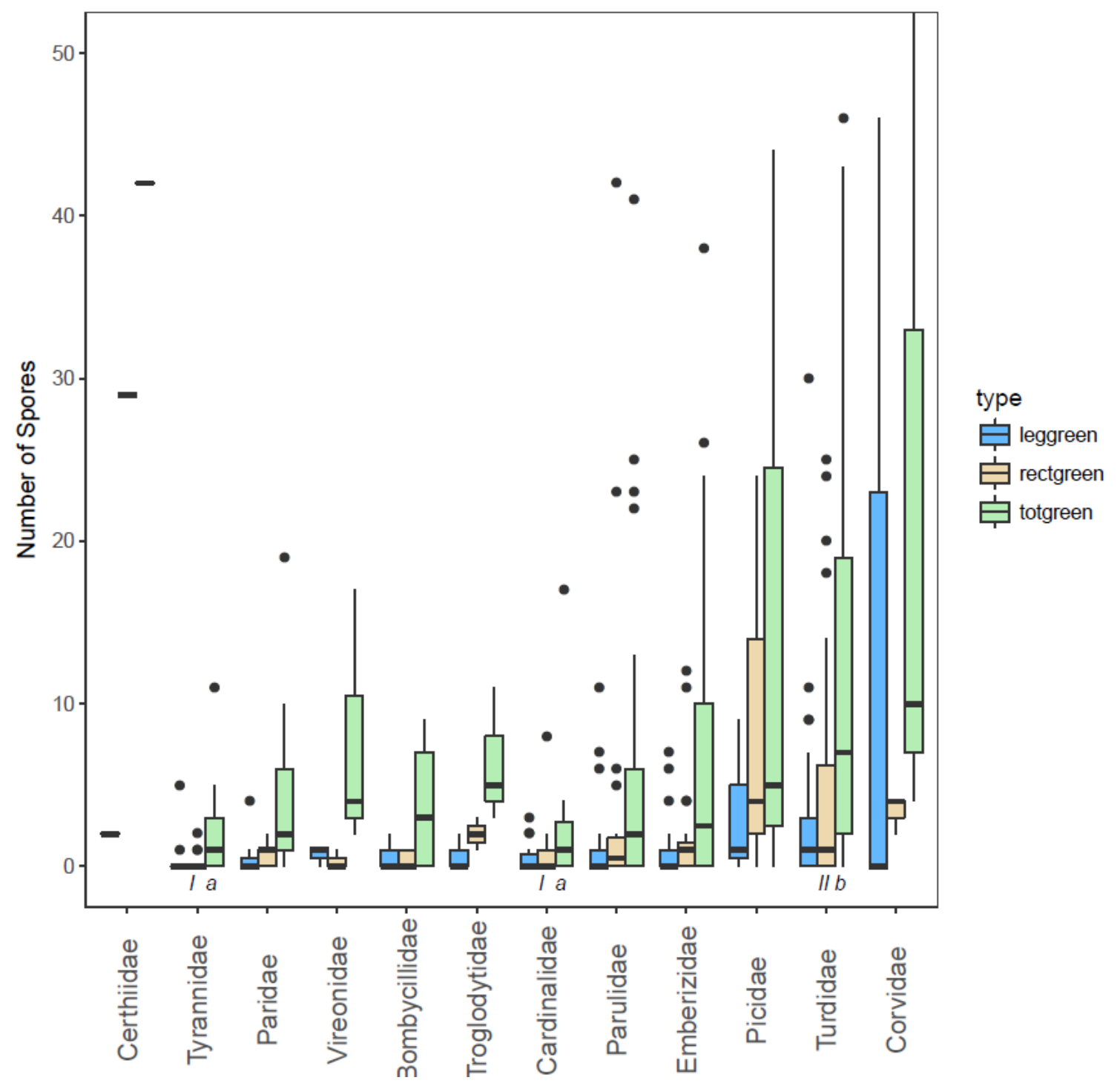




\section{References:}

1. Vellend M. 2010 Conceptual synthesis in community ecology. Q. Rev. Biol. 85, 183-206.

2. Götzenberger L et al. 2012 Ecological assembly rules in plant communitiesapproaches, patterns and prospects. Biol. Rev. 87, 111-127. (doi:10.1111/j.1469185X.2011.00187.x)

3. Leibold MA et al. 2004 The metacommunity concept: A framework for multiscale community ecology. Ecol. Lett. 7, 601-613. (doi:10.1111/j.14610248.2004.00608.x)

4. Logue JB, Mouquet N, Peter H, Hillebrand H. 2011 Empirical approaches to metacommunities: a review and comparison with theory. Trends Ecol. Evol. 26, 482-91. (doi:10.1016/j.tree.2011.04.009)

5. Löbel S, Snäll T, Rydin H. 2009 Mating system, reproduction mode and diaspore size affect metacommunity diversity. J. Ecol. 97, 176-185. (doi:10.1111/j.13652745.2008.01459.x)

6. Presley SJ, Higgins CL, Willig MR. 2010 A comprehensive framework for the evaluation of metacommunity structure. Oikos 119, 908-917. (doi:10.1111/j.16000706.2010.18544.x)

7. Meynard CN, Lavergne S, Boulangeat I, Garraud L, Van Es J, Mouquet N, Thuiller W. 2013 Disentangling the drivers of metacommunity structure across spatial scales. J. Biogeogr. 40, 1560-1571. (doi:10.1111/jbi.12116)

8. Nathan R, Muller-landau HC. 2000 Spatial patterns of seed dispersal, their determinants and consequences for recruitment. Trends Ecol. Evol. 15, 278-285. (doi:10.1016/S0169-5347(00)01874-7)

9. Levine JM, Murrell DJ. 2003 The community-level consequences of seed dispersal patterns. Annu. Rev. Ecol. Evol. Syst. 34, 549-574.

(doi:10.1146/annurev.ecolsys.34.011802.132400)

10. Schupp E. 1993 Quantity, Quality and the Effectiveness of Seed Dispersal by Animals. Vegetatio 107/108, 15-29.

11. Wang BC, Smith TB. 2002 Closing the seed dispersal loop. Trends Ecol. Evol. 17, 379-386. (doi:10.1016/S0169-5347(02)02541-7)

12. Carlo TA, Tewksbury JJ. 2014 Directness and tempo of avian seed dispersal increases emergence of wild chiltepins in desert grasslands. J. Ecol. 102, 248-255. (doi:10.1111/1365-2745.12180)

13. Tiffney BH. 2004 Vertebrate dispersal of seed plants through time. Annu. Rev. Ecol. Evol. Syst. 35, 1-29. (doi:10.1146/annurev.ecolsys.34.011802.132535) 
14. Crepet WL, Niklas KJ. 2009 Darwin's second 'abominable mystery': Why are there so many angiosperm species? Am. J. Bot. 96, 366-81.

(doi:10.3732/ajb.0800126)

15. Kenrick P, Crane PR. 1997 The origin and early evolution of plants on land. Nature 389, 33-39.

16. Gensel PG. 2008 The earliest land plants. Annu. Rev. Ecol. Syst. 39, 459-477. (doi:10.1146/annurev.ecolsys.39.110707.173526)

17. Mishler BD, Kelch DG. 2009 Phylogenomics and early land plant evolution. In Bryophyte Biology (eds B Goffinet, AJ Shaw), pp. 173-197. Cambridge University Press.

18. Turetsky MR. 2003 The role of bryophytes in carbon and nitrogen cycling. Bryologist 106, 395-409.

19. Lindo Z, Gonzalez A. 2010 The Bryosphere: An integral and influential component of the Earth's biosphere. Ecosystems 13, 612-627. (doi:10.1007/s10021-010-9336-3)

20. Jonsson M, Kardol P, Gundale MJ, Bansal S, Nilsson M-C, Metcalfe DB, Wardle DA. 2014 Direct and indirect drivers of moss community structure, function, and associated microfauna across a successional gradient. Ecosystems 18, 154-169. (doi:10.1007/s10021-014-9819-8)

21. Kimmerer RW. 2005 Patterns of Dispersal and Establishment of Bryophytes Colonizing Natural and Experimental Treefall Mounds in Northern Hardwood Forests. Bryologist 108, 391-401. (doi:10.1639/00072745(2005)108[0391:PODAEO]2.0.CO;2)

22. Miles CJ, Longton RE. 1992 Deposition of moss spores in relation to distance from gametophyte. J. Bryol. 17, 355-368.

23. Lönnell N, Hylander K, Jonsson BG, Sundberg S. 2012 The fate of the missing spores--patterns of realized dispersal beyond the closest vicinity of a sporulating moss. PLoS One 7, e41987. (doi:10.1371/journal.pone.0041987)

24. Levine JM. 2003 A patch modeling approach To the community-level consequences of directional dispersal. Ecology 84, 1215-1224.

25. Muñoz J, Felicísimo ÁM, Cabezas F, Burgaz AR, Martínez I. 2004 Wind as a long-distance dispersal vector in the southern hemisphere. Science (80). 304, 1144-1147.

26. Kreier HP et al. 2010 Phylogeny of the leafy liverwort Ptilidium: Cryptic speciation and shared haplotypes between the Northern and Southern Hemispheres. Mol. Phylogenet. Evol. 57, 1260-1267.

(doi:10.1016/j.ympev.2010.10.002) 
27. Piñeiro R, Popp M, Hassel K, Listl D, Westergaard KB, Flatberg KI, Stenøien HK, Brochmann C. 2012 Circumarctic dispersal and long-distance colonization of South America: the moss genus Cinclidium. J. Biogeogr. 39, 2041-2051. (doi:10.1111/j.1365-2699.2012.02765.x)

28. Lewis LR, Rozzi R, Goffinet B. 2014 Direct long-distance dispersal shapes a New World amphitropical disjunction in the dispersal-limited dung moss Tetraplodon (Bryopsida: Splachnaceae). J. Biogeogr. 41, 2385-2395. (doi:10.1111/jbi.12385)

29. Vigalondo B, Lara F, Draper I, Valcarcel V, Garilleti R, Mazimpaka V. 2016 Is it really you, Orthotrichum acuminatum? Ascertaining a new case of intercontinental disjunction in mosses. Bot. J. Linn. Soc. 180, 30-49. (doi:10.1111/boj.12360)

30. Biersma EM, Jackson JA, Hyvönen J, Koskinen S, Linse K, Griffiths H, Convey P. 2017 Global biogeographic patterns in bipolar moss species. R. Soc. Open Sci. 4, 170147. (doi:10.1098/rsos.170147)

31. Heinken T. 2001 Epizoochorous dispersal of bryophyte stem fragments by roe deer (Capreolus capreolus) and wild boar (Sus scrofta). J. Bryol. 23, 293-300.

32. Pauliuk F, Müller J, Heinken T. 2011 Bryophyte dispersal by sheep on dry grassland. Nov. Hedwigia 92, 327-341. (doi:10.1127/0029-5035/2011/0092-0327)

33. Parsons JG, Cairns A, Johnson CN, Robson SKA, Shilton LA, Westcott DA. 2007 Bryophyte dispersal by flying foxes: a novel discovery. Oecologia 152, 112-4. (doi:10.1007/s00442-006-0639-1)

34. Barbé M, Chavel ÉE, Fenton NJ, Imbeau L, Mazerolle MJ, Drapeau P, Bergeron Y. 2016 Dispersal of bryophytes and ferns is facilitated by small mammals in the boreal forest. Écoscience 23, 67-76. (doi:10.1080/11956860.2016.1235917)

35. Kimmerer RW, Young CC. 1995 The role of slugs in dispersal of the asexual propagules of Dicranum flagellare. Bryologist 98, 149-153.

36. Boch S, Berlinger M, Fischer M, Knop E, Nentwig W, Türke M, Prati D. 2013 Fern and bryophyte endozoochory by slugs. Oecologia 172, 817-822. (doi:10.1007/s00442-012-2536-0)

37. Rudolphi J. 2009 Ant-mediated dispersal of asexual moss propagules Antmediated dispersal of asexual moss propagules. Bryologist 112, 73-79.

38. Proctor VW. 1961 Dispersal of Riella Spores by Waterfowl. Bryologist 64, 58-61.

39. Wilkinson DM, Lovas-Kiss A, Callaghan DA, Green AJ. 2017 Endozoochory of Large Bryophyte Fragments by Waterbirds. Cryptogam. Bryol. 38, 223-228. (doi:10.7872/cryb/v38.iss2.2017.223)

40. Osorio-Zuñiga F, Fontúrbel FE, Rydin H. 2014 Evidence of mutualistic synzoochory between cryptogams and hummingbirds. Oikos 123, 553-558. (doi:10.1111/j.1600-0706.2013.01027.x) 
41. Manno P. 2009 The ecology and evolution of fly dispersed dung mosses (Family Splachnaceae ): Manipulating insect behaviour through odour and visual cues. Symbiosis 47, 61-76.

42. Lewis LR et al. 2014 First evidence of bryophyte diaspores in the plumage of transequatorial migrant birds. PeerJ 2, e424. (doi:10.7717/peerj.424)

43. Glime J. 2007 Bryophyte Ecology. Volume 1. Physiological Ecology. See http://digitalcommons.mtu.edu/bryophyte-ecology1/ (accessed on 20 June 2017).

44. Breil DA, Moyle SM. 1976 Bryophytes used in construction of bird nests. Bryologist 79, 95-98.

45. Parnikoza I, Dykyy I, Ivanets V, Kozeretska I, Kunakh V, Rozhok A, Ochyra R, Convey P. 2012 Use of Deschampsia antarctica for nest building by the kelp gull in the Argentine Islands area (maritime Antarctica) and its possible role in plant dispersal. Polar Biol. 35, 1753-1758. (doi:10.1007/s00300-012-1212-5)

46. Honorato MT, Altamirano TA, Ibarra JT, de la Maza M, Bonacic C. 2016 Composición de nidos de vertebrados nidificadores de cavidades en el bosque templado andino de Chile. Bosque 37, 485-492. (doi:10.4067/S071792002016000300005)

47. Nadkarni NM, Matelson TJ. 1989 Bird use of epiphyte resources in neotropical trees. Condor 91, 891-907.

48. Sillet TS. 1994 Foraging Ecology of Epiphyte-Searching Insectivorous Birds in Costa Rica. Condor 96, 863-877.

49. Evans RN, Prusso DC. 1969 Spore dispersal by birds. Mycologia 61, 832-835.

50. Suthers HB. 1985 Ground-feeding migratory songbirds as cellular slime mold distribution vectors. Oecologia 65, 526-530.

51. Pyle P. 1997 Identification Guide to North American Birds: Columbidae to Ploceidae. Slate Creek Press.

52. McDaniel SF. 2015 BCD-a Media. McDaniel Lab Protoc. Data. See http://sites.clas.ufl.edu/mcdaniellab/files/BCD-media-recipie.pdf (accessed on 9 September 2015).

53. Poole A. 2005 The Birds of North America Online. Ithaca Cornell Lab Ornithol. See http://bna.birds.cornell.edu/BNA/.

54. Venables WN, Ripley BD. 2002 Modern Applied Statistics with S. 4th edn. New York: Springer. See http://www.stats.ox.ac.uk/pub/MASS4.

55. Bates D, Mächler M, Bolker B, Walker S. 2014 Fitting Linear Mixed-Effects Models using lme4. 67. (doi:10.18637/jss.v067.i01)

56. R Core Team. 2017 R: A language and environment for statistical computing. R 
Foundation for Statistical Computing Vienna, Austria.

57. Lenth R V. 2016 Least-Squares Means: The $\{\mathrm{R}\}$ Package $\{$ lsmeans $\}$. J. Stat. Softw. 69, 1-33. (doi:10.18637/jss.v069.i01)

58. Wickham H. 2009 ggplot2: Elegant Graphics for Data Analysis. Springer-Verlag New York. See http://ggplot2.org.

59. Wenny DG. 2001 Advantages of seed dispersal: A re-evalution of directed dispersal. Evol. Ecol. Res. 3, 51-74. (doi:10.1002/(SICI)10982345(200004)50:4<275::AID-AJP4>3.0.CO;2-K)

60. Herrera CM. 1998 Long-term dynamics of Mediterranean frugivorous birds and fleshy fruits: A 12-year study. Ecol. Monogr. 68, 511-538. (doi:10.1890/00129615(1998)068[0511:LTDOMF]2.0.CO;2)

61. Rising JD, Somers KM. 1989 The measurement of overall body size in birds. Auk 106, 666-674. (doi:10.2307/4087673)

62. Freeman S, Jackson WM. 1990 Univariate metrics are not adequate to measure avian body size. Auk 107, 69-74.

63. Franzreb KE. 1985 Foraging ecology of brown creepers in a mixed-coniferous forest. J. F. Ornithol. 56, 9-16.

64. Villard P, Beninger CW. 1993 Foraging behavior of male Black-Backed and Hairy Woodpeckers in a forest burn. J. F. Ornithol. 64, 71-76.

65. Weikel JM, Hayes JP. 1999 The foraging ecology of cavity-nesting birds in young forests of the Northern Coast Range of Oregon. Condor 101, 58-66.

66. Jackson JA. 1971 The adaptive significance of reversed sexual dimorphism in tail length of woodpeckers: An alternative hypothesis. Bird-Banding 42, 18-20.

67. Lawton E. 1971 Moss Flora of the Pacific Northwest. Hattori Botanical Library.

68. Pojar J, MacKinnon A. 2004 Plants of the Pacific Northwest Coast. Partners Publishing Group.

69. Milá B, Wayne RK, Fitze P, Smith TB. 2009 Divergence with gene flow and finescale phylogeographical structure in the wedge-billed woodcreeper, Glyphorynchus spirurus, a neotropical rainforest bird. Mol. Ecol. 18, 2979-2995. (doi:10.1111/j.1365-294X.2009.04251.x)

70. Sabo SR, Holmes RT. 1983 Foraging niches and the structure of forest bird communities in contrasting montane habitats. Condor 85, 121-138.

71. De Graaf RM, Tilghman NG, Anderson SH. 1985 Foraging guilds of North American birds. Environ. Manage. 9, 493-536. (doi:10.1007/BF01867324)

72. Viana DS, Santamaría L, Figuerola J. 2016 Migratory Birds as Global Dispersal Vectors. Trends Ecol. Evol. 31, 763-775. (doi:10.1016/j.tree.2016.07.005) 
73. Beringer J, Lynch AH, Stuart F, Mack M, Bonan GB. 2001 The Representation of Arctic Soils in the Land Surface Model: The Importance of Mosses. J. Clim. 14, 3324-3335.

74. Cornelissen JHC, Lang SI, Soudzilovskaia NA, During HJ. 2007 Comparative cryptogam ecology: A review of bryophyte and lichen traits that drive biogeochemistry. Ann. Bot. 99, 987-1001. (doi:10.1093/aob/mcm030)

75. Palozzi JE, Lindo Z. 2017 Boreal peat properties link to plant functional traits of ecosystem engineers. Plant Soil 418, 277-291. (doi:10.1007/s11104-017-3291-0) 


\section{Chapter 3}

\section{Species-specific interactions in avian-bryophyte dispersal networks}

\section{Abstract}

Animal dispersal of plant propagules fundamentally alters the success of dispersal events, and thus shapes plant community composition through time. While this is welldocumented in seed plants, spore-bearing plants have received little attention with regards to this phenomenon. Birds are particularly attractive as a potential bryophyte dispersal vector given their highly vagile nature as well as their association with bryophytes when foraging and building nests. Despite this, species-specific dispersal relationships between birds and bryophytes have never been examined. We captured birds in Gifford Pinchot National Forest to sample their legs and tails for bryophyte spores. We found 24 bryophyte species across 34 species of bird. We examined the level of specialization 1) within the overall interaction network to assess community level patterns and 2) at the plant species level to determine the effect of bird behavioral type on the plant-animal interaction. Our results suggest that associations within the network are more constrained than expected by chance. Additionally, we found that avian behavioral group impacted the variety of bryophytes found on an individual bird. Foliage gleaners and ground foragers had particularly specialized associations within the overall disperserbryophyte network. Our finding suggest that diffuse bird-bryophyte dispersal networks are likely to be common in habitats where birds readily encounter bryophytes and that further work aimed at understanding individual bird-bryophyte species relationships may prove valuable in determining nuance within this newly described dispersal mechanism. 


\section{Introduction}

Dispersal is often a brief period of an organism's life history, but is an especially important life stage for sessile organisms such as plants, which otherwise maintain a sedentary lifestyle. Dispersal sets the context for the majority of the plant life cycle, from germination through senescence. By moving, plant propagules are potentially able to escape competition with conspecifics and avoid density-dependent mortality due to herbivores and/or parasites $[1,2]$. The deposition of propagules in locations with particular characteristics can largely impact seedling germination and survival $[3,4]$. At a population level, dispersal maintains gene flow within metapopulations and increases connectivity across the landscape [5]. In addition, it plays a pivotal role in ecological assembly by generating and maintaining diversity within and among communities $[6,7]$. The movement of propagules can drive community composition through priority effects $[8,9]$ as well as the differential species-specific dispersal of seeds [10]. Dispersal contributes to inter-community connectivity $[11,12]$, and diversity within and among communities depends on the extent of connectivity among parts of a metacommunity [13] and varies across spatial scale [14].

Mechanisms that increase the probability of a plant settling in a particular locale within the landscape can have outsized impacts on the distribution of a wide variety of taxa, and the subsequent local community composition [15]. Biased movement toward appropriate habitat can improve the quality of dispersal outcomes, increasing the effectiveness of the dispersal event [16]. Animal vectors are particularly suited to altering plant propagule distribution patterns by integrating behaviorally directed propagule 
deposition toward appropriate locations within a largely heterogenous environment [1719]. Indeed, behaviorally mediated dispersal via associations with animal vectors has been shown to have widespread impacts on plant propagule outcomes [20,21]. Birds, being highly vagile organisms that are sensitive to particular habitat characteristics, are especially likely to increase dispersal distance for vascular plants as well as improve quality and connectivity of seed dispersal from local to landscape scales [22-26].

While much effort has been applied toward understanding how animal behavior may shape the dispersal outcomes of seed plants, we know little about the ramifications of animal dispersal of plant spores. Plant reproduction via spores predates the advent of seeds, and understanding more about the dispersal strategies of spore-bearing plants may provide insight into the context in which seeds and seed dispersal evolved [27-29]. Bryophytes strongly influence ecosystem processes, including nutrient cycling, soil water storage, and a better understanding of the drivers of assembly within bryophyte communities may increase our understanding of the rate and pattern of how bryophyteassociated ecosystem services develop. This is of particular interest in habitats recovering from direct anthropogenic disturbance [30], and in high latitude regions where significant snow and ice melt is generating areas newly open to bryophyte colonization due to a warming climate [31-34].

Researchers have argued that spore-bearing plants are unlikely to be limited by dispersal, but studies have been mainly focused on Sphagnum spp. [35,36], inferring dispersal distance [37,38], or implying that niche constraints solely drive bryophyte distributions [39]. Mounting evidence suggests that dispersal can impact richness, 
diversity, and metacommunity dynamics in bryophytes [40-44]. Multiple studies have shown that mammals and invertebrates harbor bryophyte diaspores, and may therefore be contributing to bryophyte dispersal outcomes [45-49]. Recently, mounting evidence has suggested that birds may also be vectors for bryophytes. Hummingbirds have been found to transport gametophytic material between sites to build nests, and these bryophytes were shown to be capable of reproducing in their new sites [50]. Additionally, Lewis et $a l$. found bryophyte propagules on nesting shorebirds [51]. While dependent on a small sample, this work provided the first published evidence of bryophyte propagules on bird surfaces. Lewis also provided some genetic evidence that long distance dispersal, perhaps by birds, is the likely explanation for the genetic structure of otherwise disjunct Tetraplodon populations [52]. Our own work has found that bryophyte spores are found on the feathers and legs of a wide range of passerine taxa, and that these spores are viable [53]. While these studies suggest birds transport bryophyte propagules, further work that considers species-specific dispersal interactions is necessary to understand the potential importance and underlying structure of this dispersal mechanism.

To determine whether avian species and foraging behavior influence the diversity and identity of topically vectored bryophyte species, we captured birds within Gifford Pinchot National Forest, WA, Pacific Northwest USA and sampled them for bryophyte propagules. We sampled bird legs and tail feathers, germinated samples, and used a chloroplast marker to identify individual bryophyte species associated with each bird. We predicted that 1) bird species would vary in the diversity of bryophyte propagules that they carried due to differential use of habitat; 2) different foraging behaviors would 
expose birds to different bryophytes throughout the site, which would be reflected in the identity of propagules found on birds within foraging guilds; and 3) the diversity of bryophytes on a focal avian group (across both species and behavioral guild) would be constrained relative to a random sample from the available species pool.

\section{Methods:}

\section{(a) Mist netting and sampling for bryophytes}

To sample bird surfaces for bryophyte spores, we captured birds along a recreational trail adjacent to the Wind River Experimental Forest within Gifford Pinchot National Forest, WA, USA. We deployed ten 12 x 3m, 30 mm mesh mist nets from dawn to midafternoon throughout an Oregon Ash (Fraxinus latifolia Bentham) forest, surrounding a banding station at $4548^{\prime} 40^{\prime \prime} \mathrm{N}, 12156^{\prime} 35^{\prime \prime} \mathrm{W}$. We checked nets at least every 30 minutes, retaining birds for banding and sampling prior to release. Our site is adjacent to mixed Western Hemlock (Tsuga heterophylla Sargent) and Douglas-Fir (Pseudotsuga menziesii (Mirbel)) forest, and is bounded on one side by a small patch of meadow. The variety of surrounding habitat at our field site generated a diversity of avifauna with different habitat and foraging predilections. We sampled the legs and tails of each captured individual for bryophytes using cotton swabs (see [53] for details). Birds were additionally fitted with individually numbered USGS leg bands to account for recaptures. Avian capture data, along with age, sex, and morphometrics were submitted 
the to the USGS Bird Banding Laboratory. In order to better contextualize the bryophytes sampled from bird surfaces relative to the abundance of bryophytes in our field site, we measured the cover of bryophytes on both tree trunks and the ground by quadrat sampling every 10 meters along multiple transects. We sampling along transects both in the Oregon Ash dominant forest that contained our mist nets, as well as adjacent Douglas Fir dominant forest.

\section{(b) Sample processing and molecular methods}

Samples were vortexed twice each for one minute in filtered tap water and vacuum filtered onto gridded $0.45 \mu \mathrm{m}$ mixed cellulose ester membranes (EMD Millipore). We placed filters onto $60 \times 15 \mathrm{~mm}$ petri plates containing BCD nutrient agar [54] and grew them under a 12:12 L:D light cycle at approximately 500 lux at room temperature (22$\left.25^{\circ} \mathrm{C}\right)$. Plates that germinated over the next year were stored and later sampled for tissue. DNA was extracted using the manufacturer's protocol (Sigma Aldrich Extract-N-Amp PCR kit) and frozen for storage. Samples were later thawed and the trnF-L region [5558] of the chloroplast genome was amplified via PCR using the manufacturer's protocol. PCR products were Sanger sequenced on ABI 3730xl instruments (Functional Biosciences, Inc.). Additionally, we sequenced known species collected at our field site to improve our ability to confirm species identification.

\section{(c) Sequence processing and tree building}

We aligned forward and reverse Sanger reads to generate a consensus sequence for each sample, which we then trimmed to remove primer annealing sites. Samples were then 
preliminarily identified by comparison with NCBI accessioned trnF-L sequences via BLAST search [59]. Both bird swab and known field sample sequences were aligned in Geneious (v. 8.0.5) and used to build an UPGMA tree using the ape and phangorn packages in the R statistical computing platform version 3.3.3 [60-62]. Known samples from the field were used to confirm avian-derived sample identities before being removed from the tree. One Orthotrichum grouping of sequences failed to align appropriately within our tree and was removed from our analysis of phylogenetic distance. Finally, the single Marchantia sample in our dataset was removed prior to analyzing phylogenetic because it proved to be an overly influential outgroup, resulting in our final tree. Both avian species and family were substituted for bryophyte species names in separate trees for use in analyzing phylogenetic distance, and individual species associations plotted across the bryophyte phylogeny.

\section{(d) Data analysis}

Avian-bryophyte dispersal networks were assessed by examining bipartite (two level) ecological network structure. While initially developed for assessing the interaction between two trophic levels, these methods have since been applied to a variety of interaction networks, including dispersal networks[63,64]. The level of specialization (H2') of the overall network was assessed using an information theoretic approach derived from Shannon's Diversity Index. This global network index was then compared to a null distribution of specialization developed by iterating species interactions over 1000 runs while maintaining species abundances present in the original dataset [65]. Significance ( $\mathrm{p}$ value) of a given network-level degree of specialization when compared 
to a random distribution of associations can be derived as the proportion of values of the random distribution of values that exceed or are equal to the observed $\mathrm{H} 2$ ' [66]. We conducted a similar analysis on subsets of the interaction network based on avian behavioral group, allowing for a comparison of specialization across behavioral groups. We additionally calculated species-level specialization (d') of the bryophytes in the overall avian-association network, as well as subset networks defined by avian behavioral guild [67]. We assessed how avian foraging guild impacts bryophyte specialization by building linear models comparing d' for each bryophyte species in the total dataset to d' within networks constructed from individual behavioral types.

We analyzed Faith's Phylogenetic Distance (PD) by treating each avian species as an aggregate "site" type, calculating the minimal path of connectivity across the bryophyte tree of all species found on each individual bird species (Figure C3). For each species, a sample-size controlled null distribution was generated by permuting bryophyte species identities randomly 1000 times across the tree and calculating minimal path of connectivity [68]. Observed values of PD were compared with the mean $\pm 95 \%$ CI of the null distributions to determine whether avian-vectored bryophyte species were more clumped than random. Analyses and visualizations were constructed in $\mathrm{R}$ using the bipartite, picante, and ggplot2 packages [69-71].

\section{Results:}

\section{a) Bird and bryophyte species}


We captured 34 different species of birds comprised of 192 individuals. We most commonly captured Swainson's Thrushes (Catharus ustulatus 47 captures), with Rufous Hummingbirds (Selasphorus rufus, 25), MacGillivray’s Warblers (Geothlypis tolmiei, 19), Oregon Juncos (Junco hyemalis oreganus, 13), and Lazuli Buntings (Passerina amoena, 12) being well represented in the dataset. On these 192 birds, we found 24 species of bryophytes. The most common species was Ceratodon purpureus, a weedy species with a wide distribution that grows on a wide variety of substrates including soils, rocks, and anthropogenically disturbed substrates [72]. Other common species included Aulacomnium androgynum, Isothecum myosuroides, and Kindbergia oregana. Similarly, our field survey of bryophytes included abundant cover of Isothecium myosuroides on trees and Kindbergia oregana on the ground, but also included abundant Hypnum circinale and Neckera douglasii which were not found on our avian samples. (Table C1).

\section{b) Network level analysis}

The overall bird-bryophyte dispersal network exhibited nonrandom species-specific association structure, providing evidence that bird species identity impacts the types of bryophytes being carried on bird surfaces (Figures 3.1, C2). The overall interaction network was more highly specialized than would be expected if associations were random ( $\mathrm{p}<0.01$, Figure 3.2a). When interaction networks of specific behavioral groups were examined, both ground foragers $(\mathrm{p}<0.01$, Figure 3.2b) and foliage gleaners $(\mathrm{p}<$ 0.01, Figure 3.2c) also exhibited more specialization of interactions across the network than expected by chance. By contrast, aerial insectivores appeared to associate with bryophytes simply by chance $(\mathrm{p}=0.39$, Figure $3.2 \mathrm{~d})$. 


\section{c) Species-level analyses}

Individual bryophyte species varied in their specialization (d') within the overall interaction network (Figure 3.3a). When species associations were examined within subset networks defined by avian foraging behavior, bryophytes associating with foliage gleaners significantly reflected overall specialization within the network, though with generally reduced specialization $\left(\mathrm{F}_{1,19}=95.27, \mathrm{p}<0.001\right.$; Figure $\left.3.3 \mathrm{c}\right)$. Dicranum tauricum showed a particularly marked decrease in d', while Zygodon intermedius was the only species that increased in specialization within the foliage gleaner network. Bryophytes associated with both ground foragers $(\mathrm{F} 1,16=0.75, \mathrm{p}=0.39$; Figure 3.3b) and aerial salliers $\left(\mathrm{F}_{1,2}=0.43, \mathrm{p}=0.58\right.$; Figure $\left.3.3 \mathrm{~d}\right)$ did not reflect specialization patterns exhibited by the overall network. Individual bryophyte species within the ground foraging network varied in their specialization when compared with the overall network, with d' increasing and decreasing in relatively equal proportions. The network comprised of aerial salliers exhibited a binary relational structure. The phylogenetic distance, our other measure of bryophyte-avian specialization, was lower than expected by chance across the avian species we sampled, with the exception of those found on Spotted Towhees (Figure 3.4a). At the family level, we similarly found a lower phylogenetic distance than expected by chance across all groups (Figure 3.4b).

\section{Discussion}


Our results describe the first species-specific interaction network between birds and topically resident bryophyte propagules. The variety of bryophyte propagules that we found on a wide array of passerine species suggests that this is a general phenomenon, with potential implications for understanding the impact of animal behavior on bryophyte dispersal. Our study system reflects a network structure in which certain bryophyte-bird associations are more common than others, and this demonstrates that bipartite species relationships show significant specialization. As this was also true for networks comprised of only foliage gleaning or ground foraging bird species, specialization appears to be nuanced within broadly defined habitat partitions. Use of overlapping local niche space within the ground and arboreal portions of the habitat is therefore likely to drive species associations within Pacific Northwest forests. Our dataset was relatively depauperate of aerial species, and we found that these birds may have been associated with bryophytes by chance. Further study of aerial foraging species is necessary to determine whether this group demonstrates any meaningful interaction structure with topically-vectored bryophytes.

From a bryophyte species-specific point of view, specialization varied widely, with some species such as Grimmia pulvinata and Orthotrichum pulchellum exhibiting tight associations with certain avian species while others such as Sanionia uncinata and Rhytidiadelphus triquetrus were found across a wide variety of birds. The foliage gleaning network demonstrated generally similar patterns of specialization as the overall network, though with generally slightly reduced specialization. This suggests that avianbryophyte associations within this study are mostly driven by foliage gleaning behavior, and that foliage gleaners tend to pick up a more diverse set of bryophyte species than 
ground foraging species. One species, Dicranum tauricum, exhibited a much-reduced d' in the foliage gleaners, suggesting that it had broader associations with birds in the behavioral group when compared with ground foraging birds. As this species is known to grow on trees and fragments easily, it may be particularly well suited to being carried on the surfaces of birds that used arboreal habitat as a foraging space [73].

Bryophytes within the ground foraging network shifted unpredictably in specialization of connections with bird species relative to the total network. This variability suggests that ground foraging generates a significantly different network of connections than foliage gleaning, and that the likelihood of being transported on a bird surface depends on the behavior of the birds using local habitat. Certain species of bryophytes, therefore are more likely to be transported by different species, and foraging guilds, of birds.

While demonstrating a level of specialization greater than expected should bryophyte propagules be ubiquitously dispersed, the bryophytes and birds in our study system fail to exhibit tight individual species-species dependencies. This diffuse dispersal network is similar in nature to what is seen in seed plant-animal dispersal relationships, where associations between plant seeds and suites of animals with similar traits rather than associations with specific species is the norm [74]. We therefore expect that with further work it may become apparent that individual bird species co-vector specific groups of bryophytes together. Thus, understanding these relationships will allow for better prediction of how the variety of birds in a given location may impact bryophyte dispersal outcomes. 
While avian dispersal may prove to be a fractional component of the overall dispersal outcomes of a given bryophyte species, to date bryologists have to date lagged behind vascular plant ecologists in considering the specific impacts that a combination of multiple and varied dispersal mechanisms may have on bryophyte populations. Compared with passive, aerial dispersal, zoochorous dispersal may specifically increase dispersal to appropriate niche-space, as animal dispersers are likely to be drawn to specific localities within a patch of habitat. The dispersal kernels of bryophytes carried by birds are likely to differ in both distance and timing compared with abiotic dispersal. By increasing the deposition of propagules at particular localities within the available niche space that reflect areas already visited by birds, dispersal volume, rate, and timing may have impacts on the structure exhibited by the bryophyte component at the level of both the local community and the metacommunity. In turn this realized assemblage stands to influence the composition and abundance of microbes and microfauna that live within bryophyte mats and contribute to local resource availability and nutrient cycling.

Diversity generated and maintained by these processes contributes to a variety of the functional services provided by bryophytes, including contributing to atmospherebiosphere interactions, altering water dynamics, increasing atmospheric nutrient deposition, and mediating the soil-atmosphere interface [30,75]. These attributes of bryophytes create microhabitats for an array of microarthropods, in turn generating rich foraging grounds for insectivorous birds [76] as well as nesting material. Thus, the avian contribution to bryophyte dispersal is likely to influence the resources available to birds themselves, and therefore impact both their behavioral ecology and fitness in a given locale. 
We suggest that future work should focus on how propagule loads of various bird species may specifically influence the co-dispersal of bryophytes on bird surfaces to determine whether certain species pairs are more likely to arrive in novel sites together via an animal vector. Additionally, quantifying the topical retention time of spores and fragments on bird surfaces would allow us to predict the dispersal distance potential of bryophytes during both local and migratory avian movements.

\section{Ethics}

All birds were captured under U.S. Geological Survey Bird Banding permit number 22230 - S, and were also overseen by the Portland State University Institute Animal Care and Use Committee (IACUC protocol \#52).

\section{Data accessibility}

Data will made available in the Dryad Digital Repository upon manuscript acceptance. The code and data to reproduce the analysis are freely available at https://github.com/mwchmiel/windriver. Additionally, all bird capture data have been submitted to the U.S. Geological Survey's Bird Banding Laboratory.

\section{Competing Interests}

The authors have no competing interests to declare. 


\section{Authors' Contributions.}

MWC designed the study with input from SME. MWC carried out the study and analyzed the data. MWC and SME wrote the manuscript.

\section{Acknowledgements}

The authors would like to thank Ariadna Covarrubias-Ornelas, Sara Herrejon Chavez and Samantha Martin for assistance in the laboratory. We would also like to thank Claudia Candia and Jess Shamek for assistance in the field. We thank the United States Forest Service, especially Ken Bible for logistical support in the field, and the Portland State University Institute Animal Care and Use Committee, Washington State Department of Fish and Wildlife, and the United States Geological Survey Bird Banding Laboratory for permitting and animal research oversight.

Funding. The Portland State Biology Department, American Bryological and Lichenological Society, and National Science Foundation (DEB-1701756) provided financial support. 


\section{Figures}

Figure 3.1: Network connectivity between bryophytes and birds within a dispersal association network. The relative width of species bars on either end of the association network represents the relative representation of a particular species within the dataset, with the width of connections between species representing the strength of the dispersal association. Species are identified via their Bird Banding Laboratory four-letter identification code as follows: American Robin (AMRO), Black Headed Grosbeak (BHGR), Brown Creeper (BRCR), Black-throated Gray Warbler (BTYW), Chestnutbacked Chickadee (CBCH), Cedar Waxwing (CEDW), Chipping Sparrow (CHSP), Dusky Flycatcher (DUFL), Gray Jay (GRAJ), Hairy Woodpecker (HAWO), Hammond's Flycatcher (HAFL), Hermit Thrush (HEWA), Lazuli Bunting (LAZB), MacGillivray's Warbler (MGWA), Oregon Junco (ORJU), Pacific Wren (PAWR), Pacific Slope Flycatcher (PSFL), Song Sparrow (SOSP), Spotted Towhee (SPTO), Stellar's Jay (STJA), Swainson's Thrush (SWTH), Warbling Vireo (WAVI), White Crowned Sparrow (WCSP), Western Tanager (WETA), and Wilson's Warbler (WIWA). 


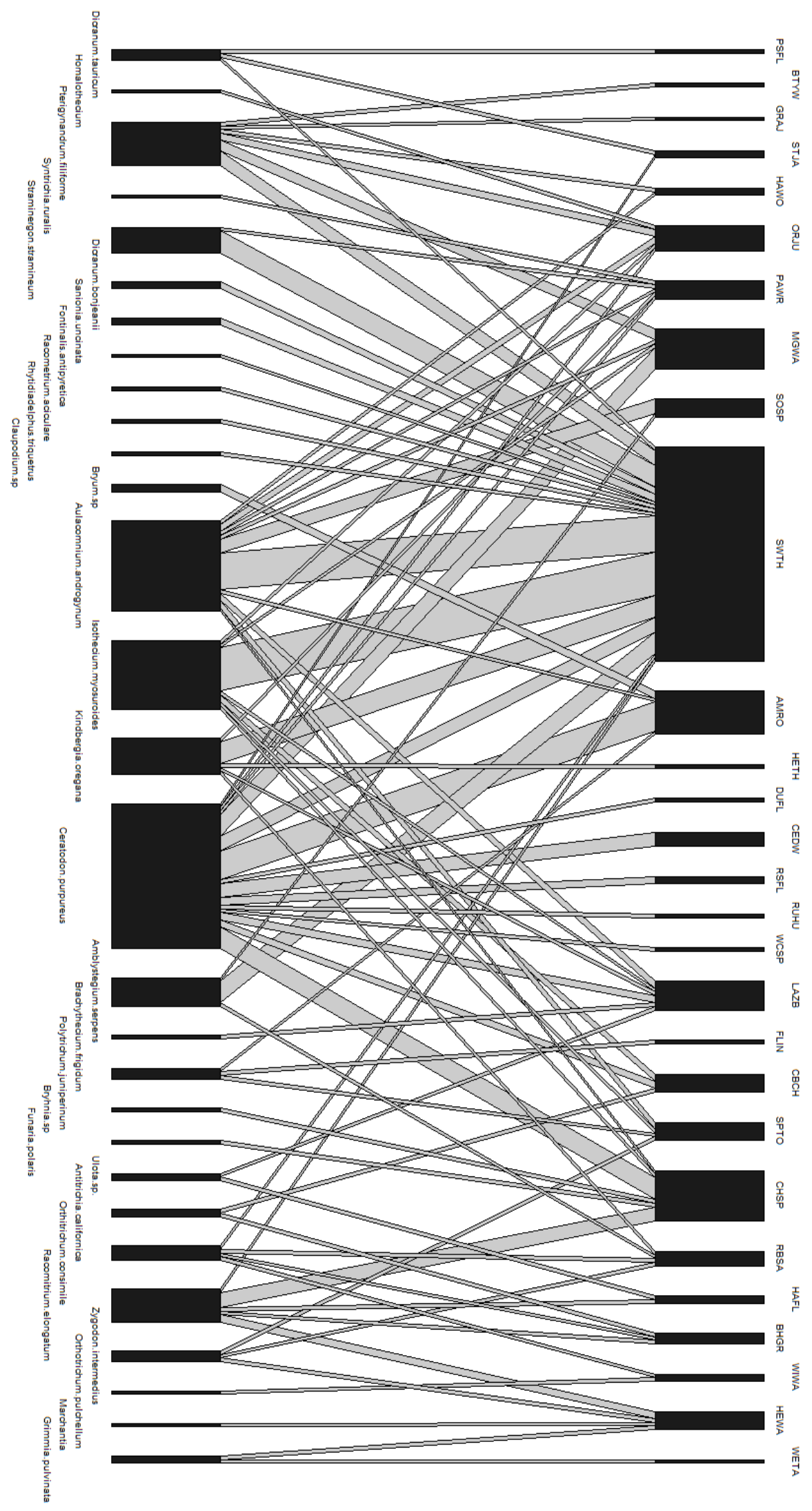


Figure 3.2: The level of observed specialization of connections within an avian-bryophyte dispersal network compared with the level of specialization within a null distribution of networks. Higher values of H2' indicate a higher degree of specialization within the network, Null distributions were computed by randomizing bipartite associations across the network over 1000 permutations. A) Specialization within the overall network was higher than expected by chance, B) specialization within a subset network including only foliage gleaners was also higher than expected by chance, C), and specialization within a subset network including only ground foragers was higher than expected by chance. D) Specialization within a subset network including only aerial salliers was not significantly different than expected by chance. 

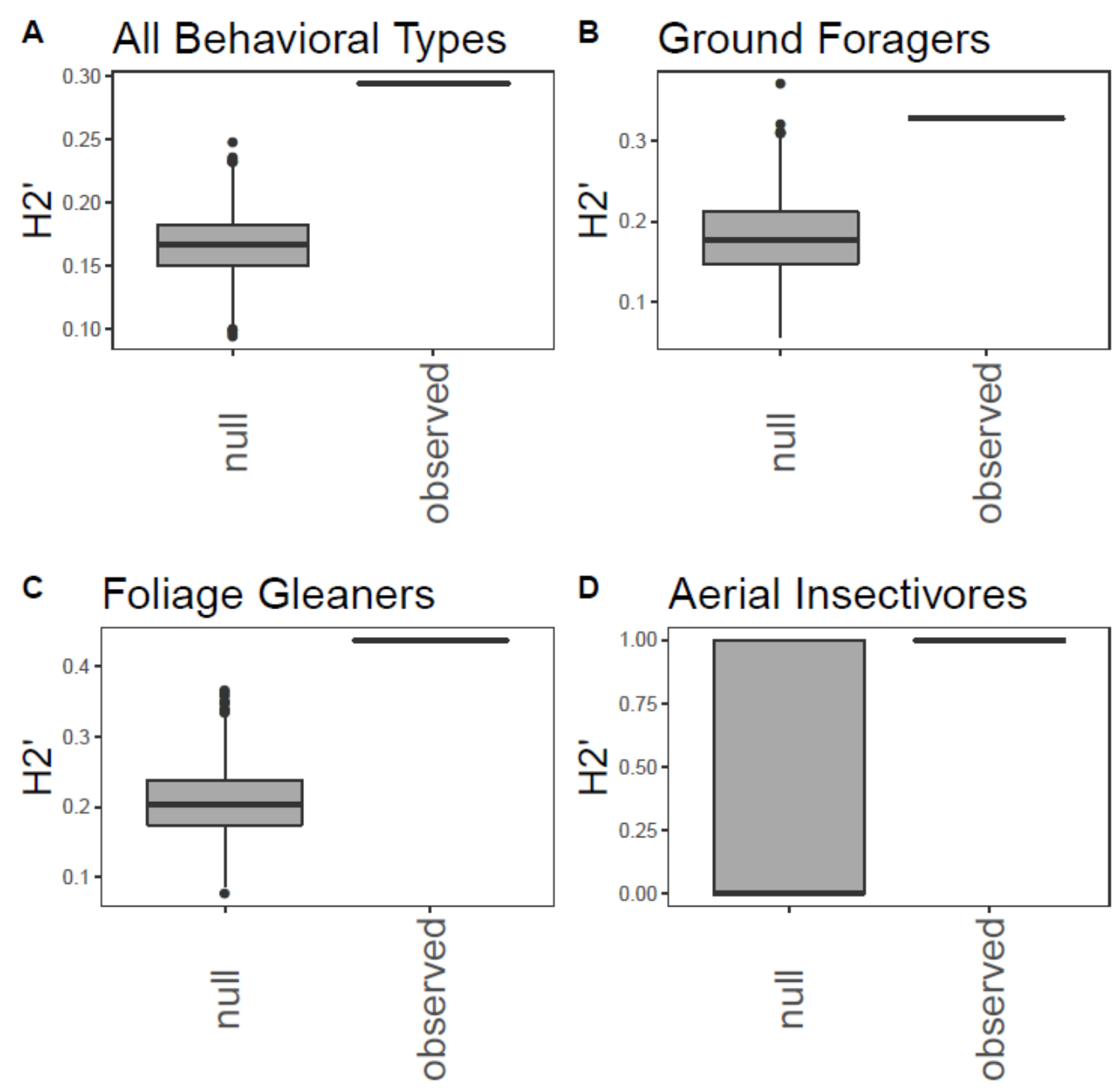

D Aerial Insectivores

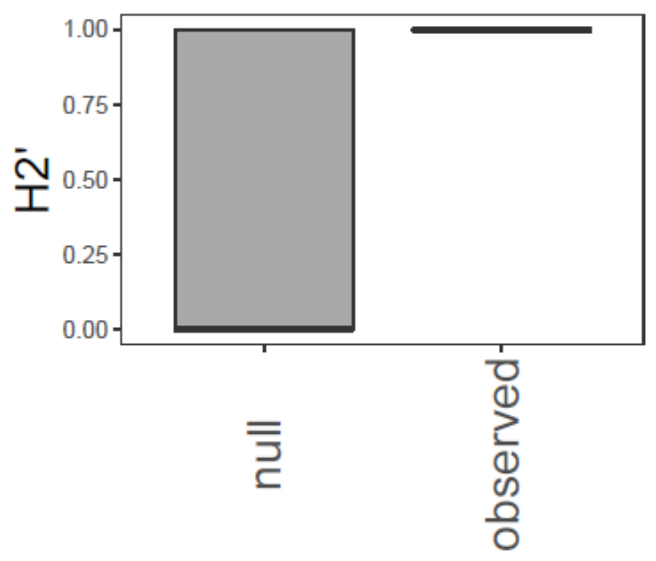


Figure 3.3: The level of specialization of individual bryophytes in an avian-bryophyte dispersal network. Higher values of d' indicate that the individual bryophyte species has more specialized associations with birds within the bipartite network. A) Species-level specialization of individual bryophytes within the overall network. Darker colors correspond to lower levels of specialization within the overall network. B) Specialization of bryophytes within the ground foraging network. Colors represent the level of specialization within the overall network, and shifts along the $\mathrm{x}$ axis indicate changes in specialization when compared with the overall network. The inset panel plots d' from the overall network against d' from the ground foraging network, with the diagonal line representing a 1:1 relationship such that points above the line indicate more specialization within the overall network. C) Specialization of bryophytes within the foliage gleaning network. Colors and inset panel follow panel B. D) Specialization of bryophytes within the foliage gleaning network. Colors and inset panel follow panel B. 

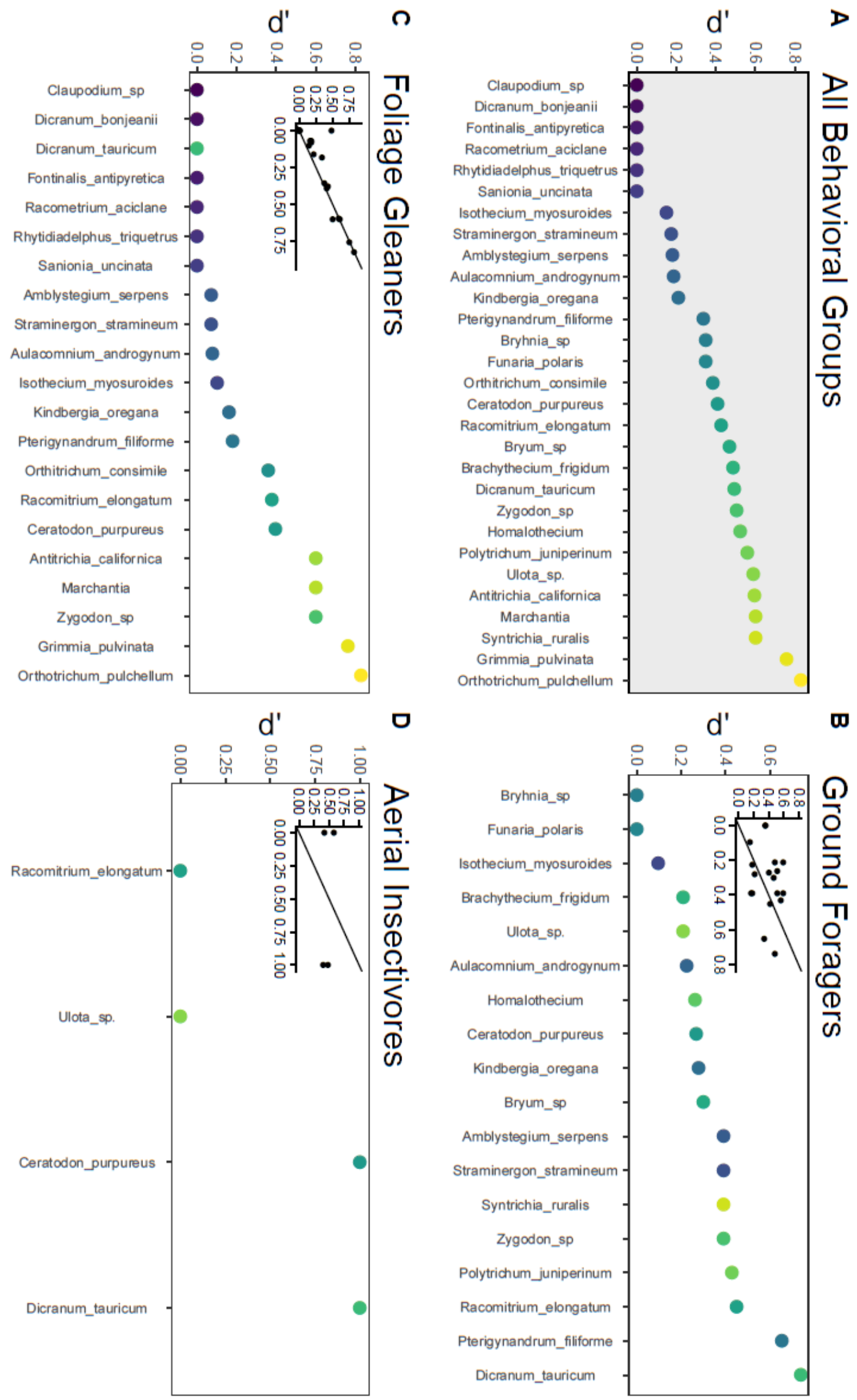

62 
Figure 3.4: Phylogenetic distance of all bryophytes found on individual A) species and B) families (red dots) of birds compared with null distributions $+/-95 \% \mathrm{CI}$ (blue dots and surrounding bars) generated by placing bryophyte species randomly across the phylogenetic tree over 1000 iterations. All families and all species except Spotted Towhees exhibited a smaller distance that expected by chance, indicating specialization in bryophyte-bird associations. 


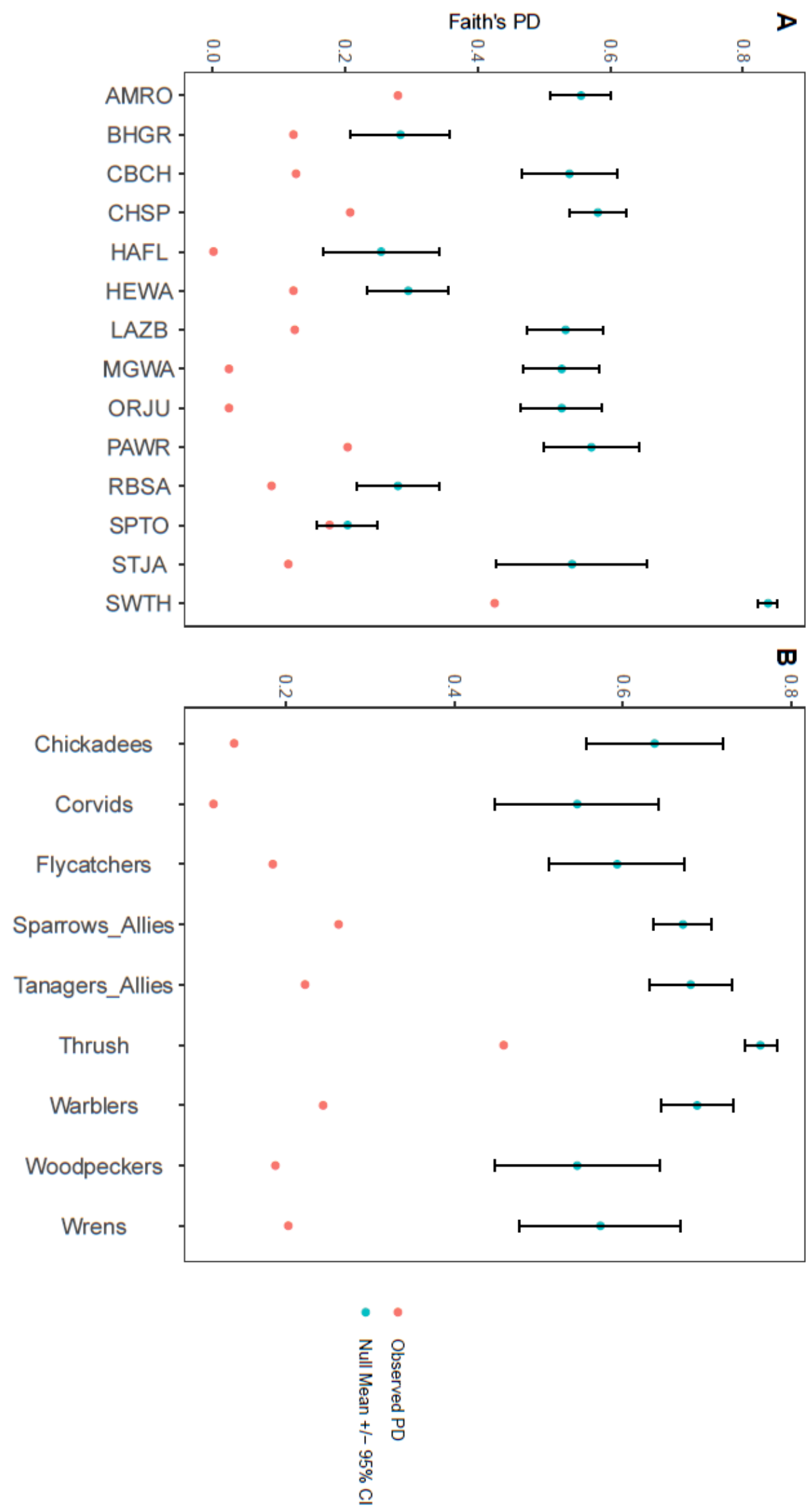




\section{References.}

1. Janzen DH. 1970 Herbivores and the Number of Tree Species in Tropical Forests. Am. Nat. 104, 501-528.

2. Connell JH. 1971 On the role of natural enemies in preventing competitive exclusion in some marine animals and in rain forest trees. In Dynamics of numbers in populations. (eds PJ Den Boer, G Gradwell), pp. 298-312. Wagenigen: PUDOC.

3. Nathan R, Muller-landau HC. 2000 Spatial patterns of seed dispersal, their determinants and consequences for recruitment. Trends Ecol. Evol. 15, 278-285. (doi:10.1016/S0169-5347(00)01874-7)

4. Muller-Landau HC, Hardesty BD. In press. Seed dispersal of woody plants in tropical forests: Concepts, examples, and future directions. In Biotic interactions in the tropics (eds D Burslem, M Pinard, S Hartley), pp. 267-309. Cambridge: Cambridge University Press.

5. Baguette M, Blanchet S, Legrand D, Stevens VM, Turlure C. 2013 Individual dispersal , landscape connectivity and ecological networks. , 310-326. (doi:10.1111/brv.12000)

6. Vellend M. 2010 Conceptual synthesis in community ecology. Q. Rev. Biol. 85, $183-206$.

7. Götzenberger L et al. 2012 Ecological assembly rules in plant communities- 
approaches, patterns and prospects. Biol. Rev. 87, 111-127. (doi:10.1111/j.1469185X.2011.00187.x)

8. Martin LM, Wilsey BJ. 2012 Assembly history alters alpha and beta diversity , exotic - native proportions and functioning of restored prairie plant communities. , 1436-1445. (doi:10.1111/j.1365-2664.2012.02202.x)

9. Goodale KM, Wilsey BJ. 2018 Priority effects are affected by precipitation variability and are stronger in exotic than native grassland species. Plant Ecol. 219, 429-439. (doi:10.1007/s11258-018-0806-6)

10. Antonio MD, Suttle KB. 2006 Ecological resistance, seed density and their interactions determine patterns of invasion in a California coastal grassland. , 160 170. (doi:10.1111/j.1461-0248.2005.00857.x)

11. Presley SJ, Higgins CL, Willig MR. 2010 A comprehensive framework for the evaluation of metacommunity structure. Oikos 119, 908-917. (doi:10.1111/j.16000706.2010.18544.x)

12. Meynard CN, Lavergne S, Boulangeat I, Garraud L, Van Es J, Mouquet N, Thuiller W. 2013 Disentangling the drivers of metacommunity structure across spatial scales. J. Biogeogr. 40, 1560-1571. (doi:10.1111/jbi.12116)

13. Chisholm C, Lindo Z, Gonzalez A. 2011 Metacommunity diversity depends on connectivity and patch arrangement in heterogeneous habitat networks. Ecography (Cop.). 34, 415-424. (doi:10.1111/j.1600-0587.2010.06588.x) 
14. Moritz C, Meynard CN, Devictor V, Guizien K, Labrune C, Guarini J-M, Mouquet N. 2013 Disentangling the role of connectivity, environmental filtering, and spatial structure on metacommunity dynamics. Oikos 122, 1401-1410.

(doi:10.1111/j.1600-0706.2013.00377.x)

15. Wang BC, Smith TB. 2002 Closing the seed dispersal loop. Trends Ecol. Evol. 17, 379-386. (doi:10.1016/S0169-5347(02)02541-7)

16. Beckman NG, Rogers HS. 2013 Consequences of seed dispersal for plant recruitment in tropical forests : Interactions within the seedscape. Biotropica $\mathbf{4 5}$, $666-681$.

17. Wenny DG. 2001 Advantages of seed dispersal: A re-evalution of directed dispersal. Evol. Ecol. Res. 3, 51-74. (doi:10.1002/(SICI)10982345(200004)50:4<275::AID-AJP4>3.0.CO;2-K)

18. Howe HF, Smallwood J. 1982 Ecology of Seed Dispersal. Annu. Rev. Ecol. Syst. 13, 201-228. (doi:10.1146/annurev.es.13.110182.001221)

19. Cavallero L, Aizen MA, Raffaele E. 2012 Endozoochory decreases environmental filtering imposed to seedlings. 23, 677-689. (doi:10.1111/j.16541103.2012.01392.x)

20. Schupp E. 1993 Quantity, Quality and the Effectiveness of Seed Dispersal by Animals. Vegetatio 107/108, 15-29.

21. Schupp EW, Jordano P, Gomez JM. 2010 Seed dispersal effectiveness revisited : a 
conceptual review. New Phytol. 188, 333-353.

22. Carlo TA, Tewksbury JJ. 2014 Directness and tempo of avian seed dispersal increases emergence of wild chiltepins in desert grasslands. J. Ecol. 102, 248-255. (doi:10.1111/1365-2745.12180)

23. Viana DS, Santamaría L, Figuerola J. 2016 Migratory Birds as Global Dispersal Vectors. Trends Ecol. Evol. 31, 763-775. (doi:10.1016/j.tree.2016.07.005)

24. Sekercioglu CH. 2006 Increasing awareness of avian ecological function. 21. (doi:10.1016/j.tree.2006.05.007)

25. Viana DS, Gangoso L, Bouten W, Figuerola J. 2016 Overseas seed dispersal by migratory birds. Proc. R. Soc. B Biol. Sci. 283, 20152406. (doi:10.1098/rspb.2015.2406)

26. Viana DS, Santamaría L, Michot TC, Figuerola J. 2013 Allometric scaling of longdistance seed dispersal by migratory birds. Am. Nat. 181, 649-62. (doi:10.1086/670025)

27. Kenrick P, Crane PR. 1997 The origin and early evolution of plants on land. Nature 389, 33-39.

28. Gensel PG. 2008 The earliest land plants. Annu. Rev. Ecol. Syst. 39, 459-477. (doi:10.1146/annurev.ecolsys.39.110707.173526)

29. Mishler BD, Kelch DG. 2009 Phylogenomics and early land plant evolution. In Bryophyte Biology (eds B Goffinet, AJ Shaw), pp. 173-197. Cambridge University 
Press.

30. Lindo Z, Gonzalez A. 2010 The Bryosphere: An integral and influential component of the Earth's biosphere. Ecosystems 13, 612-627. (doi:10.1007/s10021-010-9336-3)

31. Beringer J, Lynch AH, Stuart F, Mack M, Bonan GB. 2001 The Representation of Arctic Soils in the Land Surface Model: The Importance of Mosses. J. Clim. 14, $3324-3335$.

32. Convey P, Smith RIL. 1993 Investment in Sexual Reproduction by Antarctic Mosses. Oikos 68, 293-302.

33. Convey P, Smith RIL. 2005 Responses of terrestrial Antarctic ecosystems to climate change. In Plants and Climate Change (eds J Rozema, R Aerts, H Cornelissen), pp. 1-12. Dordrecht: Springer.

34. Gornall JL, Jónsdóttir IS, Woodin SJ, Van der Wal R. 2007 Arctic mosses govern below-ground environment and ecosystem processes. Oecologia 153, 931-941. (doi:10.1007/s00442-007-0785-0)

35. Sundberg S. 2012 Spore rain in relation to regional sources and beyond. , 1-10. (doi:10.1111/j.1600-0587.2012.07664.x)

36. Karlin EF, Andrus RE, Boles SB, Shaw a J. 2011 One haploid parent contributes $100 \%$ of the gene pool for a widespread species in northwest North America. Mol. Ecol. 20, 753-67. (doi:10.1111/j.1365-294X.2010.04982.x) 
37. Lönnell N, Hylander K, Jonsson BG, Sundberg S. 2012 The fate of the missing spores--patterns of realized dispersal beyond the closest vicinity of a sporulating moss. PLoS One 7, e41987. (doi:10.1371/journal.pone.0041987)

38. Stoneburner A, Lane DM, Anderson LE. 1992 Spore Dispersal Distances in Atrichum angustatum ( Polytrichaceae ). Bryologist 95, 324-328.

39. Wiklund K, Rydin H. 2004 Ecophysiological constraints on spore establishment in bryophytes. Funct. Ecol. 18, 907-913. (doi:10.1111/j.0269-8463.2004.00906.x)

40. Löbel S, Snäll T, Rydin H. 2009 Mating system, reproduction mode and diaspore size affect metacommunity diversity. J. Ecol. 97, 176-185. (doi:10.1111/j.13652745.2008.01459.x)

41. Kimmerer RW. 2005 Patterns of Dispersal and Establishment of Bryophytes Colonizing Natural and Experimental Treefall Mounds in Northern Hardwood Forests. Bryologist 108, 391-401. (doi:10.1639/00072745(2005)108[0391:PODAEO]2.0.CO;2)

42. Löbel S, Rydin H. 2010 Trade-offs and habitat constraints in the establishment of epiphytic bryophytes. Funct. Ecol. 24, 887-897. (doi:10.1111/j.13652435.2010.01705.x)

43. Löbel S, Snäll T, Rydin H. 2012 Epiphytic bryophytes near forest edges and on retention trees: reduced growth and reproduction especially in old-growth-forest indicator species. J. Appl. Ecol. 49, 1334-1343. (doi:10.1111/j.13652664.2012.02201.x) 
44. Löbel S, Rydin H. 2009 Dispersal and life history strategies in epiphyte metacommunities: alternative solutions to survival in patchy, dynamic landscapes. Oecologia 161, 569-79. (doi:10.1007/s00442-009-1402-1)

45. Heinken T. 2001 Epizoochorous dispersal of bryophyte stem fragments by roe deer (Capreolus capreolus) and wild boar (Sus scrofta). J. Bryol. 23, 293-300.

46. Pauliuk F, Müller J, Heinken T. 2011 Bryophyte dispersal by sheep on dry grassland. Nov. Hedwigia 92, 327-341. (doi:10.1127/0029-5035/2011/0092-0327)

47. Parsons JG, Cairns A, Johnson CN, Robson SKA, Shilton LA, Westcott DA. 2007 Bryophyte dispersal by flying foxes: a novel discovery. Oecologia 152, 112-4. (doi:10.1007/s00442-006-0639-1)

48. Barbé M, Chavel ÉE, Fenton NJ, Imbeau L, Mazerolle MJ, Drapeau P, Bergeron Y. 2016 Dispersal of bryophytes and ferns is facilitated by small mammals in the boreal forest. Écoscience 23, 67-76. (doi:10.1080/11956860.2016.1235917)

49. Boch S, Berlinger M, Fischer M, Knop E, Nentwig W, Türke M, Prati D. 2013 Fern and bryophyte endozoochory by slugs. Oecologia 172, 817-822. (doi:10.1007/s00442-012-2536-0)

50. Osorio-Zuñiga F, Fontúrbel FE, Rydin H. 2014 Evidence of mutualistic synzoochory between cryptogams and hummingbirds. Oikos 123, 553-558. (doi:10.1111/j.1600-0706.2013.01027.x)

51. Lewis LR et al. 2014 First evidence of bryophyte diaspores in the plumage of 
transequatorial migrant birds. PeerJ 2, e424. (doi:10.7717/peerj.424)

52. Lewis LR, Rozzi R, Goffinet B. 2014 Direct long-distance dispersal shapes a New World amphitropical disjunction in the dispersal-limited dung moss Tetraplodon (Bryopsida: Splachnaceae). J. Biogeogr. 41, 2385-2395. (doi:10.1111/jbi.12385)

53. Chmielewski MW, Eppley SM. 2019 Forest passerines as a novel dispersal vector of viable bryophyte propagules. Proc. R. Soc. B Biol. Sci. 286. (doi:10.1098/rspb.2018.2253)

54. McDaniel SF. 2015 BCD-a Media. McDaniel Lab Protoc. Data. See http://sites.clas.ufl.edu/mcdaniellab/files/BCD-media-recipie.pdf (accessed on 9 September 2015).

55. Taberlet P, Gielly L, Pautou G, Bouvet J, Biologie L De, Fourier UJ. 1991 Universal primers for amplification of three non-coding regions of chloroplast DNA. , 1105-1109.

56. Utilization S, Garden B, Sciences E. 2010 Evaluation of 10 plant barcodes in Bryophyta ( Mosses ). 48, 36-46. (doi:10.1111/j.1759-6831.2009.00063.x)

57. Lang AS, Michael JDK. 2014 DNA barcoding of Arctic bryophytes : an example from the moss genus Dicranum ( Dicranaceae, Bryophyta ). , 1157-1169. (doi:10.1007/s00300-014-1509-7)

58. Vijayan K, Tsou CH. 2014 DNA barcoding in plants : taxonomy in a new perspective. 
59. Stech M, Quandt D. 2010 20,000 species and five key markers: The status of molecular bryophyte phylogenetics. Phytotaxa 9, 196-228.

60. R Core Team. 2017 R: A language and environment for statistical computing. R Foundation for Statistical Computing Vienna, Austria.

61. Paradis E, Schliep K. 2018 ape 5.0: an environment for modern phylogenetics and evolutionary analyses in $\{\mathrm{R}\}$. Bioinformatics $\mathbf{x x}, \mathrm{xxx}-\mathrm{xxx}$.

62. Schliep, Klaus, Potts, J. A, Morrison, A. D, Grimm, W. G. 2017 Intertwining phylogenetic trees and networks. Methods Ecol. Evol. 8, 1212-1220. (doi:10.1111/2041-210X.12760)

63. Donatti CI, Guimarães PR, Galetti M, Pizo MA, Marquitti FMD, Dirzo R. 2011 Analysis of a hyper-diverse seed dispersal network: Modularity and underlying mechanisms. Ecol. Lett. 14, 773-781. (doi:10.1111/j.1461-0248.2011.01639.x)

64. Mello MAR, Marquitti FMD, Guimarães PR, Kalko EKV, Jordano P, de Aguiar MAM. 2011 The missing part of seed dispersal networks: Structure and robustness of bat-fruit interactions. PLoS One 6, 1-10. (doi:10.1371/journal.pone.0017395)

65. Dormann CF, Frund J, Bluthgen N, Gruber B. 2009 Indices, Graphs and Null Models: Analyzing Bipartite Ecological Networks. Open Ecol. J. 2, 7-24. (doi:10.2174/1874213000902010007)

66. Blüthgen N, Menzel F, Blüthgen N. 2006 Measuring specialization in species interaction networks. BMC Ecol. 6. (doi:10.1186/1472-6785-6-9) 
67. Dormann CF. 2011 How to be a specialist ? Quantifying specialisation in pollination networks. Netw. Biol. 1, 1-20. (doi:10.0000/issn-2220-8879networkbiology-2011-v1-0001)

68. Faith DP. 1992 Conservation evaluation and phylogenetic diversity., 1-10.

69. Wickham H. 2009 ggplot2: Elegant Graphics for Data Analysis. Springer-Verlag New York. See http://ggplot2.org.

70. Dormann CF, Gruber B, Fründ J. 2008 Introducing the bipartite Package: Analysing Ecological Networks. R News 8, 8-11. (doi:10.1159/000265935)

71. Kembel SW, Cowan PD, Helmus MR, Cornwell WK, Morlon H, Ackerly DD, Blomberg SP, Webb CO. 2010 Picante : R tools for integrating phylogenies and ecology. 26, 1463-1464. (doi:10.1093/bioinformatics/btq166)

72. Shaw AJ, Gaughan JF. 1993 Control of Sex Ratios in Haploid Populations of the Moss , Ceratodon purpureus. Am. J. Bot. 80, 584-591.

73. Missouri Botanical Garden, Harvard University Herbaria. 2019 Efloras. FNA Vol 27, Dicranum. , 418. See www.efloras.org.

74. Tiffney BH. 2004 Vertebrate dispersal of seed plants through time. Annu. Rev. Ecol. Evol. Syst. 35, 1-29. (doi:10.1146/annurev.ecolsys.34.011802.132535)

75. Turetsky MR. 2003 The role of bryophytes in carbon and nitrogen cycling. Bryologist 106, 395-409.

76. Sillett TS. 1994 Foraging ecology of epiphyte-searching insectivorous birds in 
Costa Rica. Condor 96, 863-877. 


\title{
Chapter 4
}

\section{Metacommunity structure of epiphytic bryophytes in fog-maintained patches of relict Valdivian forest of north-central Chile}

\begin{abstract}
Metacommunity ecology strives to examine how interactions among local communities influence the patterns of diversity that we see within each community as well as at landscape scales. Determining the effects of metacommunity processes across different spatial scales in real communities has generally proven difficult. The scale and assigned connectivity among patches can lead to assumptions about a system that undermine our understanding of community processes. Most community landscapes are not ideally discrete, making designation of the appropriate boundaries of a given study difficult, and questions about the appropriate scale of study often remain. We examined the metacommunity structure of epiphytic bryophyte communities in Parque Nacional Bosque Fray Jorge in north-central Chile. Our field site is characterized by fog-sustained relict patches of olivillo (Aextoxicon punctatum) surrounded by an arid scrub matrix. These patches harbor communities of epiphytic bryophytes that are not found in the surrounding matrix, and are thus found at tree-landscape scales. We sampled individual trees in distinct patches across the park for bryophyte cover at tow heights, the base (low) and at breast height (high). We applied the elements of metacommunity (EMS) structure framework at various spatial scales to determine how the delineation of scale impacts inferred structure. Across the landscape, the overall metacommunity exhibited a Gleasonian structure (characterized by a diffuse structure), but both low and high samples conformed to a Clementsian (low) or quasi-Clementsian (high) structure (characterized


by a defined structure). Individual forest patch structures varied widely from patch to patch. This was not directly explained by similar patterns in diversity. Matching both scale and sampling locality to an appropriately informed natural history context is therefore necessary when designing studies aimed at elucidating metacommunity dynamics.

\section{Introduction}

Metacommunities are characterized by local communities that are variously connected by dispersal [1]. Local dynamics influence the species composition within particular communities, forming local species pools that then interact via dispersal at larger, metacommunity scales. A variety of dynamics have been identified that work at the metacommunity level to alter the species on a landscape, with species sorting, mass effects, patch dynamics, and neutrality driving structured species distribution patterns $[2,3]$. These mechanisms, in turn, produce a number of distribution structures that ecologists have spent much effort in distinguishing from stochasticity. The initial modern framework for defining the structure of ecological communities began with Clements, who argued that structure was generated by cohesive groups of species that replaced each other over space, due to tight evolutionary and ecological histories in which species are entangled in deeply codependent relationships, rather than communities being completely random [4]. Following this work, Gleason argued that while structured communities were the norm, they were generated by more diffuse community boundaries that are defined by distributions that are species specific, rather than being an attribute of cohesive assemblages, and are ultimately products of similar environmental tolerances among 
suites of species [5]. Additional structures have been suggested that arise from situations in which intense interspecific competition creates evenly spaced distributions with respect to an environmental gradient [6], or when competition may result in exclusionary checkerboard patterns of species distributions [7].

Together, these ideas have been synthesized into a formal theoretical framework in which a suite of idealized metacommunity structures have been identified, with three attributes of species distributions delineating the boundaries between these structures [1]. Leibold and Mikkelson defined these attributes of a metacommunity as coherence (the number of embedded absences in an ordinated matrix of species distributions), turnover (the number of species replacements across the metacommunity), and boundary clumping (the extent to which the edge of species ranges co-occur). By examining these attributes (termed Elements of Metacommunity Structure, hereafter EMS), it is possible to disentangle six competing hypotheses of how metacommunity species distributions are structured (random, evenly spaced, Clementsian, Gleasonian, checkerboard, and nested distributions). Further work expanded this framework to include quasi-structures that more fully explore the range of possible species distributions within a metacommunity [8].

Since its inception, application of the EMS framework to field data has been largely focused on animals, ranging from small mammal [9-11], freshwater fish and invertebrate [12-14], and amphibian [15] metacommunities . Plant-focused applications of the EMS have been limited to grasslands, English woodland patches and landscapescale forest models [16-19]. Bryophytes have been used to examine how metacommunity 
spatial processes impact resident microarthropods,[20-22] but bryophytes themselves have not been the focus of any application of the EMS framework. A single study focused on Finnish drainage basin metacommunities included bryophytes, growing in riffle zones along streams [23]. Despite this, bryophyte communities themselves could provide a much-overlooked potential contribution to studies in metacommunity dynamics. While historically considered ubiquitous in their dispersal, many bryophytes have now been shown to be dispersal limited [24-26]. This, combined with communities that are often easily defined by their fidelity to a particular substrate, makes them ideal communities in which to ask questions about how structure of communities alters across a metacommunity landscape. Furthermore, studies that place bryophyte metacommunity structures within spatial and environmental contexts may further our understanding of the drivers that dictate realized bryophyte community assemblages.

There is evidence that the spatial scale at which metacommunity studies are conducted may play a role in determining observed structures as well as their environmental drivers $[16,27,28]$. Notably, Willig and Presley found that taxa respond differently in both metacommunity structure and underlying metrics of diversity to changes in elevation [29]. The extent to which this occurs in terrestrial plant communities remains an open question, as most studies have focused on other systems, or have not taken multiple spatial scales into account [30].

To determine the metacommunity structure of epiphytic bryophytes in naturally patchy landscape, we surveyed epiphytic bryophyte communities in Parque Nacional Bosque Fray Jorge, Chile. We asked whether patch-level metacommunity structure 
differed across the park, and whether this reflected park-wide metacommunity structure. In addition, we asked whether two different height compartments differed in their structure. We determined species diversity for our sites and determined whether metacommunity pattern and diversity at the patch level were driven by the east-west fog deposition gradient that maintains these forest patches. We predicted that the park-wide metacommunity structure would be Gleasonian in nature, and that this would be reflected in the epiphyte community sampled at two different heights (tree base and at breast height). In addition, we predicted that diversity would decrease from west to east and that patch-level metacommunity structures would exhibit similar patterns across longitude.

\section{Methods:}

\section{a) Site Characteristics}

We sampled bryophytes in Parque Nacional Bosque Fray Jorge in north-central Chile. Our field site is characterized by distinct patches of olivillo (Aextoxicon punctatum, Aexotoxicacae) surrounded by an arid scrub matrix. Olivillo is a large evergreen Angiosperm tree that is native to Chile and Argentina, and is the sole species within the genus. The tree is a characteristic component of Valdivian temperate rainforest, which once formed a continuous landcover in the region [31]. As climate changed through the Quaternary and the area received less precipitation, the only patches of the forest that remained were those on top of a range of mountain peaks, which are maintained by coastal fog deposition along a strong east-west gradient [32]. These patches, dominated by olivillo, harbor communities of epiphytic bryophytes not found in the surrounding 
habitat matrix. Thus, epiphytes exist at a microsite (individual tree), patch, and regional (array of patches) scale due to natural processes.

\section{b) Field Sampling}

We ran a $100 \mathrm{~m}$ transect through 20 distinct patches (Figure D1) of forest across the park in which we chose to sample bryophytes. Individual olivillo trees at every $10 \mathrm{~m}$ interval were selected for sampling. We determined the percent cover of each bryophyte species visually, using a 0.25 x 0.25 m quadrat subdivided into 16 sections. We measured epiphytic bryophyte cover at both the base of each tree as well as at breast height $(1.3 \mathrm{~m}$ above ground level) by estimating the cover of each species within each quadrat subdivision, which we used to calculate an average species coverage for each quadrat. In total, we measured percent cover in 400 quadrats (20 per patch). For each tree, we also recorded latitude, longitude, diameter at breast height $(\mathrm{DBH})$, and took a digital photograph of the canopy to determine percent cover, and recorded aspect of each patch. We collected confirmation vouchers of each species of bryophyte from each quadrat for all trees. Species identities were determined with the assistance of Chilean bryologist Juan Larraín.

\section{c) Data Analysis}

We assessed the primary elements of metacommunity (EMS) structure [1] to determine community patterns at the patch and landscape scale, as well as two different height compartments using the metacom [33] package for R. This approach computationally arranges the species occurrence matrix via iterative reciprocal averaging until the 
eigenvectors of species and sample scores remain stable. This allows for idealized ordination of matrix species values independent of environmental or spatial gradient. We used the EMS approach to examine the coherence of matrix species ranges by quantifying the embedded absences within the matrix that are indicative of disjunct species arrangements (Figure D2). We then determined nestedness (the likelihood of species occurrences being nested within subsets of other species occurrences) and boundary clumping (the tendency for species compositional shifts within the matrix to change together) to determine metacommunity patterns across and within our sampling sites.

We measured canopy cover by manually setting photograph thresholds to parse canopy from sky in each image prior to converting images to binary data using the ImageJ software platform [34]. We then calculated percent cover by determining the proportion of black pixels present in the overall image. In addition, we calculated Shannon's Diversity Index (hereafter diversity) for each quadrat using the vegan package for R [35]. We built a series of linear models to determine the relationship between diversity and environmental variables (aspect, DBH, height, latitude, longitude), metacommunity structures and environmental variables, and diversity and metacommunity structure.

\section{Results:}

Community composition of the bryoflora of our sites included an array of liverworts and mosses from numerous families. We found 9 species of liverworts and 6 species of mosses (Table D3). Chiloscyphus aequifolius, Rigodium toxarion, and Radula 
decora were particularly abundant in lower level quadrats, while Metzgeria $c f$. decrescens was dominant in our higher quadrats.

Across the park, we found that the metacommunity structure varied from patch to patch, representing six different idealized structures within the EMS framework (Table 4.1, Figure 4.1). A Clementisan or quasi-Clementsian structure was the most frequently detected structure in our study site (9/20 patches), while a Gleasonian structure was exhibited by 6 of our patches. The remaining patches exhibited either random and quasirandom species loss (2/20), or quasi-clumped loss (3/20). When considering each patch as contributing to a park-wide metacommunity, we found that bryophytes within the park exhibited a Gleasonian metacommunity structure. When split by sampling height, both low and high samples conformed to a Clementsian (low) or quasi-Clementsian (high) structure.

Both canopy cover $(\mathrm{F}=5.84, \mathrm{p}<0.01)$ and $\mathrm{DBH}(\mathrm{F}=3.37, \mathrm{p}<0.01)$ differed significantly among metacommunity structures (Figures $4.2 \& 4.3$ ). Diversity varied among patches across the park $(\mathrm{F}=1.68, \mathrm{p}=0.04$, Figures $4.4 \& 4.5)$, but was not significantly correlated with metacommunity structure $(\mathrm{F}=1.64, \mathrm{p}=0.15$, Figure 4.6). Furthermore, diversity was not driven by a park-wide spatial gradient (longitude $(\mathrm{F}=$ $0.83, \mathrm{p}=0.40)$, latitude $(\mathrm{F}=3.79, \mathrm{p}=0.052)$, Figures $\mathrm{D} 4-\mathrm{D} 7)$, or sampling height $(\mathrm{F}$ $=2.27, \mathrm{p}=0.13$, Figure D8).

Canopy cover and DBH were significantly, though weakly positively correlated $\left(\mathrm{F}=12.65, \mathrm{p}<0.01, \mathrm{R}^{2}=0.03\right)$ and both varied by patch $(\mathrm{F}=4.83, \mathrm{p}<0.01 ; \mathrm{F}=2.24$, $\mathrm{p}<0.01$, respectively) . Canopy cover was not significantly associated with diversity $(\mathrm{F}=$ $0.14, \mathrm{p}=0.70$, though DBH was $(\mathrm{F}=8.37, \mathrm{p}<0.01)$. 


\section{Discussion}

The diversity of metacommunity structures that we found at different spatial scales across the park suggests that metacommunity structure in epiphytic bryophytes is variable, and the assessment of structure is sensitive to how the breadth of a metacommunity is delineated. The Gleasonian structure exhibited by the overall metacommunity of epiphytic bryophytes across the park indicates that individual bryophyte species respond to a park wide spatial gradient in an individualistic manner, rather than being structured either stochastically or turning over as cohesive association assemblages. In contrast, when the communities were compartmentalized by height on the tree, the true and quasi-Clementsian structures reflect cohesive clumping of species suites throughout the park. Taken together, this suggests that the high and low Clementsian compartments turn over asynchronously to create the park-wide Gleasonian pattern. Studies that fail to accommodate spatially distinct habitat compartments that may act differently from one another, or than broader-grained definitions of the metacommunity, may therefore fail to identify underlying structures across varying scales. Researchers aiming to identify dispersal, connectivity, and environmental gradient drivers of metacommunity structure should consider how these factors interact with the scale that they are working at to better understand turnover in species assemblages.

The metacommunity studies that have made considerations for spatial scale are often confounded by relying on large scale datasets that have been collected over many years without considering temporal shifts in metacommunity dynamics [16,17,19,23,36], or have been conducted in artificial microcosms [37] (though see [38]). This is despite 
the fact that it has been demonstrated that temporal shifts in metacommunity patterns are possible over annual and seasonal scales $[10,39,40]$. We suggest therefore, that researchers aiming to identify dispersal, connectivity, and environmental gradient drivers of metacommunity structure should consider not only how these factors interact with the scale that they are working, but should also consider disentangling potential shifts in metacommunity structure over time from consideration in spatial scale.

Canopy cover and DBH were unsurprisingly related, and varied by patch. Despite this, Shannon diversity varied by patch and DBH, but was not sensitive to canopy cover. The existence of an environmental gradient from west (toward the coast, and coastallygenerated fog influx) to east did not appear to impact diversity, as position in the park relative to this axis (longitude) did not predict diversity. Diversity did not differ significantly along a N-S axis either. Thus, Shannon diversity as driven by our measured environmental variables is not, in itself, driving the turnover that determines metacommunity structure. As DBH may be a reasonable measure of tree age, it is possible that the spatial dynamics that drive the observed metacommunity structures may be time dependent, reflecting either hurdles to dispersal and establishment, or a successional trajectory.

The variety in presence and abundance of different species throughout the park suggests that some species may be more influential in driving overall metacommunity structure than other species. Species such as Radula decora, Chiloscyphus aequifolius, and Metzgeria cf. decrescens which were found in most sites appear to be fairly robust to differences in patches. Meanwhile, the Brachythecium sp. and Weymouthia mollis only occurred in a small subset of park plots. Generally, it appears that moss distributions in 
the park are more restricted than those of liverworts. This may be due either to current spatial dynamics, environmental factors, or be a product of historic range. Thus, mosses are most likely to be susceptible to changes or loss of particular patches within the park, despite evidence that liverworts tend to be more sensitive to forest fragmentation and water availability [41-43].

The forest patches of Parque Nacional Bosque Fray Jorge are regionally unique, and provide a refuge habitat for many species that otherwise would not be able to survive in the surrounding matrix. While the park experiences interannual fluctuations in fog deposition [44], the persistence of these patches of forest has been suggested to be fairly robust based on tree ring data [32]. Despite this, there is some concern regarding changing land use regionally, including the proximity of relatively new wind turbine farms between the park and the coast [45], may impact the longevity of these patches. Interestingly, there is some evidence that epiphytic bryophytes may contribute significantly to water accumulation in fog-deposition associated forest systems[46]. The abundance of bryophytes in this system, therefore, may impact overall water availability within the plots, and is a promising area of future research. Little is known about the bryophyte component of these communities, and further work aimed at understanding the underlying drivers of metacommunity patterns of these bryophytes is necessary. Disentangling the spatial and environmental drivers of bryophyte metacommunities within the park will be necessary to determine the trajectory of these populations. It has also been demonstrated that temporal shifts in metacommunity patterns are possible over annual and seasonal scales $[10,39,40]$, and we suggest further surveys over time may assist in understanding the dynamics at work in the park. 


\section{Permitting}

Field work was conducted with permitting and oversight from the Corporación Nacional Forestal, Chile.

\section{Data accessibility}

Data will made available in the Dryad Digital Repository upon manuscript acceptance.

The code and data to reproduce the analysis are freely available at https://github.com/mwchmiel/pnfjbryos.

\section{Competing Interests}

The authors have no competing interests to declare.

\section{Authors' Contributions.}

MWC designed the study with input from SME. MWC carried out the study and analyzed the data. MWC and SME wrote the manuscript.

\section{Acknowledgements}

We would like to thank the staff at Parque Nacional Bosque Fray Jorge, especially Victor Emilio Cook Mena.

\section{Funding.}

This work was possible with funding support from the Fulbright U.S. Student program. 
Table 4.1: Metacommunity structures associated with epiphytic bryophytes of Parque Nacional Bosque Fray Jorge in North-central Chile. Structures were determined for the overall park, for bryophytes found at two different strata, and for each individual patch of sampled forest within the park (A-T). Positive (+) and negative (-) Coherence, Turnover, and Boundary Clumping were significant at $\mathrm{p}<0.05$ or lower (see supplemental material). Nonsignificant (NS) findings in Turnover suggested quasi-structures that are further informed by patterns in Boundary Clumping. See text for definition of structures.

\begin{tabular}{|c|c|c|c|c|}
\hline Site & Coherence & Turnover & Boundary & Structure \\
\hline overall & + & + & NS & Gleasonian \\
\hline high & + & $\mathrm{NS}(+)$ & + & quasi-Clementsian \\
\hline low & + & + & + & Clementsian \\
\hline A & + & + & NS & Gleasonian \\
\hline B & + & $\mathrm{NS}(+)$ & + & quasi-Clementsian \\
\hline $\mathrm{C}$ & + & + & NS & Gleasonian \\
\hline $\mathrm{D}$ & + & + & NS & Gleasonian \\
\hline $\mathrm{E}$ & + & + & + & Clementsian \\
\hline $\mathrm{F}$ & + & $\mathrm{NS}(-)$ & NS & $\begin{array}{l}\text { quasi -Random Species } \\
\text { Loss }\end{array}$ \\
\hline G & + & + & NS & Gleasonian \\
\hline $\mathrm{H}$ & + & $\mathrm{NS}(+)$ & + & quasi-Clementsian \\
\hline $\mathrm{I}$ & + & NS(-) & + & $\begin{array}{l}\text { quasi -clumped species } \\
\text { loss }\end{array}$ \\
\hline $\mathrm{J}$ & + & $\mathrm{NS}(+)$ & NS & quasi-Clementsian \\
\hline $\mathrm{K}$ & + & + & + & Clementsian \\
\hline $\mathrm{L}$ & + & - & NS & Random Species Loss \\
\hline $\mathrm{M}$ & + & + & NS & Gleasonian \\
\hline
\end{tabular}




\begin{tabular}{|l|l|l|l|l|}
\hline $\mathrm{N}$ & + & $\mathrm{NS}(+)$ & $\mathrm{NS}$ & quasi-Clementsian \\
\hline $\mathrm{O}$ & + & $\mathrm{NS}(-)$ & $\mathrm{NS}$ & $\begin{array}{l}\text { quasi -clumped species } \\
\text { loss }\end{array}$ \\
\hline $\mathrm{P}$ & + & + & + & Clementsian \\
\hline $\mathrm{Q}$ & + & + & $\mathrm{NS}$ & Gleasonian \\
\hline $\mathrm{R}$ & + & $\mathrm{NS}(-)$ & + & $\begin{array}{l}\text { quasi -clumped species } \\
\text { loss }\end{array}$ \\
\hline $\mathrm{S}$ & + & $\mathrm{NS}(+)$ & + & quasi-Clementsian \\
\hline $\mathrm{T}$ & + & $\mathrm{NS}(+)$ & $\mathrm{NS}$ & quasi-Clementsian \\
\hline
\end{tabular}


Figure 4.1: Metacommunity structures varied from patch to patch across Parque Nacional Bosque Fray Jorge.

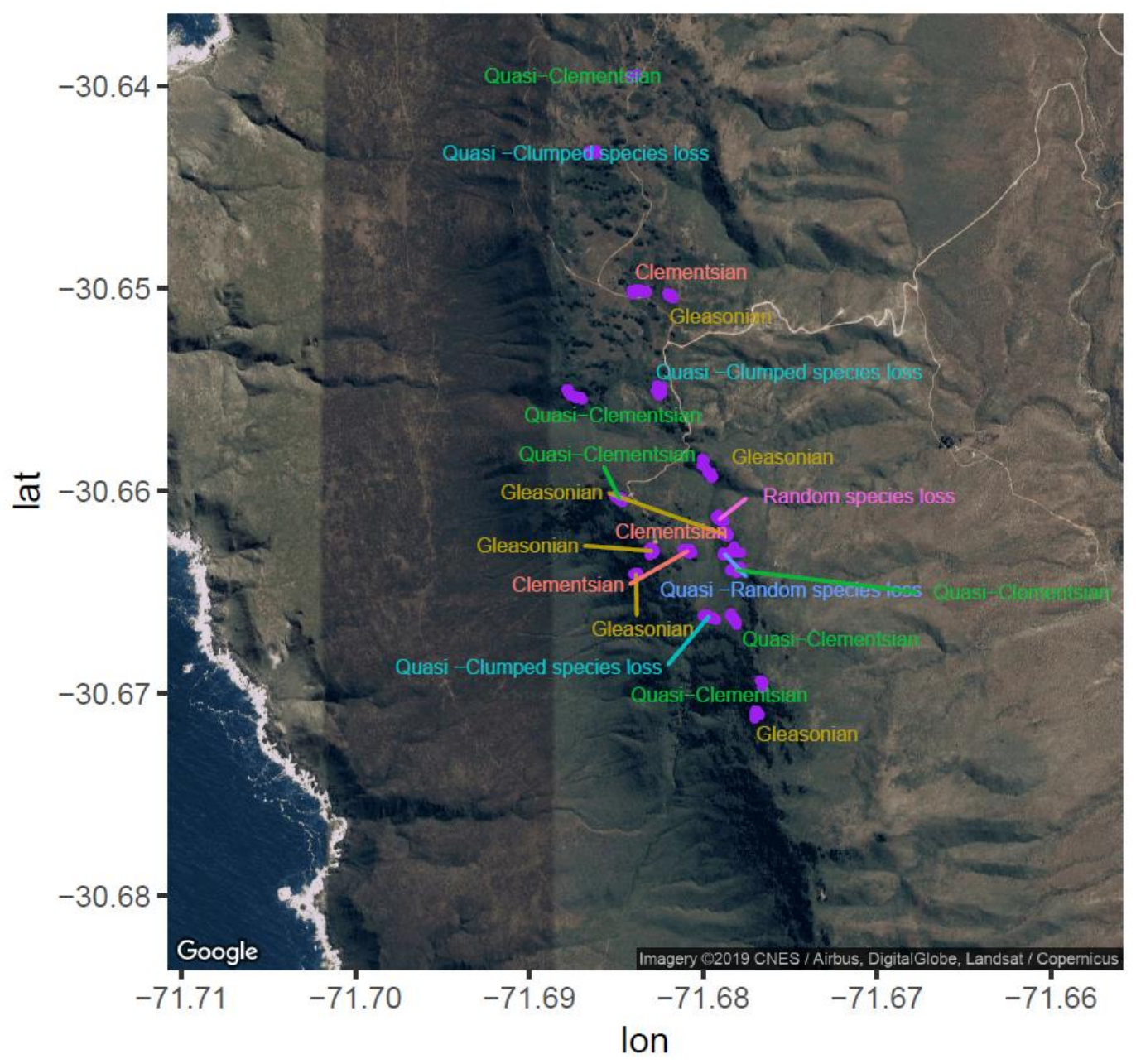

\section{pattern}

a Clementsian

a Gleasonian

a Quasi-Clementsian

a Quasi-Clumped species loss

a Quasi -Random species loss

a Random species loss 
Figure 4.2: Canopy cover differed by metacommunity structure $(F=5.84, p<0.01)$. Quasi-random loss was lower than both Clementsian $(\mathrm{p}<0.01)$ and Gleasonian $(\mathrm{p}<$ $0.01)$ structures. Quasi -clumped loss was also associated with lower canopy cover than Gleasonian structures $(\mathrm{p}=0.03)$.

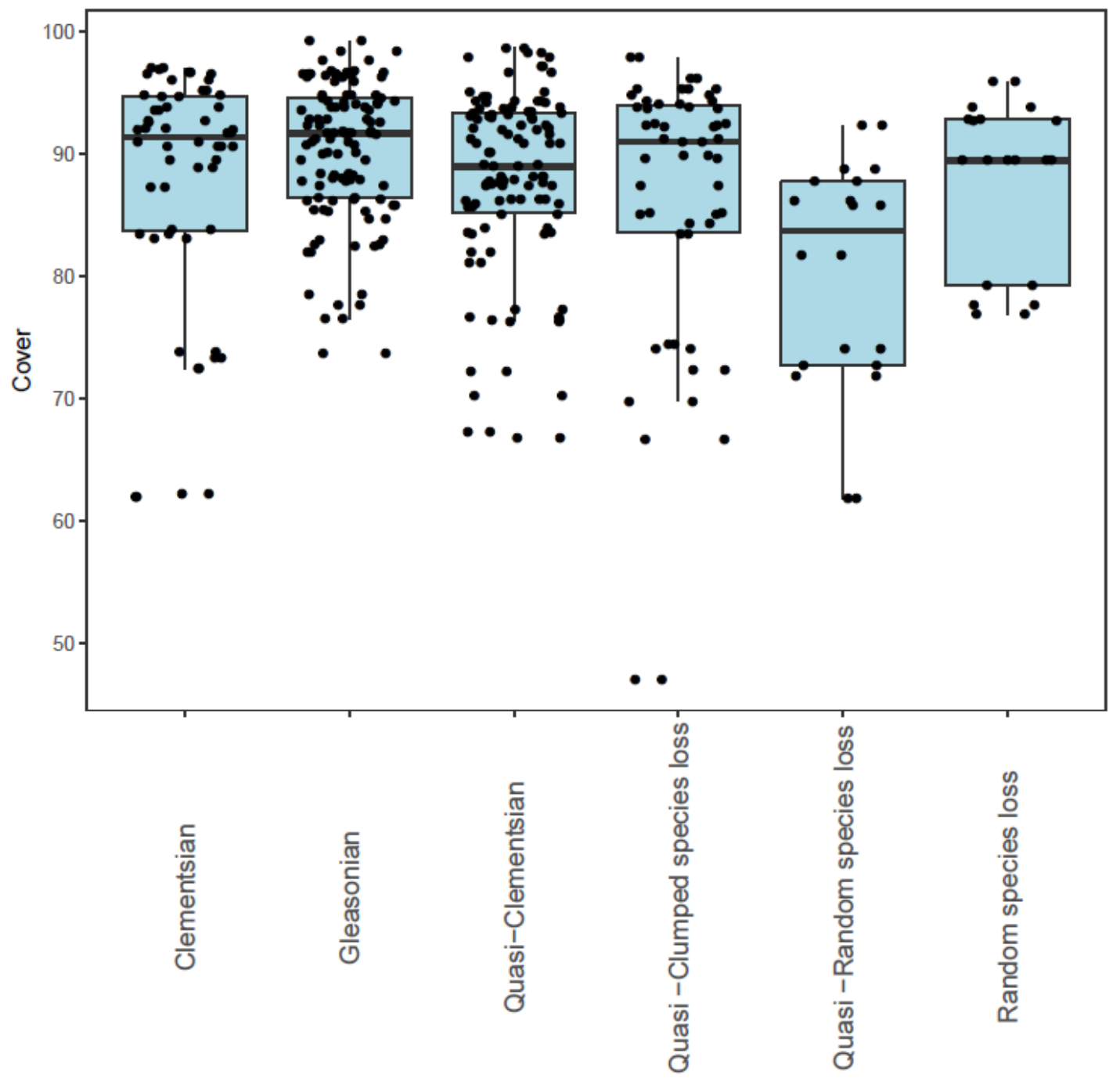


Figure 4.3: Diameter at breast height $(\mathrm{DBH})$ differed by metacommunity structure $(\mathrm{F}=$ 3.37, $\mathrm{p}<0.01)$. Quasi-random species loss was associated with significant lower DBH than Gleasonian structures $(\mathrm{p}=0.02)$.

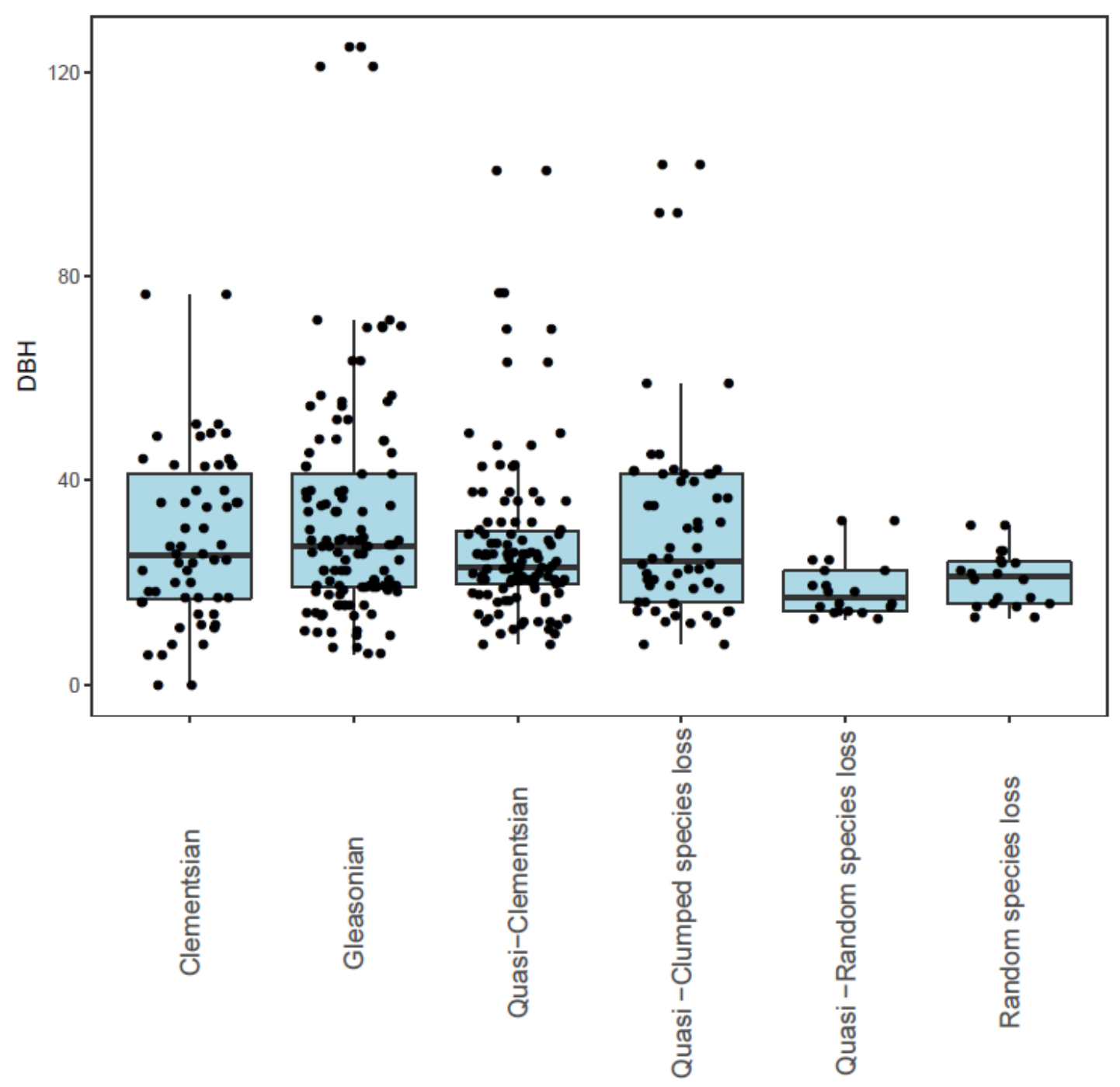


Figure 4.4: Shannon's Diversity Index of bryophyte communities on tree trunks (high compartment) throughout the park. Diversity varied significantly from patch to patch $(\mathrm{F}=$ $1.68, \mathrm{p}=0.04)$

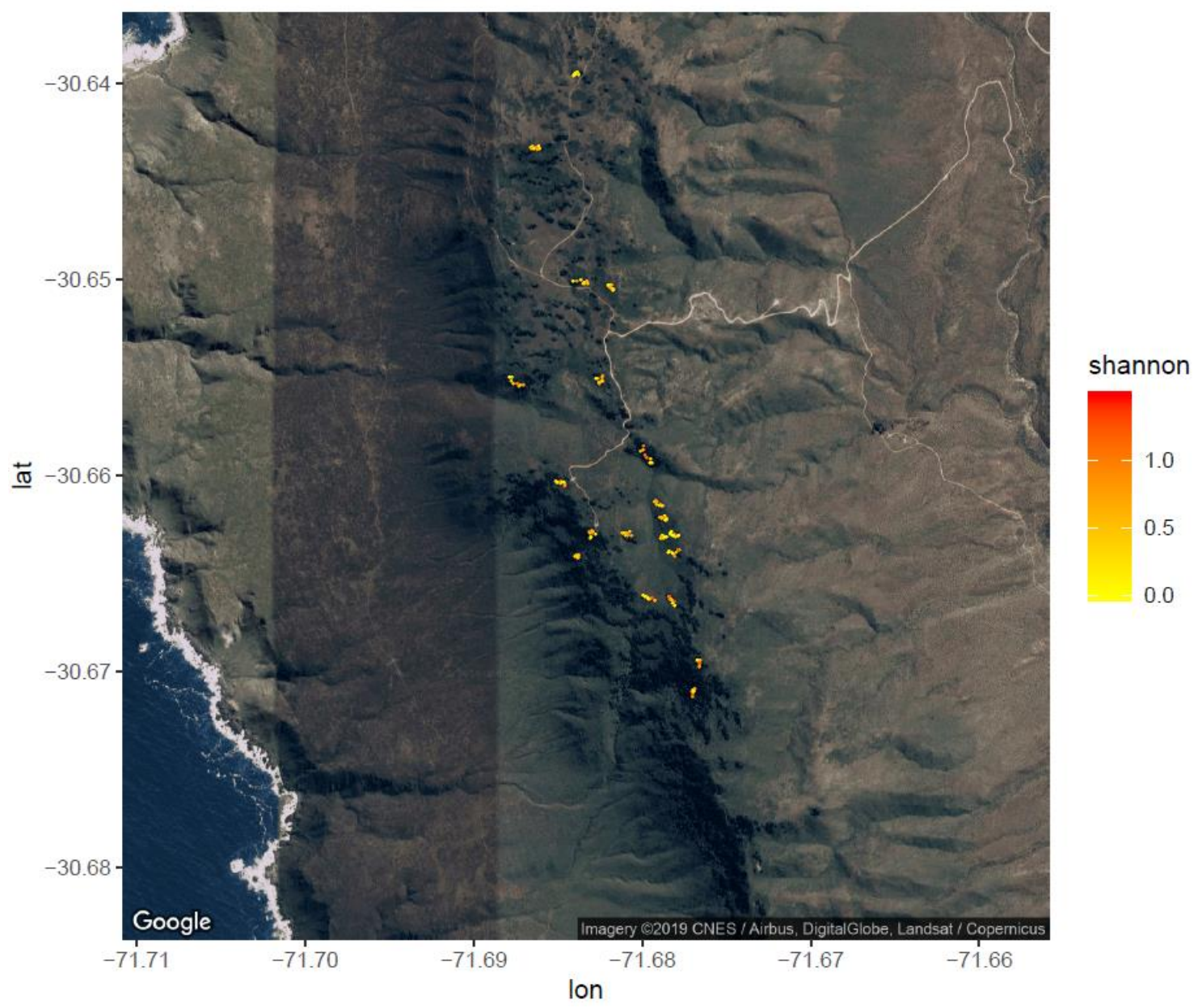


Figure 4.5: Shannon's Diversity Index of bryophyte communities on tree trunks (low compartment) throughout the park. Diversity varied significantly from patch to patch $(\mathrm{F}=$ $1.68, \mathrm{p}=0.04)$

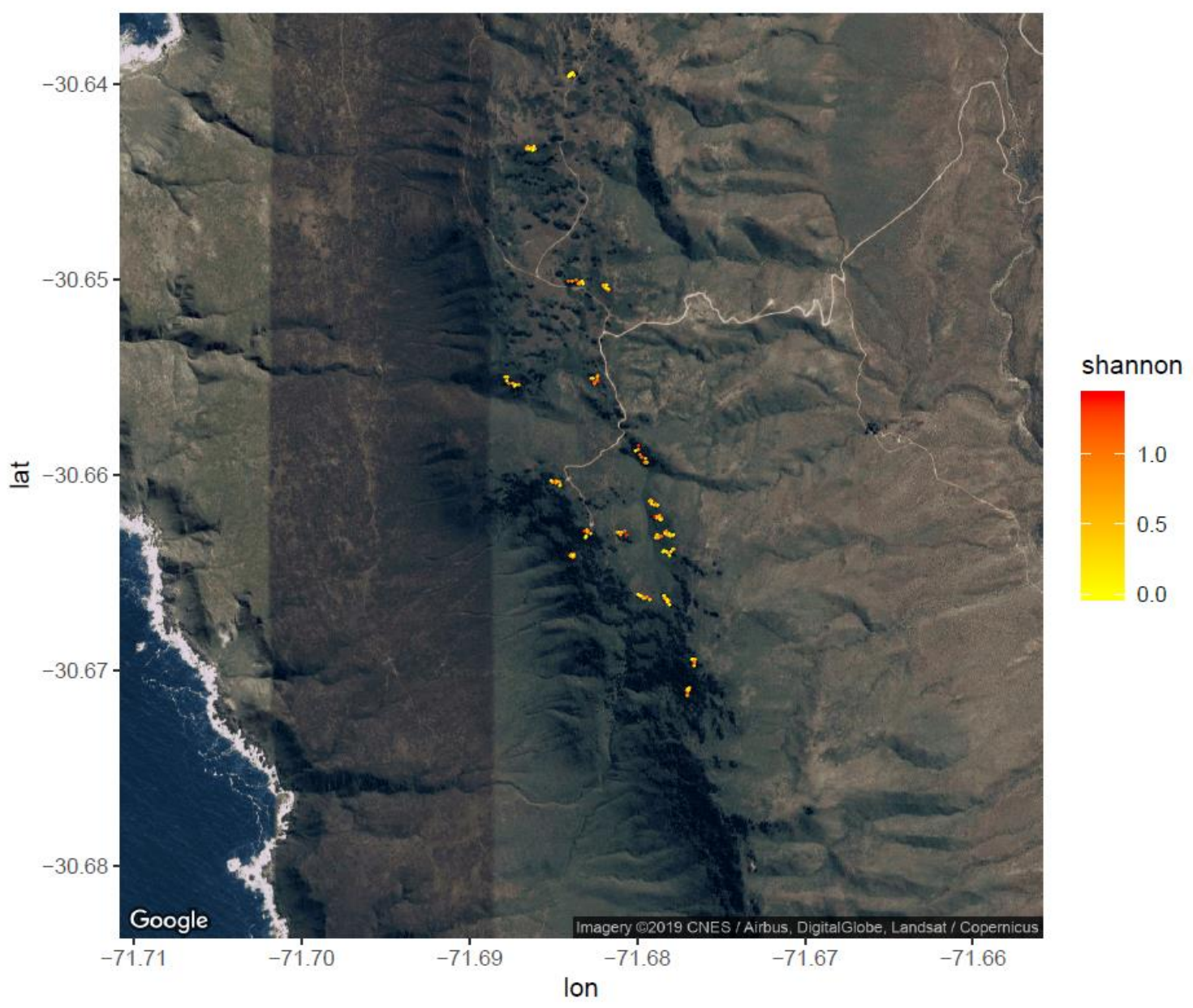


Figure 4.6: Shannon's Diversity Index of bryophyte communities by associated metacommunity structure. Diversity did not significantly differ among metacommunity structures $(\mathrm{F}=1.64, \mathrm{p}=0.15)$.

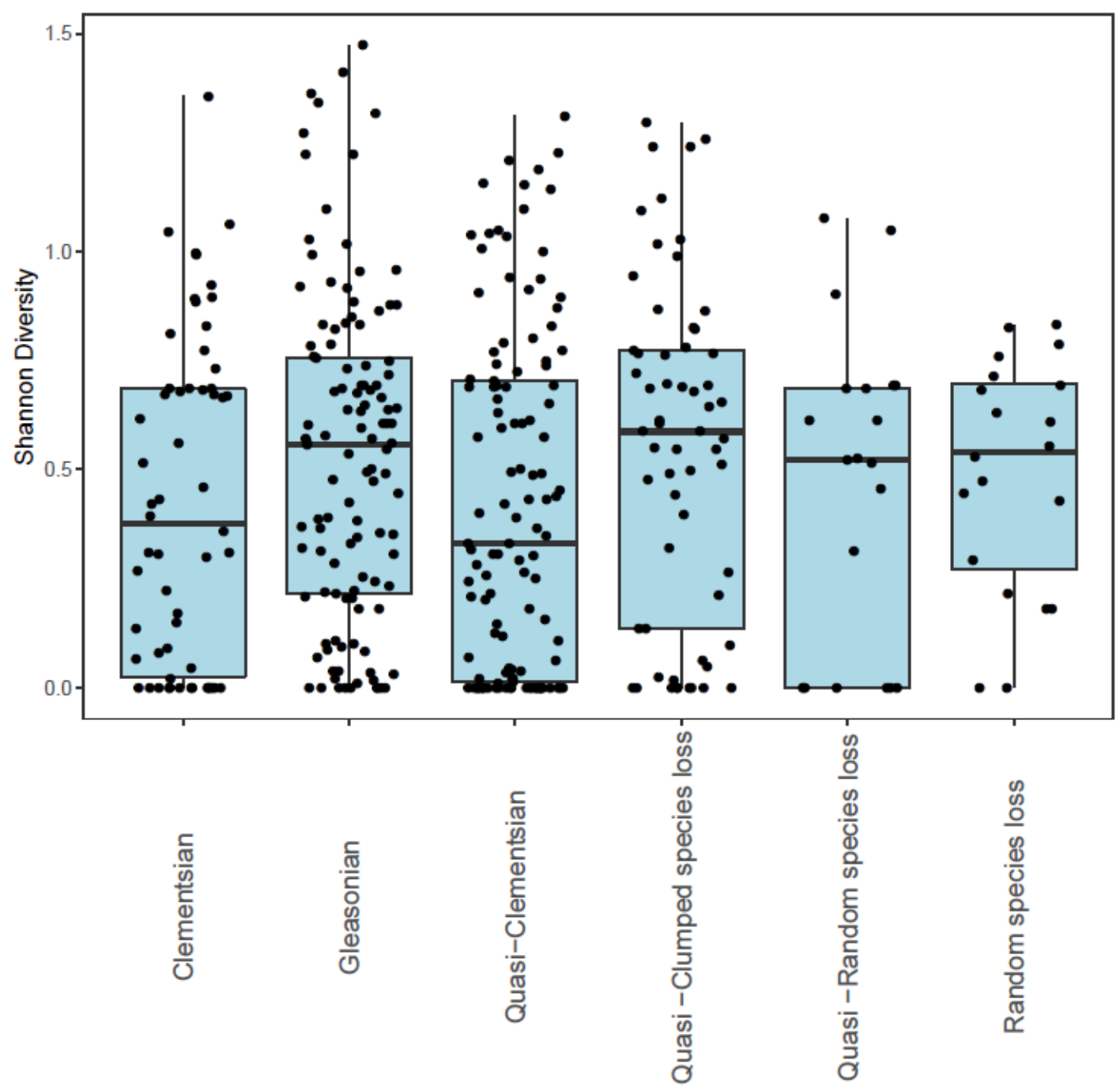




\section{References.}

1. Leibold MA, Mikkelson GM. 2002 Coherence, species turnover, and boundary clumping : elements of meta-community structure. 2, 237-250.

2. Leibold MA et al. 2004 The metacommunity concept: A framework for multiscale community ecology. Ecol. Lett. 7, 601-613. (doi:10.1111/j.14610248.2004.00608.x)

3. Holyoak M, Leibold MA, Holt RD. 2005 Metacommunities: spatial dynamics and ecological communities. Chicago, IL: University of Chicago Press.

4. Clements Frederic E. 1916 Plant succession. An analysis of the development of vegetation. Carnegie Inst. Washingt.

5. Gleason HA. 1939 The individualistic concept of the plant association. Am. Midl. Nat. 21, 92-110.

6. Tilman D. 1982 Resource competition and community structure. Princeton university press.

7. Diamond J, Pimm SL, Gilpin ME, Lecroy M, The S, Naturalist A, Nov N. 2015 The University of Chicago Rapid Evolution of Character Displacement in Myzomelid Honeyeaters. 134, 675-708.

8. Presley SJ, Higgins CL, Willig MR. 2010 A comprehensive framework for the evaluation of metacommunity structure. Oikos 119, 908-917. (doi:10.1111/j.16000706.2010.18544.x)

9. Presley SJ, Willig MR. 2010 Bat metacommunity structure on Caribbean islands and the role of endemics. Glob. Ecol. Biogeogr. 19, 185-199. (doi:10.1111/j.14668238.2009.00505.x)

10. Delciellos AC, Nelson V, Augusto J, Suzy P, Ribeiro E, Braga C, Vieira MV, Cerqueira R. 2018 Seasonality in metacommunity structure : an empirical test in the Atlantic Forest. Landsc. Ecol. 33, 1769-1783. (doi:10.1007/s10980-018-07015)

11. Presley SJ, Higgins CL, Stevens CLRD. 2009 Elements of metacommunity structure of Paraguayan bats : multiple gradients require analysis of multiple ordination axes. , 781-793. (doi:10.1007/s00442-009-1341-x)

12. Sa P. 2014 Quantifying temporal variability in the metacommunity structure of stream fishes : the influence of non-native species and environmental drivers. , 3143. (doi:10.1007/s10750-013-1673-8)

13. Tonkin JD, Death RG, Muotka T, Astorga A, Lytle DA. 2018 Do latitudinal gradients exist in New Zealand stream invertebrate metacommunities ? PeerJ 6:e4898, 1-25. (doi:10.7717/peerj.4898) 
14. Tonkin JD, Sundermann A, Jähnig SC, Haase P. 2015 Environmental Controls on River Assemblages at the Regional Scale : An Application of the Elements of Metacommunity Structure Framework. , 1-19. (doi:10.1371/journal.pone.0135450)

15. Ochoa-Ochoa LM, Whittaker RJ. 2014 Spatial and temporal variation in amphibian metacommunity structure in Chiapas, Mexico. J. Trop. Ecol. 30, 537549. (doi:10.1017/S0266467414000388)

16. Meynard CN, Lavergne S, Boulangeat I, Garraud L, Van Es J, Mouquet N, Thuiller W. 2013 Disentangling the drivers of metacommunity structure across spatial scales. J. Biogeogr. 40, 1560-1571. (doi:10.1111/jbi.12116)

17. Newton AC, Walls RM, Golicher D, Keith SA, Diaz A, Bullock JM. 2012 Structure , composition and dynamics of a calcareous grassland metacommunity over a 70-year interval. , 196-209. (doi:10.1111/j.1365-2745.2011.01923.x)

18. Keith S a., Newton AC, Morecroft MD, Golicher DJ, Bullock JM. 2011 Plant metacommunity structure remains unchanged during biodiversity loss in English woodlands. Oikos 120, 302-310. (doi:10.1111/j.1600-0706.2010.18775.x)

19. Marcilio-Silva V, Zwiener VP, Marques MCM. 2017 Metacommunity structure , additive partitioning and environmental drivers of woody plants diversity in the Brazilian Atlantic Forest. Divers. Distrib. 23, 1110-1119. (doi:10.1111/ddi.12616)

20. Lindo Z, Winchester NN, Didham RK. 2008 Nested patterns of community assembly in the colonisation of artificial canopy habitats by oribatid mites. Oikos 117, 1856-1864. (doi:10.1111/j.1600-0706.2008.16920.x)

21. Chisholm C, Lindo Z, Gonzalez A. 2011 Metacommunity diversity depends on connectivity and patch arrangement in heterogeneous habitat networks. Ecography (Сop.). 34, 415-424. (doi:10.1111/j.1600-0587.2010.06588.x)

22. Staddon P, Lindo Z, Crittenden PD, Gilbert F, Gonzalez A. 2010 Connectivity, non-random extinction and ecosystem function in experimental metacommunities. Ecol. Lett. 13, 543-52. (doi:10.1111/j.1461-0248.2010.01450.x)

23. Heino J, Nokela T, Soininen J, Tolkkinen M, Virtanen L, Virtanen R. 2015 Elements of metacommunity structure and community- environment relationships in stream organisms. Freshw. Biol. 60, 973-988. (doi:10.1111/fwb.12556)

24. Kimmerer RW. 2005 Patterns of Dispersal and Establishment of Bryophytes Colonizing Natural and Experimental Treefall Mounds in Northern Hardwood Forests. Bryologist 108, 391-401. (doi:10.1639/00072745(2005)108[0391:PODAEO]2.0.CO;2)

25. Miles CJ, Longton RE. 1992 Deposition of moss spores in relation to distance from gametophyte. J. Bryol. 17, 355-368.

26. Lönnell N, Hylander K, Jonsson BG, Sundberg S. 2012 The fate of the missing 
spores--patterns of realized dispersal beyond the closest vicinity of a sporulating moss. PLoS One 7, e41987. (doi:10.1371/journal.pone.0041987)

27. Henriques-Silva R, Lindo Z, Peres-Neto PR. 2013 A community of metacommunities: exploring patterns in species distributions across large geographical areas. Ecology 94, 627-39.

28. Massol F, Gravel D, Mouquet N, Cadotte MW, Fukami T, Leibold M a. 2011 Linking community and ecosystem dynamics through spatial ecology. Ecol. Lett. 14, 313-23. (doi:10.1111/j.1461-0248.2011.01588.x)

29. Willig MR, Presley SJ, Bloch CP, Castro-Arellano I, Cisneros LM, Higgins CL, Klingbeil BT. 2011 Tropical metacommunities along elevational gradients: effects of forest type and other environmental factors. Oikos 120, 1497-1508. (doi:10.1111/j.1600-0706.2011.19218.x)

30. Logue B, Mouquet N, Peter H. 2011 Empirical approaches to metacommunities : a review and comparison with theory. 26. (doi:10.1016/j.tree.2011.04.009)

31. Villagran C, Hinojosa LF. 1997 Hisoria de los bosques del sur de Sudamérica, II: Análisis fitogeográfico. Rev. Chil. Hist. Nat. 70, 241-267.

32. Gutiérrez AG, Barbosa O, Christie D a., Del-Val E, Ewing H a., Jones CG, Marquet P a., Weathers KC, Armesto JJ. 2008 Regeneration patterns and persistence of the fog-dependent Fray Jorge forest in semiarid Chile during the past two centuries. Glob. Chang. Biol. , 161-176. (doi:10.1111/j.13652486.2007.01482.x)

33. Dallas T. 2014 metacom: an R package for the analysis of metacommunity structure. Ecography (Cop.). 37, 402-405. (doi:10.1111/j.16000587.2013.00695.x)

34. Rueden CT, Schindelin J, Hiner MC, DeZonia BE, Walter AE, Arena ET, Eliceiri KW. 2017 ImageJ2: ImageJ for the next generation of scientific image data. $B M C$ Bioinformatics 18, 529.

35. Oksanen J et al. 2019 vegan: Community Ecology Package.

36. Henriques-silva R, Lindo Z, Peres-neto PR. 2013 A community of metacommunities : exploring patterns in species distributions across large geographical areas. Ecology 94, 627-639.

37. Venail PA, Maclean RC, Meynard CN, Mouquet N, Venail PA, Maclean RC, Meynard CN, Mouquet N. 2010 Dispersal scales up the biodiversity - productivity relationship in an experimental source-sink metacommunity Email alerting service Dispersal scales up the biodiversity - productivity relationship in an experimental source-sink metacommunity. (doi:10.1098/rspb.2009.2104)

38. Lindo Z, Winchester NN. 2009 Spatial and environmental factors contributing to patterns in arboreal and terrestrial oribatid mite diversity across spatial scales. 
Oecologia 160, 817-25. (doi:10.1007/s00442-009-1348-3)

39. Alignier A. 2018 Agriculture, Ecosystems and Environment Two decades of change in a fi eld margin vegetation metacommunity as a result of fi eld margin structure and management practice changes. Agric. Ecosyst. Environ. 251, 1-10. (doi:10.1016/j.agee.2017.09.013)

40. Alexander HM, Foster BL, Iv FB, Collins CD, Antonovics J, Holt RD. 2012 Metapopulations and metacommunities : combining spatial and temporal perspectives in plant ecology. , 88-103. (doi:10.1111/j.1365-2745.2011.01917.x)

41. Baldwin LK, Bradfield GE. 2007 Bryophyte responses to fragmentation in temperate coastal rainforests : A functional group approach. Biol. Conserv. 136, 408-42. (doi:10.1016/j.biocon.2006.12.006)

42. Soderstrom L. 1988 The Occurrence of Epixylic Bryophyte and Lichen Species in an Old Natural and a Managed Forest Stand in Northeast Sweden. Biol. Conserv. 45, 169-178.

43. Nelson CR, Nelson CR, Halpern CB. 2005 Short-term effects of timber harvest and forest edges on ground-layer mosses and liverworts. Can. J. Bot. 83, 610-620. (doi:10.1139/b05-036)

44. Barichivich J, Christie DA, Maldonado A. 2008 Interannual variability of the coastal fog at Fray Jorge relict forests in semiarid Chile. 113, 1-16. (doi:10.1029/2008JG000709)

45. Guti JR. 2016 Vegetation of Bosque Fray Jorge National Park and its surrounding matrix in the Coastal Desert of north-central Chile. 126, 12-22. (doi:10.1016/j.jaridenv.2015.10.013)

46. Chang S, Lai I, Wu J. 2002 Estimation of fog deposition on epiphytic bryophytes in a subtropical montane forest ecosystem in northeastern Taiwan. Atmos. Res. 64, $159-167$. 


\section{Chapter 5}

\section{Conclusions}

This work presents a variety of gains in our understanding of the spatial processes that influence bryophyte community assemblages by applying techniques from the molecular to landscape scale to both mechanistic and phenomenological questions. I presented the first major step in understanding the role that passerine birds may play in bryophyte dispersal. In particular I demonstrated that this dispersal syndrome is taxonomically widespread at both levels of the bipartite association network. Furthermore, the differences in spore load and bryophyte identity associated with varied bird species and behaviors reflects nuanced patterns that may hold ecological significance for the manner in which bryophyte propagules are deposited across the landscape. Directed dispersal by birds may differentially increase arrival at particular microsites within the local environment [1-3]. This mode of dispersal may also connect spatially disjunct populations and communities of bryophytes that would otherwise lack an adequate dispersal mechanism [4-7]. Bird dispersal of bryophytes may therefore influence the diversity and identity of species assemblages across spatial scales. I have also demonstrated that application of metacommunity ideas via assessing metacommunity structures across a landscape can provide increased insight into assemblages when simultaneously at multiple spatial scales, and with consideration for various habitat compartments within the environment. 
Specifically, in chapter two, I demonstrated that avian spore load increases with bird size, which I suggest may be due to an increased surface area to which spores can adhere. Additionally, I showed that the number of spores carried differs between different bird surfaces, and that this is sensitive to both the bird species in question as well as bird foraging behavior. Furthermore, I provided evidence that topically-vectored bryophyte spores collected from birds are viable, supporting the concept that avian dispersal of bryophytes may have broad-reaching impacts on the pattern of arrival of bryophytes across the landscape. Future work assessing bryophyte spore load should aim to determine what the topical retention time of spores may be and contextualize this within bird flight-distance times to understand how far various species of birds are likely to disperse bryophyte propagules.

I expanded on this work in chapter three by assessing species-specific interactions between bryophytes and birds in a bipartite dispersal network. I found structure within this network, with certain bird species being more likely to carry particular bryophyte species. When foraging behavior of the bird species was considered, the level of specialization of associations between bryophytes and birds varied, which demonstrates that avian behavior alters the likelihood of specific birds picking up propagules of various bryophyte species. Additional research that builds upon my findings of particular species-specific relationships will be necessary to disentangle the avian-bryophyte dispersal network to determine the impact of individual birds on the dispersal kernel of particular bryophytes. 
Finally, in chapter four, I examined the structure of bryophyte metacommunities growing epiphytically on trees on a patchy landscape. I found that metacommunity structure varies at the patch level, and that while species overall respond individually to the major environmental gradient within the park, they tend to turn over together when considered within habitat subcompartments of the overall environment. This study distinguishes itself from previous similar work by avoiding temporal complications that stem from applying an elements of metacommunity structure framework to aggregate data collected over multiple years without consideration for how structure may change through time. Further work in this system should aim to determine the underlying genetic structure of populations of bryophytes along the park to make stronger connections between the dispersal of bryophytes an observed metacommunity structure.

This work has significance for bryophyte ecology, in that bryologists have lagged behind vascular plant ecologists in considering the influence of varied modes of propagule transport in shaping communities. Research that expands our understanding of the role that dispersal plays in generating and maintaining bryological diversity will provide greater insight into bryophyte recruitment and succession in anthropogenicallyimpacted habitat [8-11]. In turn, this will allow us to better predict the trajectory of recovery for functional services provided by bryophyte communities $[12,13]$.

Furthermore, this work has significance for the broader field of dispersal ecology. The history of plant dispersal theory has been almost entirely constructed within the framework of seed dispersal of tracheophytes. By investigating how behavioral ecology influences the dispersal of bryophytes, we present a system that offers an opportunity to 
independently test broader theories developed in seed-bearing plants. The seed dispersal literature has called for increased effort in understanding specific dispersal mechanisms, as most findings in the field are phenomenological in nature. By understanding specific dispersal mechanisms, it is more likely that we will be able to parse the contribution of different modes of dispersal to the overall dispersal kernel. This includes both understanding how different vectors influence dispersal, but also the investment given to different strategies from a plant perspective. Bryophytes are particularly well suited to this, as they produce spores, specialized asexual structures (gemmae), and can regenerate from pluripotent gametophytic tissues. The interaction between modality of the diaspore being moved as well as the mode of dispersal itself provides a rich system in which questions regarding dispersal distance, volume, and quality may be addressed.

\section{References}

1. Wenny DG. 2001 Advantages of seed dispersal: A re-evaluation of directed dispersal. Evol. Ecol. Res. 3, 51-74. (doi:10.1002/(SICI)10982345(200004)50:4<275::AID-AJP4>3.0.CO;2-K)

2. Levin SA, Muller-Landau HC, Nathan R, Chave J. 2003 The ecology and evolution of seed dispersal: A theoretical perspective. Annu. Rev. Ecol. Evol. Syst. 34, 575-604. (doi:10.1146/annurev.ecolsys.34.011802.132428)

3. Azafindratsima ONJAHR. 2015 Assessing the impacts of nonrandom seed dispersal by multiple frugivore partners on plant recruitment $\mathrm{R}$ eports $\mathrm{R}$ eports. 96, $24-30$.

4. Vigalondo B, Lara F, Draper I, Valcarcel V, Garilleti R, Mazimpaka V. 2016 Is it really you, Orthotrichum acuminatum? Ascertaining a new case of intercontinental 
disjunction in mosses. Bot. J. Linn. Soc. 180, 30-49. (doi:10.1111/boj.12360)

5. Lewis LR, Rozzi R, Goffinet B. 2014 Direct long-distance dispersal shapes a New World amphitropical disjunction in the dispersal-limited dung moss Tetraplodon (Bryopsida: Splachnaceae). J. Biogeogr. 41, 2385-2395. (doi:10.1111/jbi.12385)

6. Gradstein SR. 2017 Amphitropical disjunctive species in the complex thalloid liverworts (Marchantiidae). J. Bryol. 39, 66-78.

(doi:10.1080/03736687.2016.1189662)

7. Szo TER. 2012 Long-distance dispersal and genetic structure of natural populations : an assessment of the inverse isolation hypothesis in peat mosses. , 5461-5472. (doi:10.1111/mec.12055)

8. Löbel S, Rydin H. 2010 Trade-offs and habitat constraints in the establishment of epiphytic bryophytes. Funct. Ecol. 24, 887-897. (doi:10.1111/j.13652435.2010.01705.x)

9. Oldén A, Ovaskainen O, Kotiaho JS, Laaka-Lindberg S, Halme P. 2014 Bryophyte species richness on retention aspens recovers in time but community structure does not. PLoS One 9, e93786. (doi:10.1371/journal.pone.0093786)

10. Resources F, Hall G, North CA. 2008 MOSS HARVEST TRUNCATES THE SUCCESSIONAL DEVELOPMENT OF EPIPHYTIC BRYOPHYTES IN THE PACIFIC NORTHWEST. 18, 146-158.

11. Löbel S, Snäll T, Rydin H. 2012 Epiphytic bryophytes near forest edges and on retention trees: reduced growth and reproduction especially in old-growth-forest indicator species. J. Appl. Ecol. 49, 1334-1343. (doi:10.1111/j.13652664.2012.02201.x) 
12. Gonzalez A, Rayfield B, Lindo Z. 2011 The disentangled bank: how loss of habitat fragments and disassembles ecological networks. Am. J. Bot. 98, 503-16. (doi:10.3732/ajb.1000424)

13. Lindo Z, Gonzalez A. 2010 The Bryosphere: An integral and influential component of the Earth's biosphere. Ecosystems 13, 612-627. (doi:10.1007/s10021-010-9336-3) 


\section{Appendices:}

\section{Appendix A: List of Tables and Figures Within the Appendices}

\section{Tables}

B1: Number of spores and photosynthetic fragments recovered from avian surfaces ....107

B3: Summary of models used to determine the difference in avian spore load in

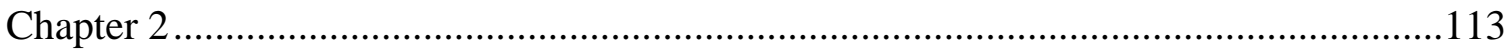

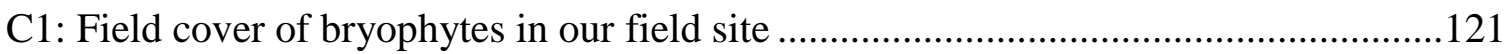

D3: Bryophyte species found on olivillo trees in Parque Nacional Bosque Fray Jorge

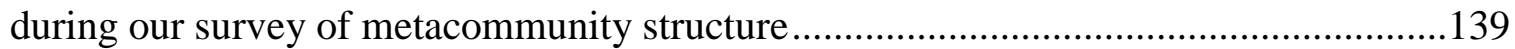

\section{Figures}

B2: Correlation of tarsus and wing length in captured birds ....................................112

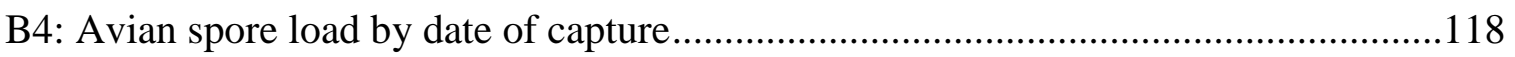

B5: Avian spore load by sampling effort ......................................................... 119

B6: First ever bryophyte grown after being sampled from a bird surface .....................120

C2: Heatmap of bird-bryophyte dispersal associations ........................................123

C3: Phylogenetic distance of bryophytes found on individual bird species ..................124

D1: Map of individual patches sampled in Parque Nacional Bosque Fray Jorge ............132

D2: Ordinated site-species matrices for bryophytes found in patches across the park....133

D4: Shannon diversity index by latitude in samples from higher in trees .....................140

D5: Shannon diversity index by longitude in samples from higher in trees ...................141

D6: Shannon diversity index by latitude in samples from lower in trees ......................142

D7: Shannon diversity index by longitude in samples from lower in trees ....................143

D8: Shannon diversity index by height in sampled trees...........................................144 


\section{Appendix B: Supplemental Figures in Support of Chapter 2}

B1: Number of captures of each bird species as well as the number of spores, photosynthetic fragments, and germination events per capture. Photosynthetic fragments include any non-spore chlorophyll-containing tissue fragment, and overestimate bryophyte gametophytic tissue abundance found on avian surfaces. Sample processing and growth methods did not allow for a separation of fragments and spores, so overall germination rates are a combination of both attributions. Germinations were likely limited by artificial growth conditions, and observed germination likely underrepresents the number of viable propagules. Number of germinations overall supports passerines as possible vectors for moss propagules 


\begin{tabular}{|c|c|c|c|c|c|c|c|c|c|c|}
\hline Species & $\begin{array}{l}\text { Total } \\
\text { Recovered } \\
\text { Spores }\end{array}$ & SD & Captures & $\begin{array}{l}\text { Spores/ } \\
\text { Captures }\end{array}$ & Germination & $\begin{array}{l}\text { Germination } \\
\text { /Capture }\end{array}$ & $\begin{array}{l}\text { Photosynthetic } \\
\text { Fragments }\end{array}$ & $\begin{array}{l}\text { Fragments } \\
\text { /Capture }\end{array}$ & $\begin{array}{l}\text { Germination } \\
\text { /Spore }\end{array}$ & $\begin{array}{l}\text { Germination } \\
\text { /Fragment }\end{array}$ \\
\hline $\begin{array}{l}\text { American Robin } \\
\text { (Turdus } \\
\text { migratorius) }\end{array}$ & 128 & 34.67 & 6 & 21.3 & 12 & 2 & 39 & 7 & 0.09 & 0.31 \\
\hline $\begin{array}{l}\text { Black-headed } \\
\text { Grosbeak } \\
\text { (Pheucticus } \\
\text { melanocephalus) }\end{array}$ & 2 & NA & 1 & 2.0 & 3 & 3 & 8 & 8 & 1.50 & 0.38 \\
\hline $\begin{array}{l}\text { Brown Creeper } \\
\text { (Certhia } \\
\text { americana) }\end{array}$ & 42 & NA & 8 & 5.3 & 1 & 0 & 2 & 0 & 0.02 & 0.50 \\
\hline $\begin{array}{l}\text { Black-throated } \\
\text { Grey Warbler } \\
\text { (Setophaga } \\
\text { nigrescens) }\end{array}$ & 29 & 10.53 & 4 & 7.3 & 1 & 0 & 63 & 16 & 0.03 & 0.02 \\
\hline $\begin{array}{l}\text { Chestnut-Backed } \\
\text { Chickadee } \\
\text { (Poecile } \\
\text { atricapillus) }\end{array}$ & 35 & 7.02 & 7 & 5.0 & 4 & 1 & 51 & 7 & 0.11 & 0.08 \\
\hline $\begin{array}{l}\text { Cedar Waxwing } \\
\text { (Bombycilla } \\
\text { cedrorum) }\end{array}$ & 35 & 3.88 & 9 & 3.9 & 9 & 1 & 256 & 28 & 0.26 & 0.04 \\
\hline $\begin{array}{l}\text { Chipping } \\
\text { Sparrow } \\
\text { (Spizella } \\
\text { passerina) }\end{array}$ & 9 & 2.10 & 8 & 1.1 & 24 & 3 & 45 & 6 & 2.67 & 0.53 \\
\hline & & & & & & & & & & \\
\hline
\end{tabular}




\begin{tabular}{|c|c|c|c|c|c|c|c|c|c|c|}
\hline $\begin{array}{l}\text { Dusky Flycatcher } \\
\text { (Empidonax } \\
\text { oberholseri) }\end{array}$ & 9 & 2.64 & 3 & 3.0 & 1 & 0 & 19 & 6 & 0.11 & 0.05 \\
\hline $\begin{array}{l}\text { Flicker } \\
\text { Intergrade }\end{array}$ & 0 & NA & 1 & 0.0 & 1 & 0 & 1 & 1 & & 1.00 \\
\hline $\begin{array}{l}\text { Gray Jay } \\
\text { (Perisoreus } \\
\text { canadensis) }\end{array}$ & 4 & NA & 5 & 0.8 & 1 & 0 & 5 & 1 & 0.25 & 0.20 \\
\hline $\begin{array}{l}\text { Hammond's } \\
\text { Flycatcher } \\
\text { (Empidonax } \\
\text { hammondii) }\end{array}$ & 10 & 1.66 & 8 & 1.3 & 6 & 1 & 41 & 5 & 0.60 & 0.15 \\
\hline $\begin{array}{l}\text { Hairy } \\
\text { Woodpecker } \\
\text { (Dryobates } \\
\text { villosus) }\end{array}$ & 44 & NA & 2 & 22.0 & 1 & 1 & 12 & 6 & 0.02 & 0.08 \\
\hline $\begin{array}{l}\text { Hermit Warbler } \\
\text { (Setophaga } \\
\text { occidentalis) }\end{array}$ & 3 & 0.70 & 2 & 1.5 & 6 & 3 & 8 & 4 & 2.00 & 0.75 \\
\hline $\begin{array}{l}\text { Lazuli Bunting } \\
\text { (Passerina } \\
\text { amoena) }\end{array}$ & 9 & 0.96 & 12 & 0.8 & 12 & 1 & 42 & 4 & 1.33 & 0.29 \\
\hline $\begin{array}{l}\text { MacGillivray's } \\
\text { Warbler } \\
\text { (Geothlypis } \\
\text { tolmiei) }\end{array}$ & 132 & 11.18 & 19 & 7.0 & 18 & 1 & 87 & 5 & 0.14 & 0.21 \\
\hline $\begin{array}{l}\text { Oregon Junco } \\
\text { (Junco hyemalis) }\end{array}$ & 79 & 15.52 & 13 & 6.1 & 16 & 1 & 80 & 6 & 0.20 & 0.20 \\
\hline
\end{tabular}




\begin{tabular}{|c|c|c|c|c|c|c|c|c|c|c|}
\hline $\begin{array}{l}\text { Pacific Wren } \\
\text { (Troglodytes } \\
\text { pacificus) }\end{array}$ & 19 & 4.16 & 3 & $\begin{array}{l}6.3 \\
\end{array}$ & 6 & 2 & 7 & 2 & 0.32 & 0.86 \\
\hline $\begin{array}{l}\text { Pacific Slope } \\
\text { Flycatcher } \\
\text { (Empidonax } \\
\text { difficilis) }\end{array}$ & 12 & 5.35 & 4 & 3.0 & 3 & 1 & 15 & 4 & 0.25 & 0.20 \\
\hline $\begin{array}{l}\text { Purple Finch } \\
\text { (Haemorhous } \\
\text { purpureus) }\end{array}$ & 0 & NA & 1 & 0.0 & 0 & 0 & 3 & 3 & & 0.00 \\
\hline $\begin{array}{l}\text { Red-shafted } \\
\text { Flicker (Colaptes } \\
\text { auratus) }\end{array}$ & 5 & NA & 1 & 5.0 & 2 & 2 & 3 & 3 & 0.40 & 0.67 \\
\hline $\begin{array}{l}\text { Ruffed Grouse } \\
\text { (Bonasa } \\
\text { umbellus) }\end{array}$ & 0 & NA & 1 & 0.0 & 1 & 1 & 12 & 12 & & 0.08 \\
\hline $\begin{array}{l}\text { Rufous } \\
\text { Hummingbird } \\
\text { (Selasphorus } \\
\text { rufus) }\end{array}$ & 8 & 0.92 & 25 & 0.3 & 2 & 0 & 0 & 0 & 0.25 & \\
\hline $\begin{array}{l}\text { Song Sparrow } \\
\text { (Melospiza } \\
\text { melodia) }\end{array}$ & 48 & 8.28 & 4 & \begin{tabular}{ll|}
12.0 \\
\end{tabular} & 7 & 2 & 33 & 8 & 0.15 & 0.21 \\
\hline $\begin{array}{l}\text { Spotted Towhee } \\
\text { (Pipilo } \\
\text { maculatus) }\end{array}$ & 28 & 11.40 & 5 & 5.6 & 8 & 2 & 38 & 8 & 0.29 & 0.21 \\
\hline $\begin{array}{l}\text { Steller's Jay } \\
\text { (Cyanocitta } \\
\text { stelleri) }\end{array}$ & 66 & 32.52 & 2 & 33.0 & 4 & 2 & 16 & 8 & 0.06 & 0.25 \\
\hline & & & & & & & & & & \\
\hline
\end{tabular}




\begin{tabular}{|c|c|c|c|c|c|c|c|c|c|c|}
\hline $\begin{array}{l}\text { Swainson's } \\
\text { Thrush } \\
\text { (Catharus } \\
\text { ustulatus) }\end{array}$ & 611 & 18.63 & 47 & 13.0 & 87 & 2 & 306 & 7 & 0.14 & 0.28 \\
\hline $\begin{array}{l}\text { Vaux's Swift } \\
\text { (Chaetura vauxi) }\end{array}$ & 0 & NA & 1 & 0.0 & 0 & 0 & 0 & 0 & & \\
\hline $\begin{array}{l}\text { Warbling Vireo } \\
\text { (Vireo gilvus) }\end{array}$ & 23 & 8.14 & 3 & 7.7 & 0 & 0 & 10 & 3 & 0.00 & 0.00 \\
\hline $\begin{array}{l}\text { White-Crowned } \\
\text { Sparrow } \\
\text { (Zonotrichia } \\
\text { leucophrys) }\end{array}$ & 5 & 2.12 & 2 & 2.5 & 1 & 1 & 20 & 10 & 0.20 & 0.05 \\
\hline $\begin{array}{l}\text { Western } \\
\text { Tanager } \\
\text { (Piranga } \\
\text { ludovicianai) }\end{array}$ & 38 & 5.01 & 9 & 4.2 & 3 & 0 & 87 & 10 & 0.08 & 0.03 \\
\hline $\begin{array}{l}\text { Wilson's } \\
\text { Warbler } \\
\text { (Cardellina } \\
\text { pusilla) }\end{array}$ & 79 & 38.1 & 4 & 19.8 & 2 & 1 & 12 & 3 & 0.03 & 0.17 \\
\hline Total & 1512 & & 220 & & 242 & & 1321 & & & \\
\hline Mean & 48.8 & & 7.1 & 6.5 & 7.8 & 1.04 & 42.6 & 6.1 & 0.43 & 0.27 \\
\hline
\end{tabular}

占 


\section{B2: Correlation of wing and tarsus lengths}

Linear regression of bird Tarsus Length and Wing chord (length). Given the fairly high correlation, and given that we expected to find legs to be more relevant (from a mechanistic standpoint) surfaces for resident spores and other propagules, we solely examined leg tarsus length as a predictor in building our models. $\mathrm{Y}=11.19+2.76 \mathrm{x}, \mathrm{R}^{2}=$ $0.61, \mathrm{~F}(1,99)=154.6, \mathrm{p}<0.01$

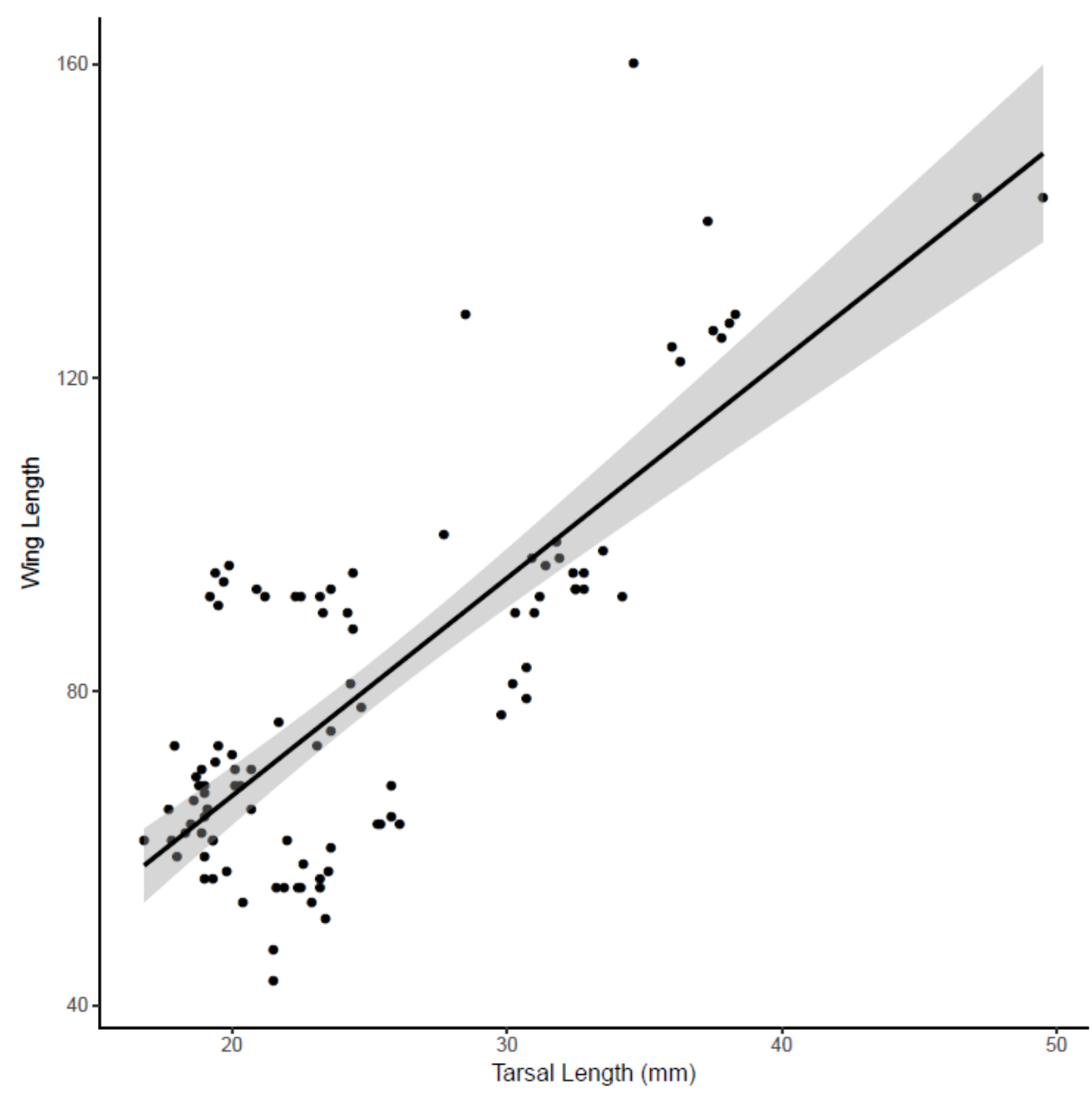




\section{B3: Summary of Models}

Presented final models were fit with a negative binomial log link. Likelihood ratio tests indicate comparison with a model without the listed predictor. Specific model coefficients are listed below by model formula(response $\sim$ predictors).

\begin{tabular}{|l|c|c|c|c|}
\hline \multicolumn{1}{|c|}{ Response } & Predictor & Chi Square & df & p \\
\hline Total Spore \# & Behavior & 11.7 & 3 & $<0.01$ \\
& Tarsus Length & 9.16 & 1 & $<0.01$ \\
Total Spore \# & Family & 63.66 & 16 & $<0.01$ \\
Total Spore \# & Species & 49.00 & 19 & $<0.01$ \\
Tail Spore \# & Behavior & 18.9 & 3 & $<0.01$ \\
Tail Spore \# & Family & 45.32 & 14 & $<0.01$ \\
Leg Spore \# & Tarsus Length & 23.08 & 1 & $<0.01$ \\
& Behavior & 6.30 & 3 & 0.09 \\
Leg Spore \# & Family & 33.72 & 14 & $<0.01$ \\
Leg Spore \# & Species & 48.4 & 19 & $<0.01$ \\
Tail Spore \# & Species & 61.86 & 19 & $<0.01$ \\
\hline
\end{tabular}

\section{All spore model coefficents}

Glmm.nb(totgreen behavior+tarsus.l)

Coefficients:

Estimate Std. Error $\mathrm{z}$ value $\operatorname{Pr}(>|\mathrm{z}|)$

$\begin{array}{lllll}\text { (Intercept) } \quad-0.27495 & 0.57984 & -0.474 & 0.63\end{array}$

behaviorbark $2.65899 \quad 1.02257 \quad 2.600 \quad 0.01 * *$

behaviorfoliage $0.94880 \quad 0.47193 \quad 2.010 \quad 0.04 *$

behaviorground $0.63990 \quad 0.51582 \quad 1.241 \quad 0.21$

$\begin{array}{lllll}\text { Tarsus.L } & 0.06333 & 0.02129 & 2.974<0.01 * *\end{array}$

Glm.nb(totgreen Alpha)

Coefficients:

Estimate Std. Error z value $\operatorname{Pr}(>|\mathrm{z}|)$

(Intercept) $3.06027 \quad 0.526925 .808<0.01 * * *$

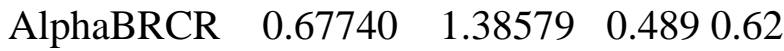

AlphaBTYW $-1.07927 \quad 0.84668-1.2750 .20$

AlphaCBCH $-1.45083 \quad 0.73314-1.9790 .05$ * 


\begin{tabular}{|c|c|}
\hline \multicolumn{2}{|c|}{ AlphaCEDW $\quad-1.70215 \quad 0.69721 \quad-2.4410 .01 *$} \\
\hline \multicolumn{2}{|c|}{ AlphaCHSP $-2.94249 \quad 0.76884-3.827<0.01 * * *$} \\
\hline & $0.96354-2.0360 .04 *$ \\
\hline $\begin{array}{ll}\text { AlphaDUFL } & -1.96166 \\
\text { AlphaGRAJ } & -1.67398\end{array}$ & $1.46513-1.1430 .25$ \\
\hline & $0.76158-3.725<0.01 * * *$ \\
\hline $\begin{array}{ll}\text { AlphaHAFL } & -2.83713 \\
\text { AlphaLAZB } & -3.34795\end{array}$ & $0.72365-4.627<0.01 * * *$ \\
\hline \multicolumn{2}{|c|}{ AlphaMGWA $-1.12191 \quad 0.60862-1.8430 .07$} \\
\hline \multicolumn{2}{|c|}{ AlphaORJU $\quad-0.48258 \quad 0.74842 \quad-0.6450 .52$} \\
\hline \multicolumn{2}{|c|}{ AlphaPAWR $\quad-1.21444 \quad 0.93270 \quad-1.3020 .19$} \\
\hline \\
\hline \multicolumn{2}{|c|}{$\begin{array}{lllll}\text { AlphaPSFL } & -1.96166 & 0.87505 & -2.242 & 0.02 * \\
\text { AlphaSOSP } & -0.57536 & 0.83858 & -0.686 & 0.49\end{array}$} \\
\hline \multicolumn{2}{|c|}{ AlphaSPTO $\quad-1.11436 \quad 0.84740 \quad-1.3150 .18$} \\
\hline \multicolumn{2}{|c|}{ AlphaSWTH $\quad-0.40637 \quad 0.56296 \quad-0.7220 .47$} \\
\hline \multicolumn{2}{|l|}{ AlphaWAVI -1.02339 } \\
\hline \multicolumn{2}{|l|}{ AlphaWETA $\quad-1.61991$} \\
\hline \multicolumn{2}{|l|}{ AlphaWIWA -0.07712} \\
\hline \multicolumn{2}{|l|}{ glm.nb(totgreen $\sim \operatorname{taxon})$} \\
\hline \multicolumn{2}{|l|}{ Coefficients: } \\
\hline \multicolumn{2}{|c|}{ Estimate Std. Error z value $\operatorname{Pr}(>|z|)$} \\
\hline \multirow{2}{*}{\multicolumn{2}{|c|}{$\begin{array}{llllll}\text { Intercept } & -1.730 \mathrm{e}+01 & 3.468 \mathrm{e}+03 & -0.005 & 0.99 & \\
\text { Taxon.groupBombycillidae } & 1.866 \mathrm{e}+01 & 3.468 \mathrm{e}+03 & 0.005 & 0.99\end{array}$}} \\
\hline \multirow{2}{*}{\multicolumn{2}{|c|}{$\begin{array}{lllll}\text { Taxon.groupBombycillidae } & 1.866 \mathrm{e}+01 & 3.468 \mathrm{e}+03 & 0.005 & 0.99 \\
\text { Taxon.groupCardinalidae } & 1.810 \mathrm{e}+01 & 3.468 \mathrm{e}+03 & 0.005 & 0.99\end{array}$}} \\
\hline & \\
\hline Taxon.groupCerthiidae & $2.104 \mathrm{e}+01 \quad 3.468 \mathrm{e}+03 \quad 0.006$ \\
\hline Taxon.groupCorvidae & $2.045 \mathrm{e}+01 \quad 3.468 \mathrm{e}+03 \quad 0.006 \quad 0.99$ \\
\hline Taxon.groupEmberizidae & $\begin{array}{llll}1.925 \mathrm{e}+01 & 3.468 \mathrm{e}+03 & 0.006 & 0.99\end{array}$ \\
\hline Taxon.groupFringillidae & $1.364 \mathrm{e}-07 \quad 4.904 \mathrm{e}+03 \quad 0.000 \quad 1.000$ \\
\hline Taxon.groupParidae & $1.891 \mathrm{e}+01 \quad 3.468 \mathrm{e}+03 \quad 0.005$ \\
\hline Taxon.groupParulidae & $1.943 \mathrm{e}+01 \quad 3.468 \mathrm{e}+03 \quad 0.006$ \\
\hline Taxon.groupPhasianidae & $\begin{array}{llll}1.364 \mathrm{e}-07 & 4.904 \mathrm{e}+03 & 0.000 & 1.000\end{array}$ \\
\hline Taxon.groupPicidae & $2.010 \mathrm{e}+01 \quad 3.468 \mathrm{e}+03 \quad 0.006 \quad 0.99$ \\
\hline \multicolumn{2}{|c|}{$\begin{array}{lllll}\text { Taxon.groupTroglodytidae } & 1.915 \mathrm{e}+01 & 3.468 \mathrm{e}+03 & 0.006 & 0.99\end{array}$} \\
\hline Taxon.groupTurdidae & $2.002 \mathrm{e}+01 \quad 3.468 \mathrm{e}+03 \quad 0.006 \quad 0.99$ \\
\hline Taxon.groupTyrannidae & $\begin{array}{llll}1.803 \mathrm{e}+01 & 3.468 \mathrm{e}+03 & 0.005 & 0.99\end{array}$ \\
\hline Taxon.groupVireonidae & $1.934 \mathrm{e}+01 \quad 3.468 \mathrm{e}+03 \quad 0.006$ \\
\hline
\end{tabular}

\section{Leg Spore Model Coefficents}

Glm.nb(legspore tarsus.1+behavior)

Coefficients: 


\begin{tabular}{lcccc}
\multicolumn{5}{c}{ Estimate Std. Error z value $\operatorname{Pr}(>|\mathrm{z}|)$} \\
$\begin{array}{lcccc}\text { (Intercept) } & -3.1808 & 0.8345 & -3.811<0.01 & * * * \\
\text { behaviorbark } & 1.6553 & 1.3659 & 1.212 & 0.23 \\
\text { behaviorfoliage } & 0.4729 & 0.6949 & 0.681 & 0.50 \\
\text { behaviorground } & -0.4370 & 0.7773 & -0.562 & 0.57 \\
\text { Tarsus.L } & 0.1311 & 0.0294 & 4.460<0.01\end{array} * * *$
\end{tabular}

Glm.nb(legspore alpha)

Coefficients:

Estimate Std. Error z value $\operatorname{Pr}(>|z|)$

$\begin{array}{lllll}\text { (Intercept) } & 1.2993 & 0.6570 & 1.978 & 0.05 *\end{array}$

$\begin{array}{lllll}\text { AlphaBRCR } & -0.6061 & 1.8025 & -0.336 & 0.73\end{array}$

$\begin{array}{lllll}\text { AlphaBTYW } & -1.5870 & 1.1594 & -1.369 & 0.17\end{array}$

$\begin{array}{lllll}\text { AlphaCBCH } & -1.6358 & 0.9812 & -1.667 & 0.09\end{array}$

$\begin{array}{lllll}\text { AlphaCEDW } & -1.9924 & 0.9855 & -2.022 & 0.04\end{array} *$

$\begin{array}{lllll}\text { AlphaCHSP } & -1.7693 & 0.9598 & -1.843 & 0.07\end{array}$

$\begin{array}{lllll}\text { AlphaDUFL } & -21.6019 & 8973.0993 & -0.002 & 0.99\end{array}$

$\begin{array}{lllllll}\text { AlphaGRAJ } & -21.6019 & 15541.8638 & -0.001 & 0.99\end{array}$

$\begin{array}{llllll}\text { AlphaHAFL } & -21.6019 & 5494.8787 & -0.004 & 0.99\end{array}$

$\begin{array}{lllll}\text { AlphaLAZB } & -21.6019 & 4486.5497 & -0.005 & 0.99\end{array}$

$\begin{array}{lllll}\text { AlphaMGWA } & -0.8097 & 0.7654 & -1.058 & 0.29\end{array}$

$\begin{array}{lllll}\text { AlphaORJU } & -1.7047 & 1.0334 & -1.650 & 0.10\end{array}$.

$\begin{array}{lllll}\text { AlphaPAWR } & -1.7047 & 1.3054 & -1.306 & 0.19\end{array}$

$\begin{array}{lllll}\text { AlphaPSFL } & -0.8938 & 1.0852 & -0.824 & 0.41\end{array}$

$\begin{array}{lllll}\text { AlphaSOSP } & -0.7397 & 1.0742 & -0.689 & 0.49\end{array}$

$\begin{array}{lllll}\text { AlphaSPTO } & -0.6061 & 1.0658 & -0.569 & 0.57\end{array}$

$\begin{array}{lllll}\text { AlphaSWTH } & -0.4654 & 0.7040 & -0.661 & 0.51\end{array}$

$\begin{array}{lllll}\text { AlphaWAVI } & -1.7047 & 1.3054 & -1.306 & 0.19\end{array}$

$\begin{array}{lllll}\text { AlphaWETA } & -1.1939 & 0.8883 & -1.344 & 0.18\end{array}$

$\begin{array}{lllll}\text { AlphaWIWA } & -21.6019 & 7770.9319 & -0.003 & 0.99\end{array}$

Glm.nb(legspore taxon)

Coefficients:

Estimate Std. Error $\mathrm{z}$ value $\operatorname{Pr}(>|\mathrm{z}|)$

$\begin{array}{lllll}\text { (Intercept) } & -1.730 \mathrm{e}+01 & 3.468 \mathrm{e}+03 & -0.005 & 0.99\end{array}$

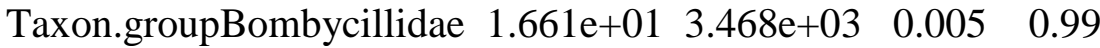

$\begin{array}{lllll}\text { Taxon.groupCardinalidae } & 1.651 \mathrm{e}+01 & 3.468 \mathrm{e}+03 & 0.005 & 0.99\end{array}$

$\begin{array}{lllll}\text { Taxon.groupCerthiidae } & 1.800 \mathrm{e}+01 & 3.468 \mathrm{e}+03 & 0.005 & 0.99\end{array}$

$\begin{array}{llllll}\text { Taxon.groupCorvidae } & 2.003 \mathrm{e}+01 & 3.468 \mathrm{e}+03 & 0.006 & 0.99\end{array}$

$\begin{array}{lllll}\text { Taxon.groupEmberizidae } & 1.730 \mathrm{e}+01 & 3.468 \mathrm{e}+03 & 0.005 & 0.99\end{array}$

Taxon.groupFringillidae $-4.090 \mathrm{e}-07 \quad 4.904 \mathrm{e}+03 \quad 0.000 \quad 1.000$ 
$\begin{array}{lllll}\text { Taxon.groupParidae } \quad & 1.697 \mathrm{e}+01 & 3.468 \mathrm{e}+03 & 0.005 & 0.99\end{array}$

$\begin{array}{llllll}\text { Taxon.groupParulidae } & 1.752 \mathrm{e}+01 & 3.468 \mathrm{e}+03 & 0.005 & 0.99\end{array}$

$\begin{array}{lllll}\text { Taxon.groupPhasianidae } & -4.090 \mathrm{e}-07 & 4.904 \mathrm{e}+03 & 0.000 & 1.00\end{array}$

$\begin{array}{lllll}\text { Taxon.groupPicidae } & 1.851 \mathrm{e}+01 & 3.468 \mathrm{e}+03 & 0.005 & 0.99\end{array}$

$\begin{array}{lllll}\text { Taxon.groupTroglodytidae } & 1.690 \mathrm{e}+01 & 3.468 \mathrm{e}+03 & 0.005 & 0.99\end{array}$

$\begin{array}{lllll}\text { Taxon.groupTurdidae } & 1.821 \mathrm{e}+01 & 3.468 \mathrm{e}+03 & 0.005 & 0.99\end{array}$

$\begin{array}{lllll}\text { Taxon.groupTyrannidae } & 1.639 \mathrm{e}+01 & 3.468 \mathrm{e}+03 & 0.005 & 0.99\end{array}$

$\begin{array}{lllll}\text { Taxon.groupVireonidae } & 1.690 \mathrm{e}+01 & 3.468 \mathrm{e}+03 & 0.005 & 0.99\end{array}$

\section{Rectrix spore model coefficents}

Glm.nb(rectspore tarsus.1+behavior)

Coefficients:

Estimate Std. Error $\mathrm{z}$ value $\operatorname{Pr}(>|\mathrm{z}|)$

(Intercept) $\quad-1.3218 \quad 0.7040 \quad-1.8780 .06$.

behaviorbark $4.5989 \quad 1.5351 \quad 2.996<0.01 * *$

behaviorfoliage $2.5412 \quad 0.7328 \quad 3.468<0.01 * * *$

behaviorground $1.8726 \quad 0.7632 \quad 2.4530 .01 *$

Glm.nb(rectspore alpha)

Coefficients:

Estimate Std. Error z value $\operatorname{Pr}(>|z|)$

$\begin{array}{lllll}\text { (Intercept) } & 1.4271 & 0.7001 & 2.038 & 0.04\end{array} *$

$\begin{array}{llllll}\text { AlphaBRCR } & 1.9402 & 1.7960 & 1.080 & 0.28\end{array}$

$\begin{array}{llllll}\text { AlphaBTYW } & -0.8675 & 1.1438 & -0.758 & 0.45\end{array}$

$\begin{array}{llllll}\text { AlphaCBCH } & -1.7636 & 1.0373 & -1.700 & 0.09\end{array}$.

AlphaCEDW $\quad-2.4079 \quad 1.0776-2.2350 .03 *$

$\begin{array}{llllll}\text { AlphaCHSP } & -3.3730 & 1.3697 & -2.463 & 0.01 *\end{array}$

$\begin{array}{llllll}\text { AlphaDUFL } & -1.8326 & 1.3750 & -1.333 & 0.18\end{array}$

$\begin{array}{lllll}\text { AlphaGRAJ } & -0.7340 & 1.9213 & -0.382 & 0.70\end{array}$

$\begin{array}{lllll}\text { AlphaHAFL } & -2.8134 & 1.1523 & -2.442 & 0.01 *\end{array}$

AlphaLAZB $\quad-3.9120 \quad 1.3097 \quad-2.987<0.01 * *$

$\begin{array}{llllll}\text { AlphaMGWA } & -0.6162 & 0.8287 & -0.744 & 0.46\end{array}$

$\begin{array}{lllll}\text { AlphaORJU } & -0.2231 & 0.9952 & -0.224 & 0.82\end{array}$

$\begin{array}{llllll}\text { AlphaPAWR } & -0.7340 & 1.4459 & -0.508 & 0.61\end{array}$

AlphaPSFL $\quad-18.7297 \quad 2002.1694 \quad-0.009 \quad 0.99$

$\begin{array}{llllll}\text { AlphaSOSP } & -1.4271 & 1.1897 & -1.200 & 0.23\end{array}$

$\begin{array}{llllll}\text { AlphaSPTO } & -0.1744 & 1.1122 & -0.157 & 0.88\end{array}$

$\begin{array}{lllll}\text { AlphaSWTH } & 0.2059 & 0.7478 & 0.275 & 0.78\end{array}$

$\begin{array}{llllll}\text { AlphaWAVI } & -2.5257 & 1.5461 & -1.634 & 0.10\end{array}$

$\begin{array}{lllll}\text { AlphaWETA } & -1.0217 & 0.9545 & -1.070 & 0.28\end{array}$ 


\section{$\begin{array}{lllll}\text { AlphaWIWA } & 0.9708 & 1.0900 & 0.891 & 0.37\end{array}$}

Glm.nb(rectspore taxon)

Coefficients:

\begin{tabular}{llllll}
\multicolumn{7}{c}{ Estimate Std. Error z value $\operatorname{Pr}(>|\mathrm{z}|)$} \\
(Intercept) & $-1.730 \mathrm{e}+01$ & $3.468 \mathrm{e}+03$ & -0.005 & 0.99 & \\
Taxon.groupBombycillidae & $1.632 \mathrm{e}+01$ & $3.468 \mathrm{e}+03$ & 0.005 & 0.99 \\
Taxon.groupCardinalidae & $1.690 \mathrm{e}+01$ & $3.468 \mathrm{e}+03$ & 0.005 & 0.99 \\
Taxon.groupCerthiidae & $2.067 \mathrm{e}+01$ & $3.468 \mathrm{e}+03$ & 0.006 & 0.99 \\
Taxon.groupCorvidae & $1.851 \mathrm{e}+01$ & $3.468 \mathrm{e}+03$ & 0.005 & 0.99 \\
Taxon.groupEmberizidae & $1.788 \mathrm{e}+01$ & $3.468 \mathrm{e}+03$ & 0.005 & 0.99 \\
Taxon.groupFringillidae & $-7.168 \mathrm{e}-08$ & $4.904 \mathrm{e}+03$ & 0.000 & 1.000 \\
Taxon.groupParidae & $1.697 \mathrm{e}+01$ & $3.468 \mathrm{e}+03$ & 0.005 & 0.99 \\
Taxon.groupParulidae & $1.852 \mathrm{e}+01$ & $3.468 \mathrm{e}+03$ & 0.005 & 0.99 \\
Taxon.groupPhasianidae & $-7.167 \mathrm{e}-08$ & $4.904 \mathrm{e}+03$ & 0.000 & 1.000 \\
Taxon.groupPicidae & $1.954 \mathrm{e}+01$ & $3.468 \mathrm{e}+03$ & 0.006 & 0.99 \\
Taxon.groupTroglodytidae & $1.800 \mathrm{e}+01$ & $3.468 \mathrm{e}+03$ & 0.005 & 0.99 \\
Taxon.groupTurdidae & $1.891 \mathrm{e}+01$ & $3.468 \mathrm{e}+03$ & 0.005 & 0.99 \\
Taxon.groupTyrannidae & $1.605 \mathrm{e}+01$ & $3.468 \mathrm{e}+03$ & 0.005 & 0.99 \\
Taxon.groupVireonidae & $1.620 \mathrm{e}+01$ & $3.468 \mathrm{e}+03$ & 0.005 & 0.99
\end{tabular}




\section{B4: Date of capture and total spore load on bird surfaces}

Number of spores found on birds plotted by capture month. There did not appear to be any particular pattern with regard to spore load through time.

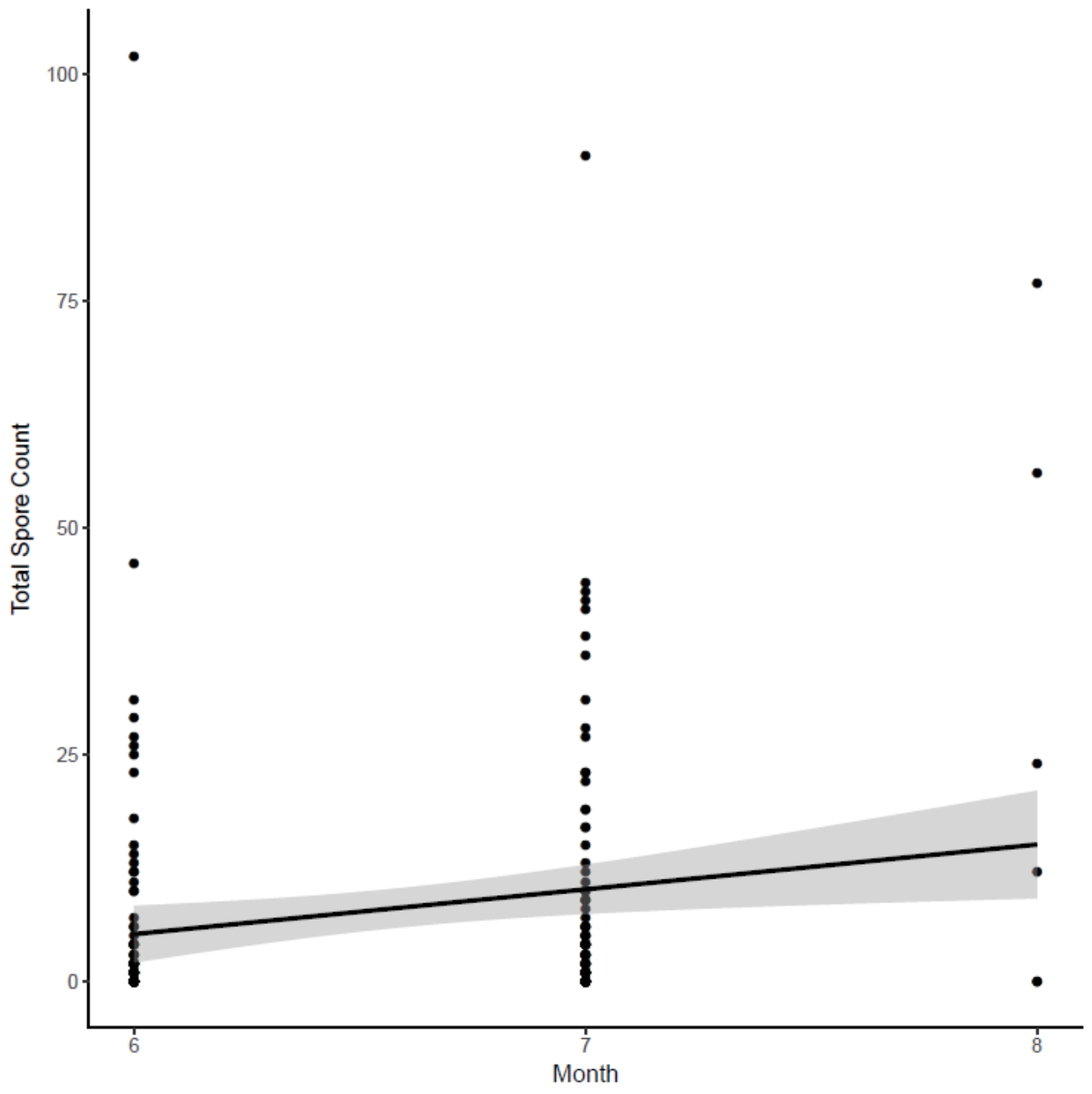




\section{B5: Sampling effort effects on spore number by species}

Mean tarsus length (Meanleg) for each bird species plotted by the mean total number of spores found per species. Size of points indicate sample size. The relationship between the number of spores found on avian legs with leg size does not appear to be influenced by sample size.

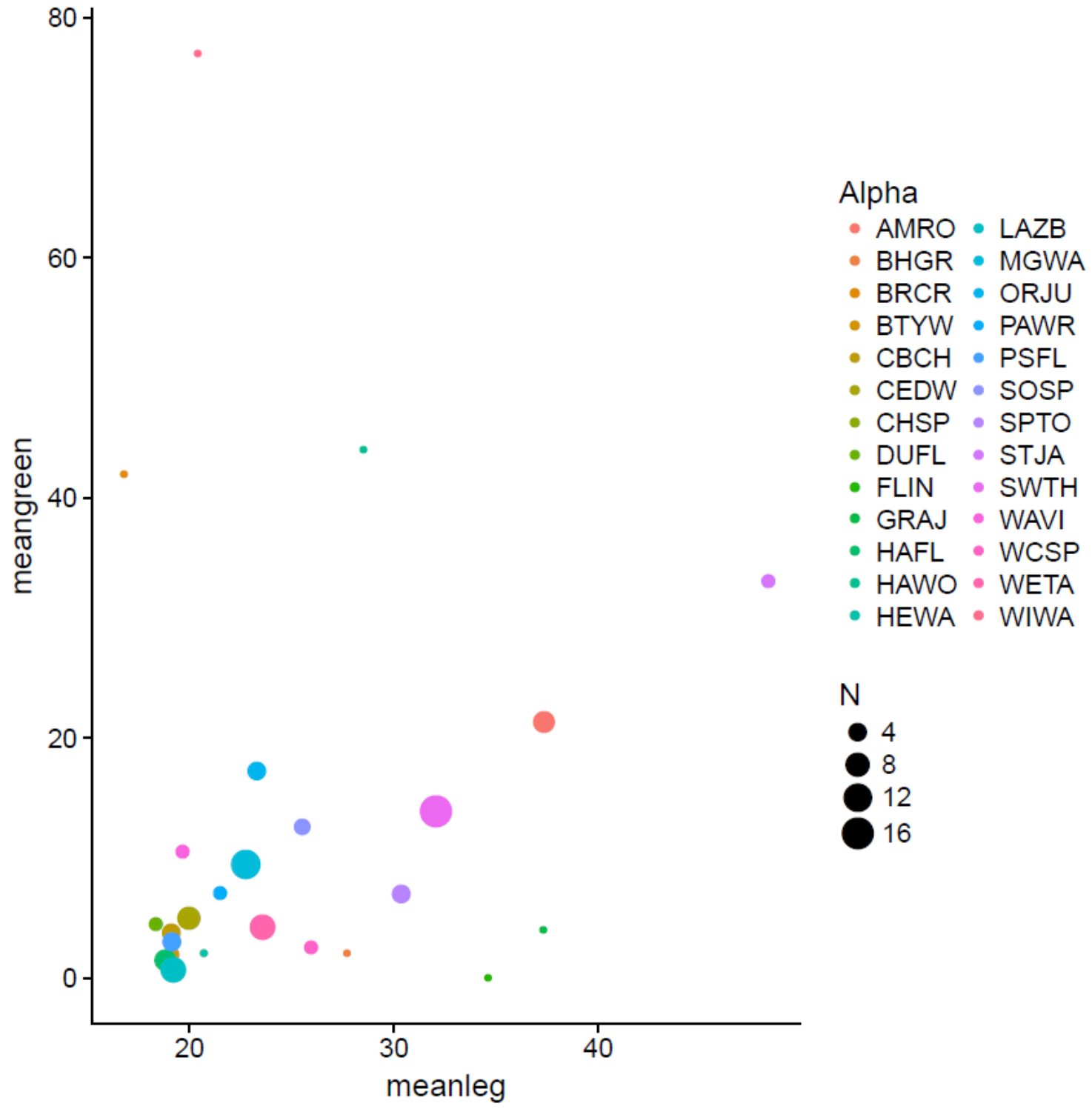




\section{B6: Protonemal growth}

First naturally occurring bryophyte (to our knowledge) to ever be germinated after being recovered from a passerine external surface. Morphological identification of species was not possible in our samples as many only grew to the protonemal stage due to artificial growth conditions.

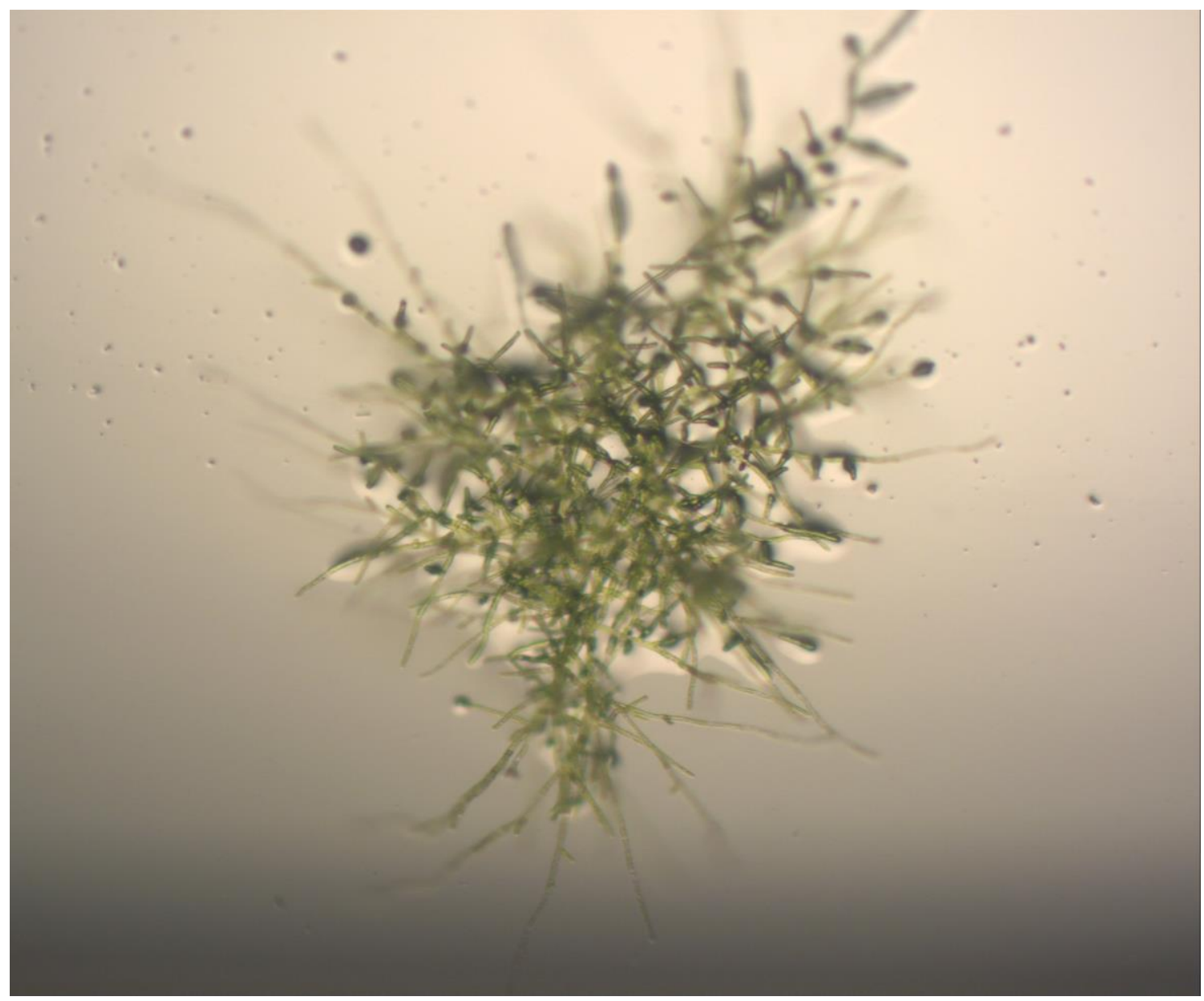




\section{Appendix C: Supplemental Figures in Support of Chapter 3}

$\mathrm{C} 1$ : Percent cover of bryophytes found growing on the trunks of trees and on the ground in Oregon Ash and adjacent Douglas Fir dominant patches surrounding our mist netting location. Mean and standard deviation of cover represent 30 samples in each forest type and substrate combination.

Oregon Ash Dominant: Ground

\begin{tabular}{|c|c|c|}
\hline Bryophyte Species & Mean Cover & Standard Deviation of Cover \\
\hline Plagiomium insigne & 13.13 & 17.94 \\
\hline Climacium dendroides & 6.37 & 13.86 \\
\hline Porella navicularis & 2.93 & 5.80 \\
\hline Kindbergia oregana & 2.03 & 5.14 \\
\hline Fontinalis antipyretica & 1.00 & 5.48 \\
\hline Orthotrichum lyelli & 0.80 & 2.04 \\
\hline Neckera douglasii & 0.70 & 2.17 \\
\hline Kindbergia praelonga & 0.67 & 2.54 \\
\hline Homatholecium & & \\
fulgescens & 0.50 & 2.74 \\
\hline Rhytidiadelphus & & \\
triquetrus & 0.47 & 1.89 \\
\hline Isothecium myosuroides & 0.33 & 0.93 \\
\hline Hypnum circinale & 0.20 & 0.18 \\
\hline Dicranum sp & 0.03 &
\end{tabular}

Oregon Ash Dominant: Trunk

\begin{tabular}{|c|c|c|}
\hline Bryophyte Species & Mean Cover & Standard Deviation of Cover \\
\hline Neckera douglasii & 28.73 & 35.72 \\
\hline Homatholecium fulgescens & 16.20 & 21.30 \\
\hline Porella navicularis & 4.83 & 9.14 \\
\hline Dicranum sp & 0.20 & 0.92 \\
\hline Isothecium myosuroides & 0.13 & 0.57 \\
\hline Orthotrichum lyelli & 0.10 & 0.40 \\
\hline Hypnum circinale & 0.07 & 0.37 \\
\hline Porella navicularus & 0.03 & 0.18 \\
\hline
\end{tabular}


Douglas Fir Dominant: Ground

\begin{tabular}{|c|c|c|}
\hline Bryophyte Species & Mean Cover & Standard Deviation of Cover \\
\hline Kindbergia oregana & 22.6 & 26.39697 \\
\hline Rhytidiadelphus triquetrus & 4.333333 & 13.9885 \\
\hline Climacium dendroides & 3.366667 & 14.92622 \\
\hline Rhytidiadelphus sp & 2.666667 & 14.60593 \\
\hline Hylacomnium splendens & 0.666667 & 3.651484 \\
\hline Dicranum sp & 0.233333 & 0.971431 \\
\hline Hypnum circinale & 0.2 & 0.761124 \\
\hline Neckera douglasii & 0.066667 & 0.365148 \\
\hline Plagiomium insigne & 0.033333 & 0.182574 \\
\hline
\end{tabular}

Douglas Fir Dominant: Trunk

\begin{tabular}{|c|c|c|}
\hline Bryophyte Species & Mean Cover & Standard Deviation of Cover \\
\hline Hypnum circinale & 39.33333 & 37.61725 \\
\hline Isothecium myosuroides & 9.333333 & 22.11776 \\
\hline Rhytidiadelphus triquetrus & 6.333333 & 20.7586 \\
\hline Neckera douglasii & 3.8 & 16.42622 \\
\hline Climacium dendroides & 1.833333 & 10.04158 \\
\hline Radula complanata & 1.5 & 8.215838 \\
\hline Porella navicularis & 0.9 & 2.643796 \\
\hline Antitricia curtipendula & 0.666667 & 3.651484 \\
\hline Dicranum sp & 0.333333 & 0.994236 \\
\hline Dendroalsia abietina & 0.033333 & 0.182574 \\
\hline
\end{tabular}


C2: Heatmap of bipartite relationships between bryophytes and birds within a dispersal association network. Darker boxes indicate more frequent associations between bryophytes and birds.

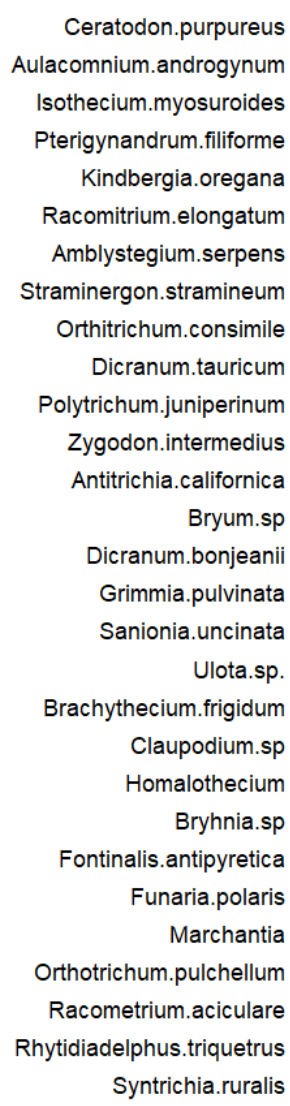

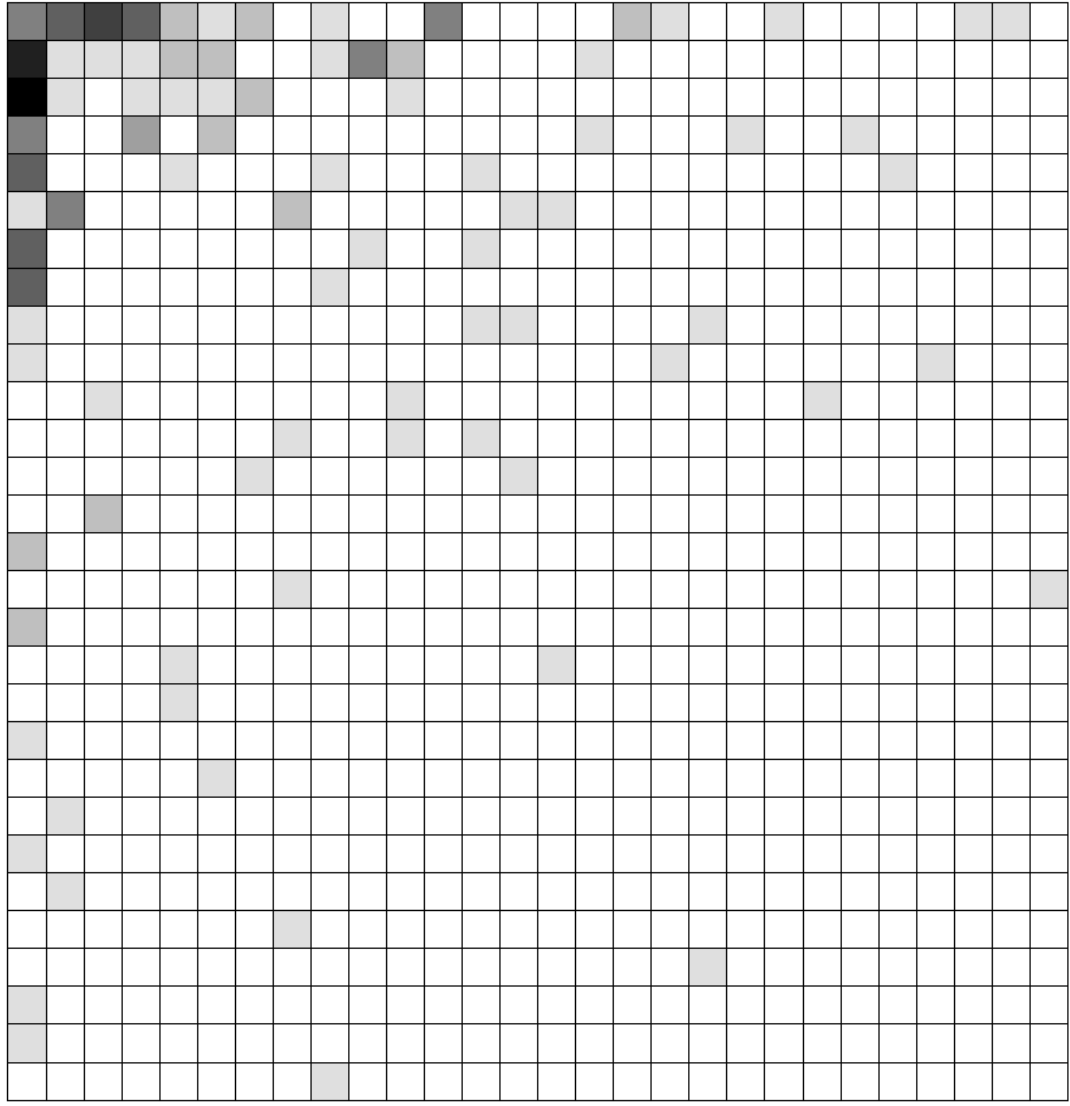

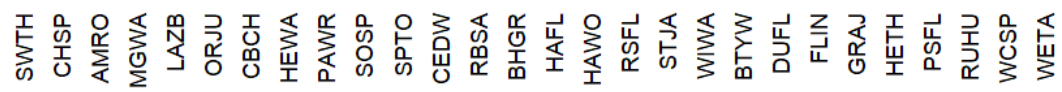


C3: Phylogenetic trees displaying the occurrence of bryophyte species on a bryophyte phylogenetic tree associated with bird species in our study, used to calculate Faith's Phylogenetic Distance. Bird species are identified by their American Ornithological Union four-letter code.

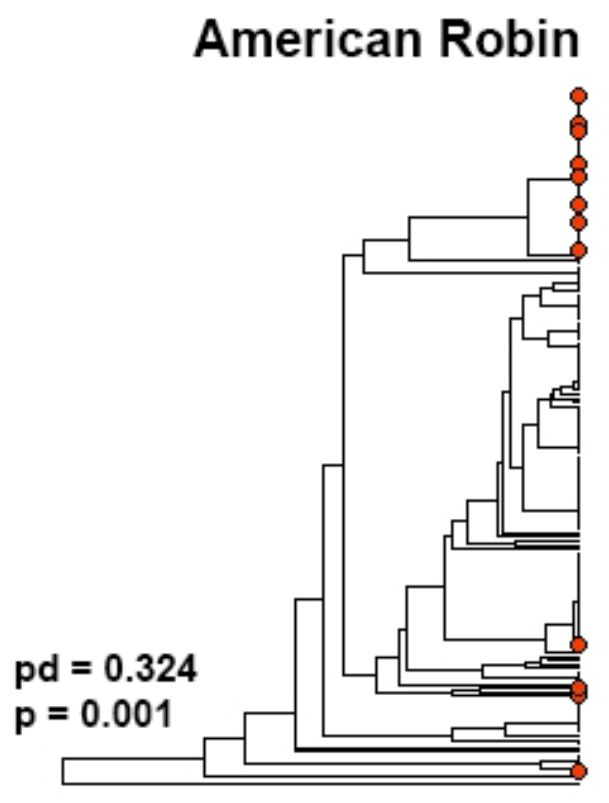

\section{Black-headed Grosbeak}

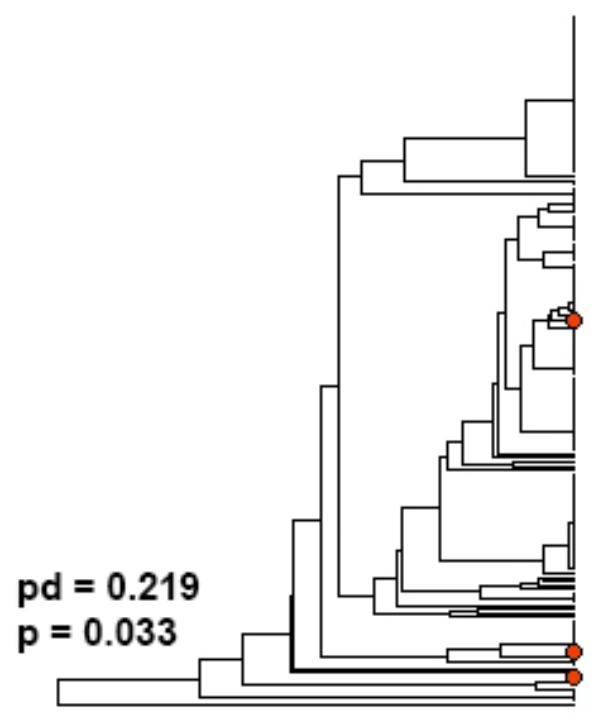



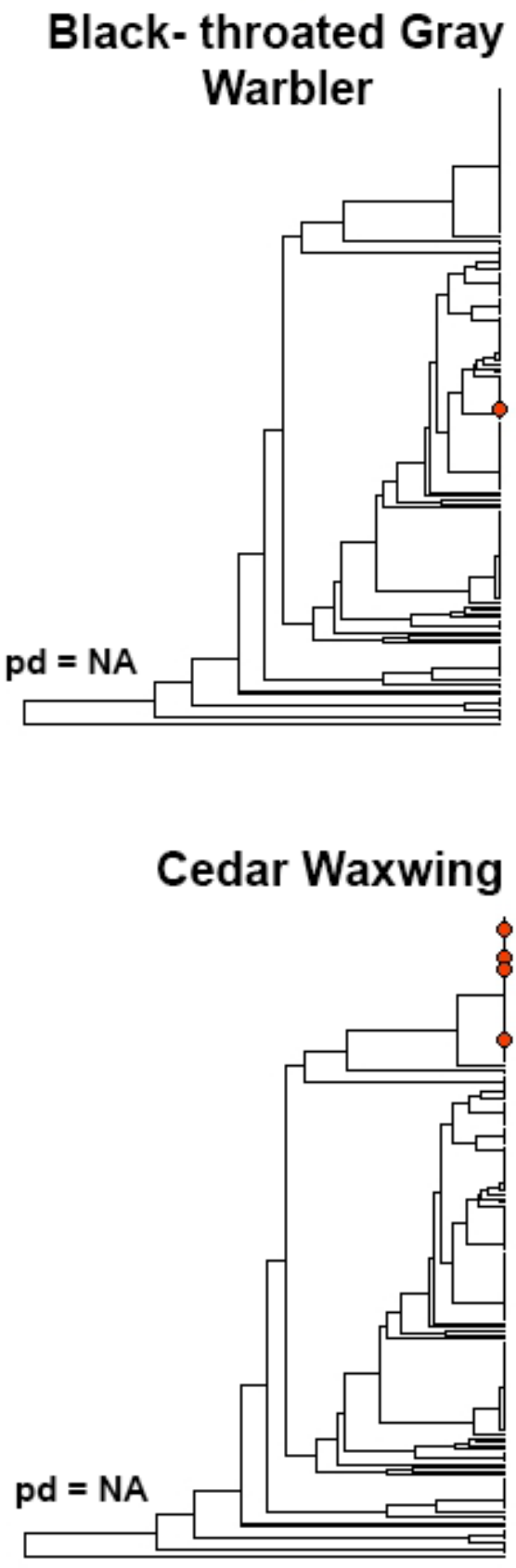

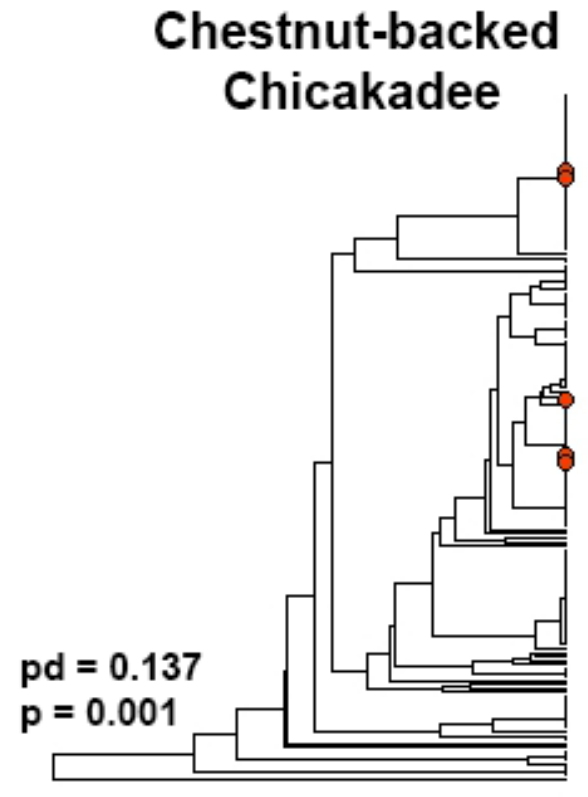

Chipping Sparrow

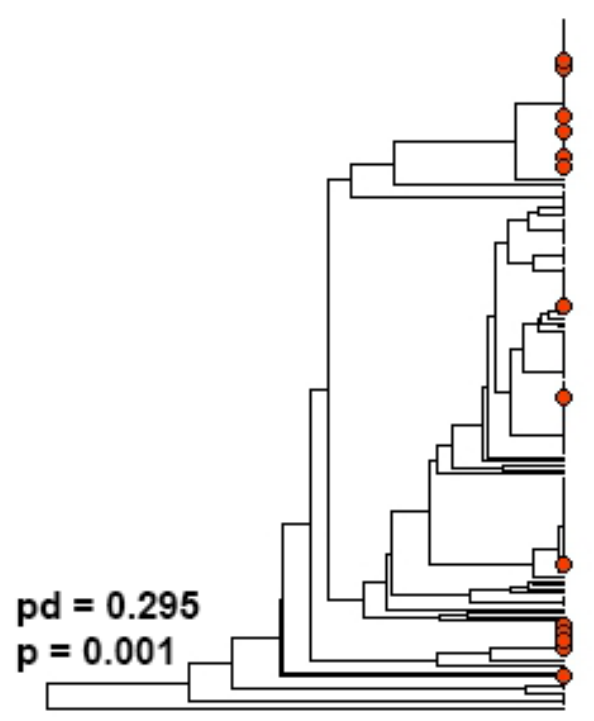



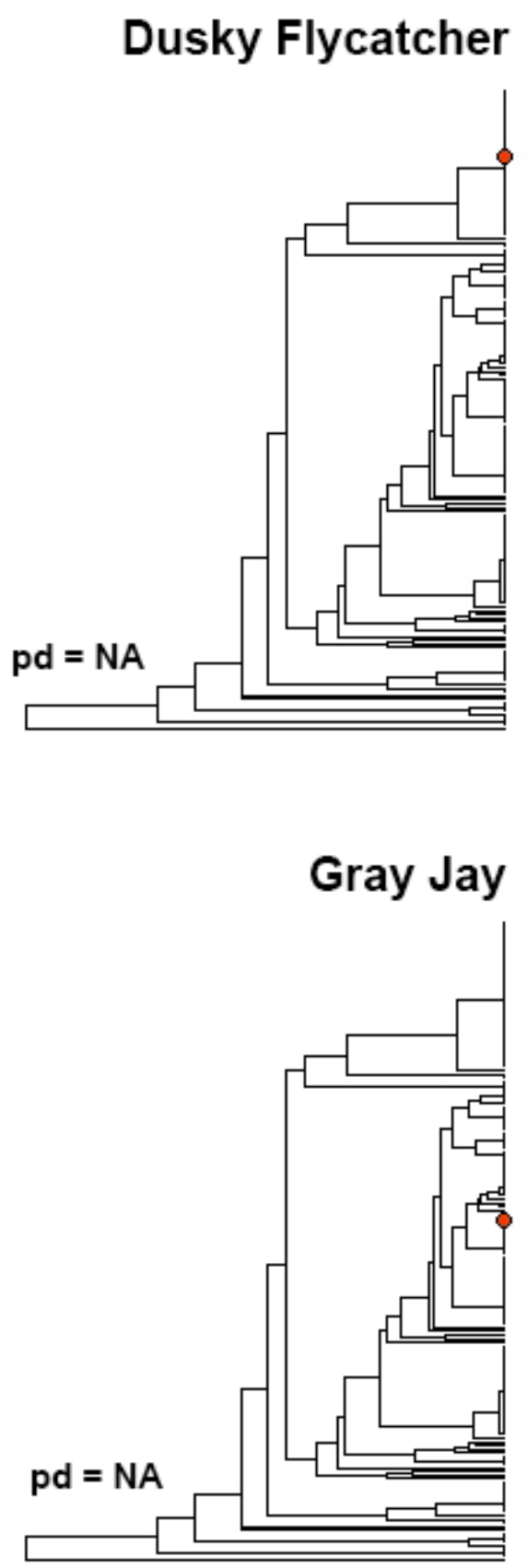

Flicker Intergrade

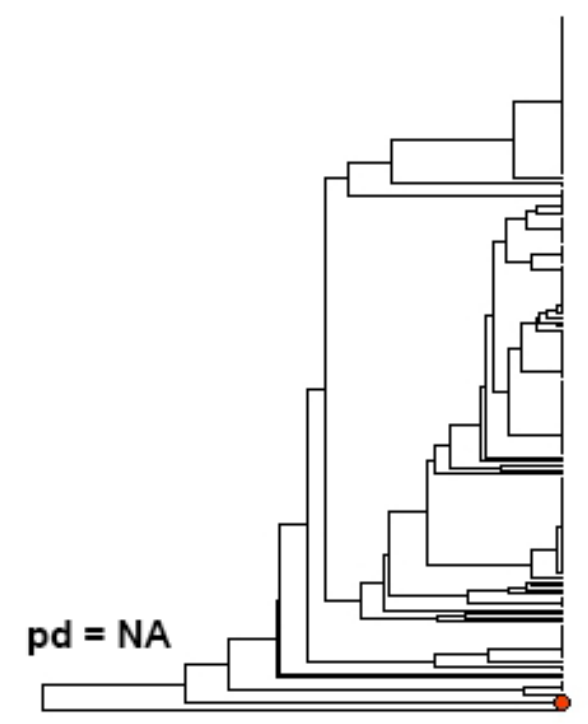

Hammond's Flycatcher

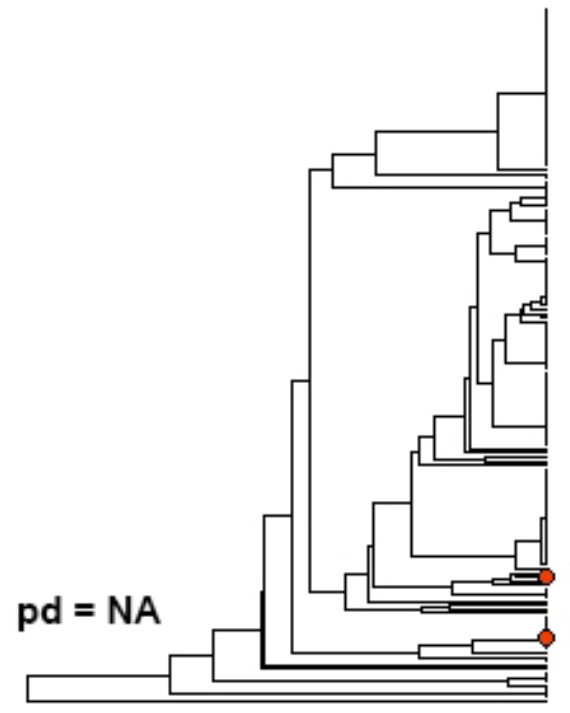




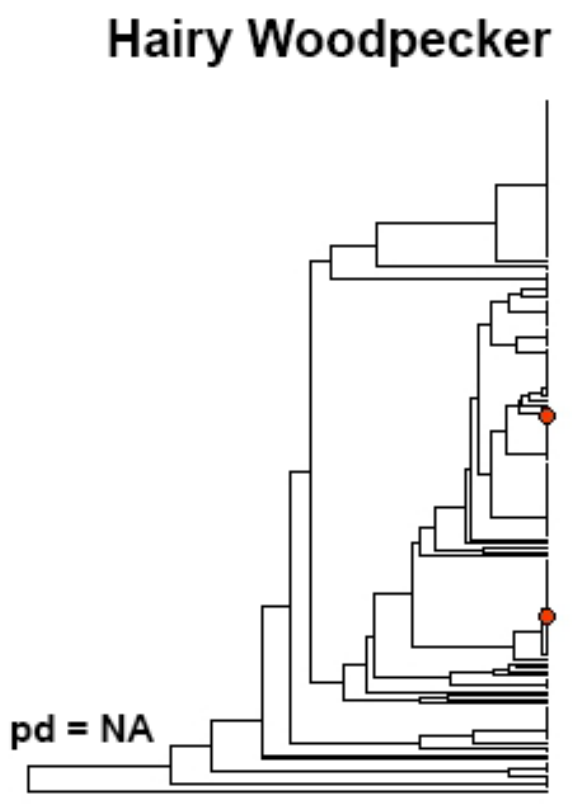

Hermit Thrush

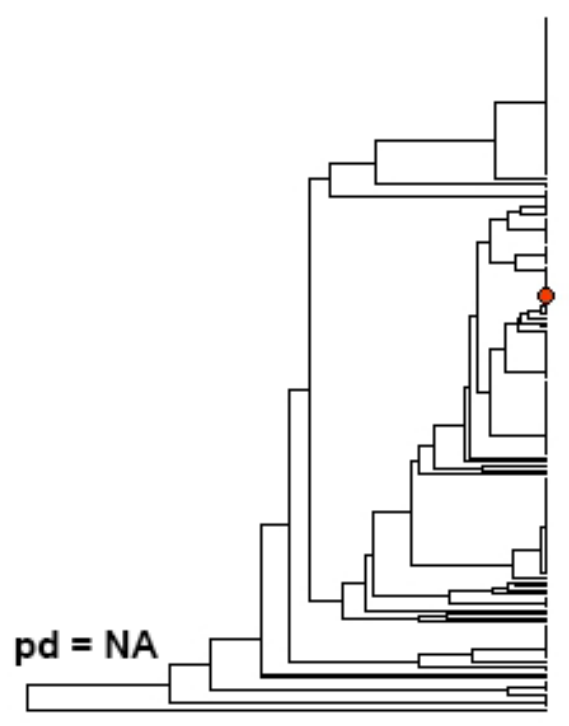

Hermit Warbler

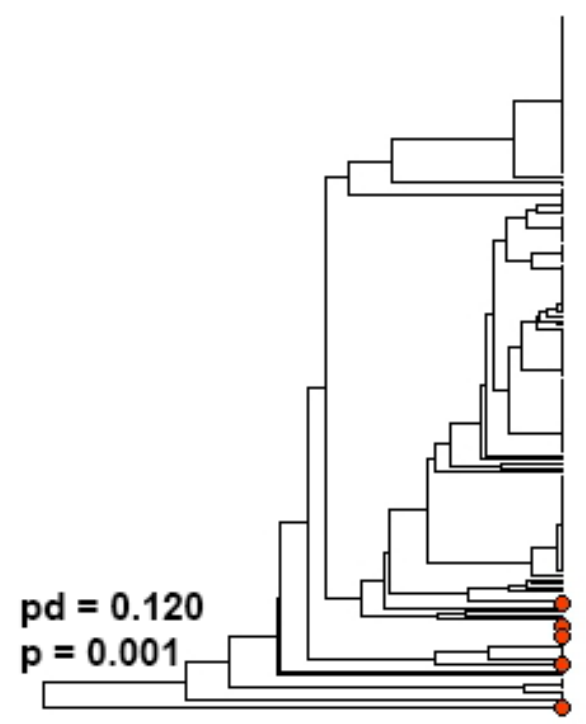

\section{Lazuli Bunting}

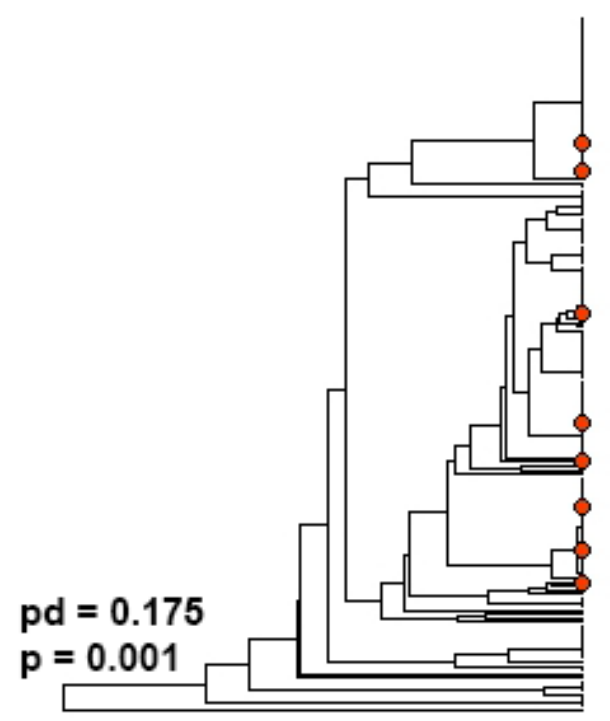



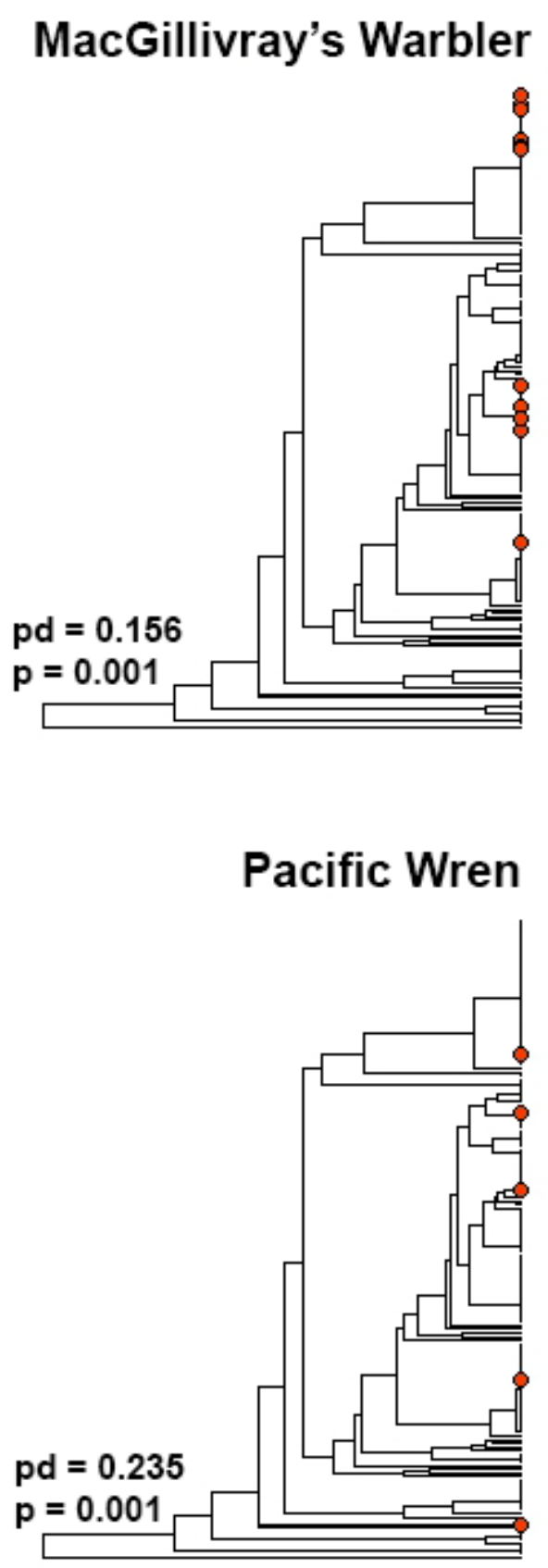

Oregon Junco

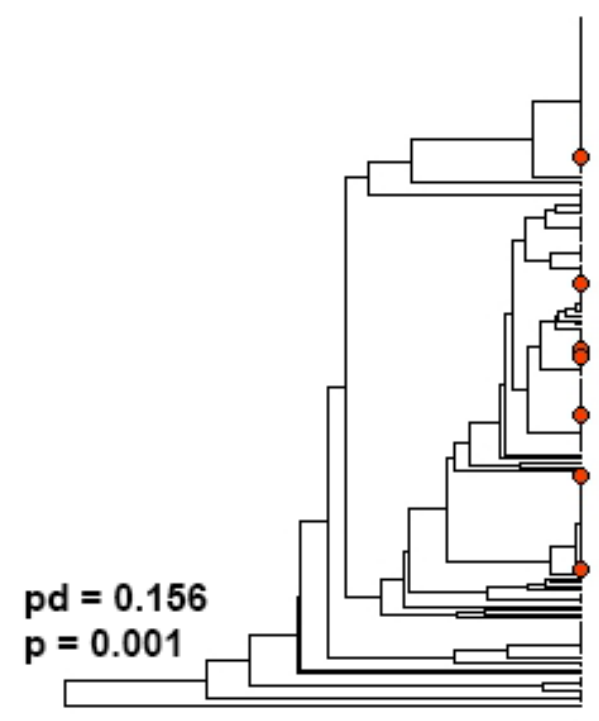

Pacific Slope Flycatcher

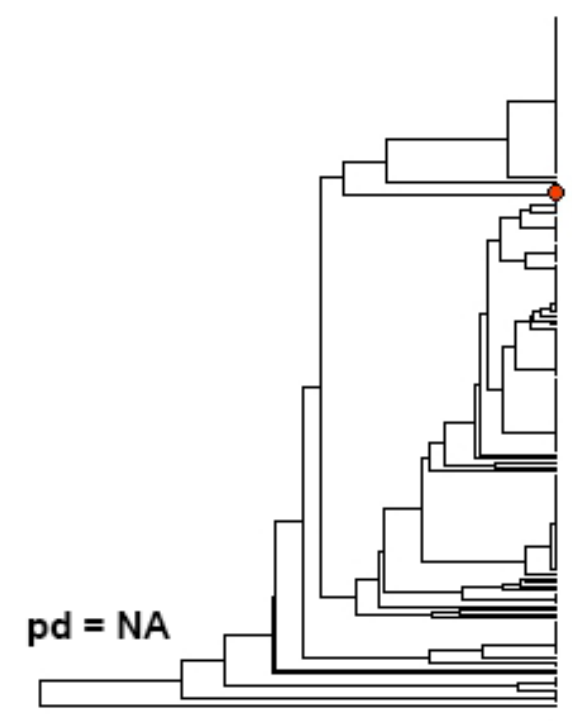


Red-breasted Sapsucker

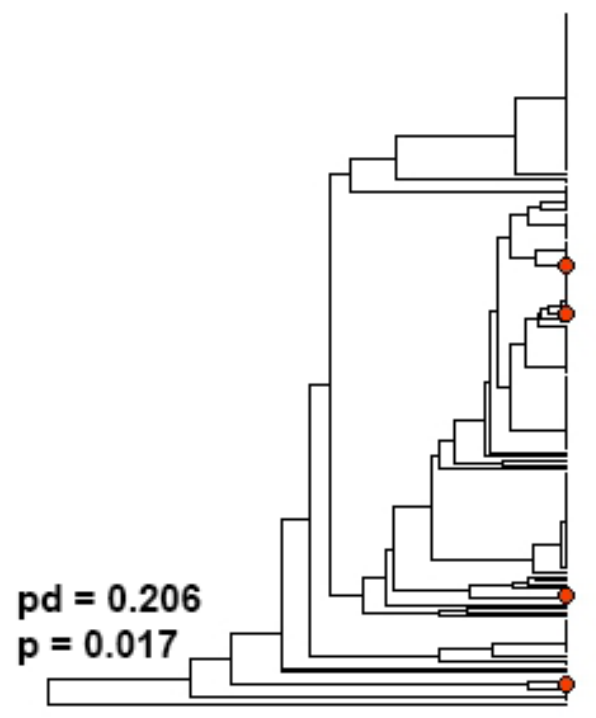

Rufous Hummingbird

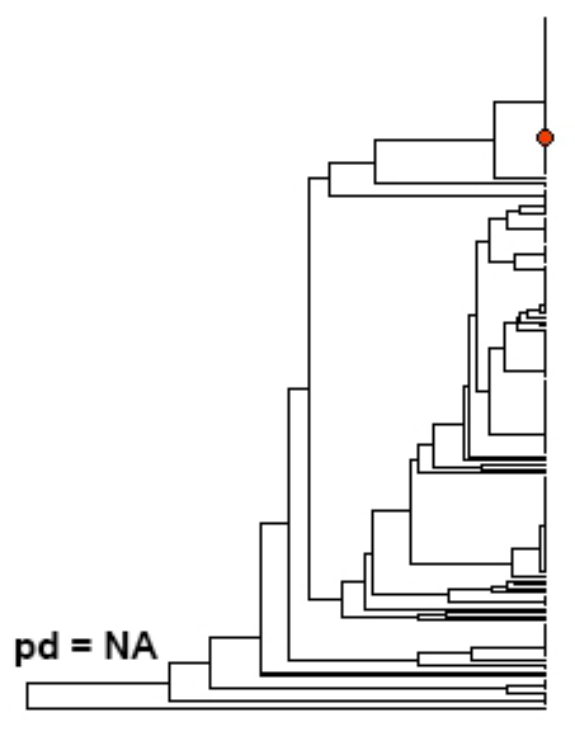

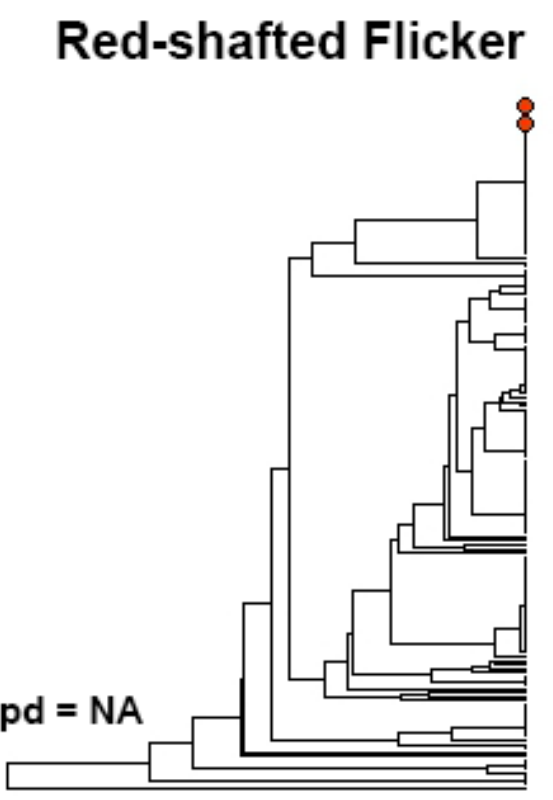

Song Sparrow

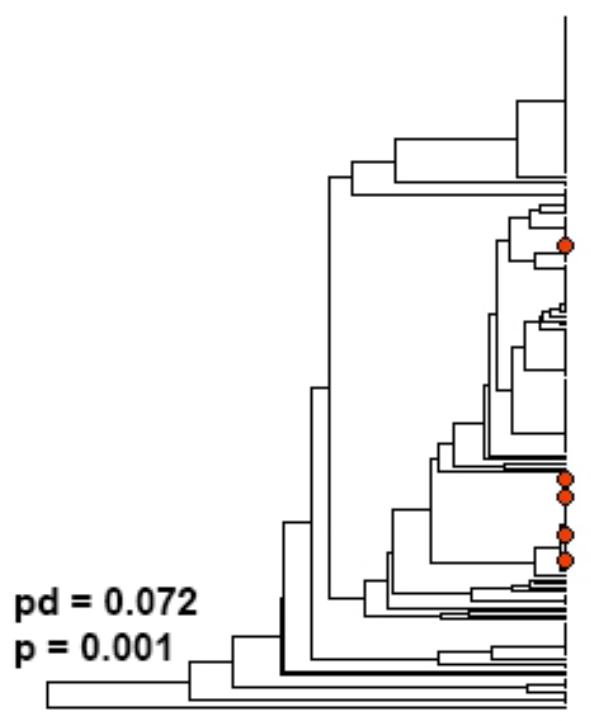



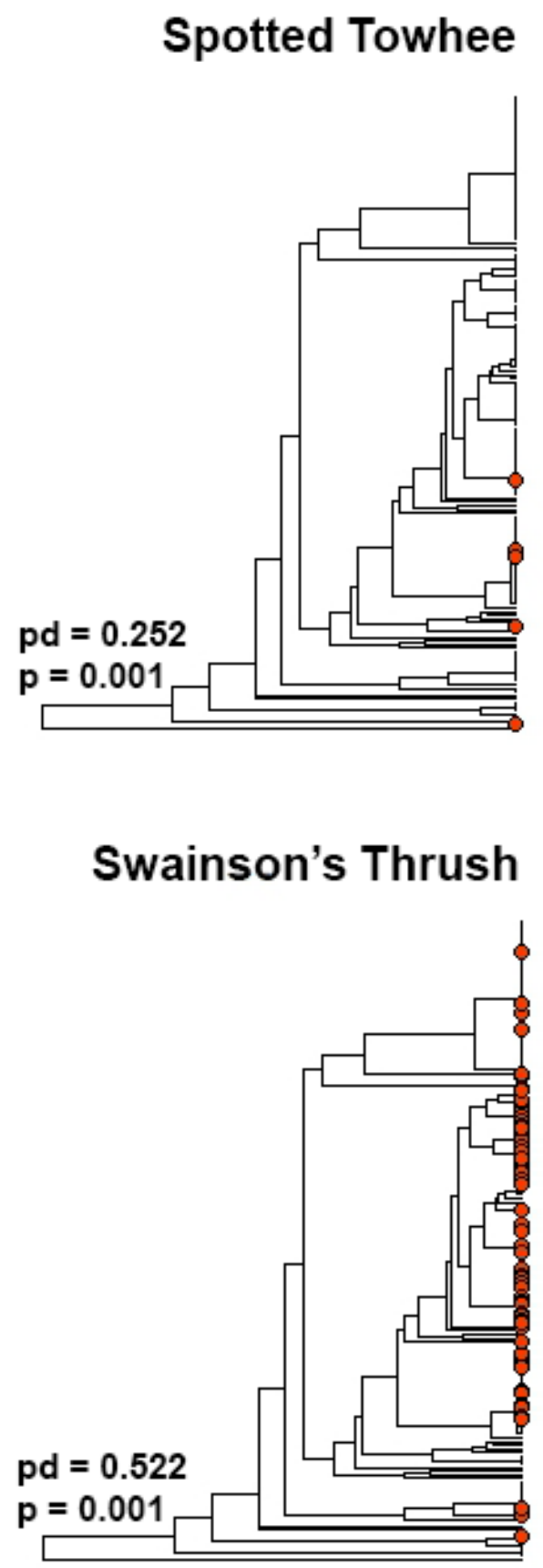

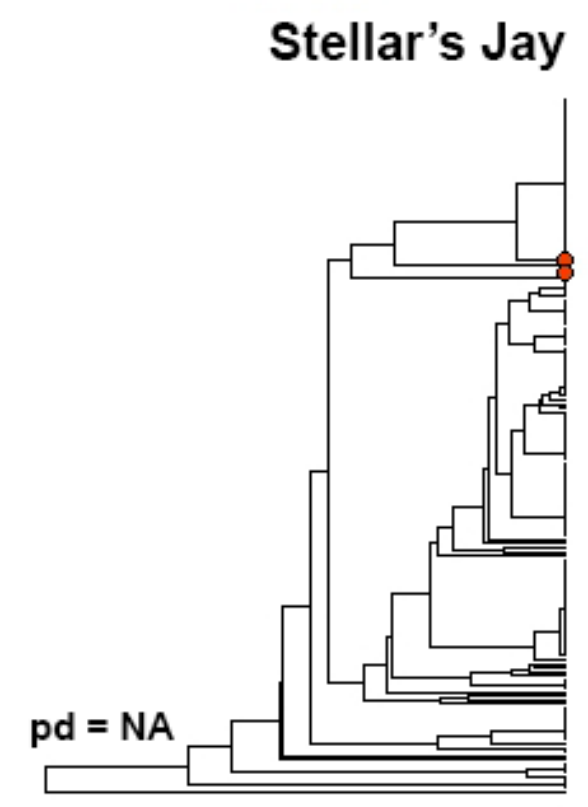

\section{White-crowned Sparrow}

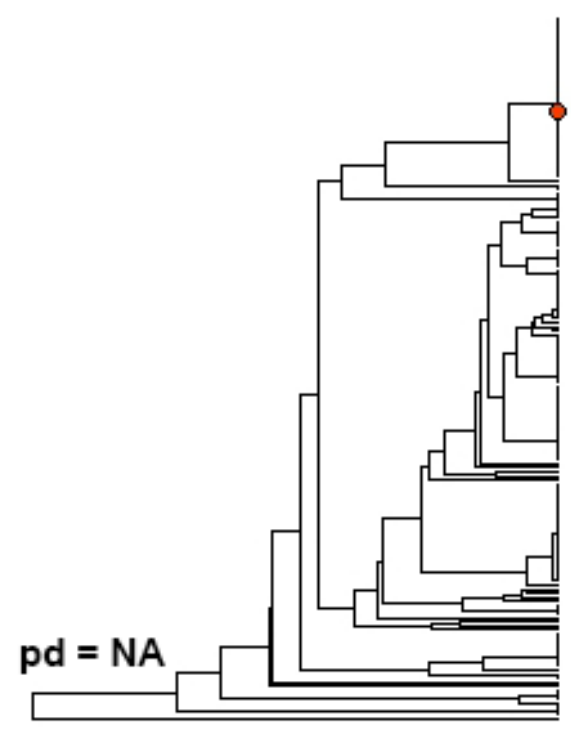



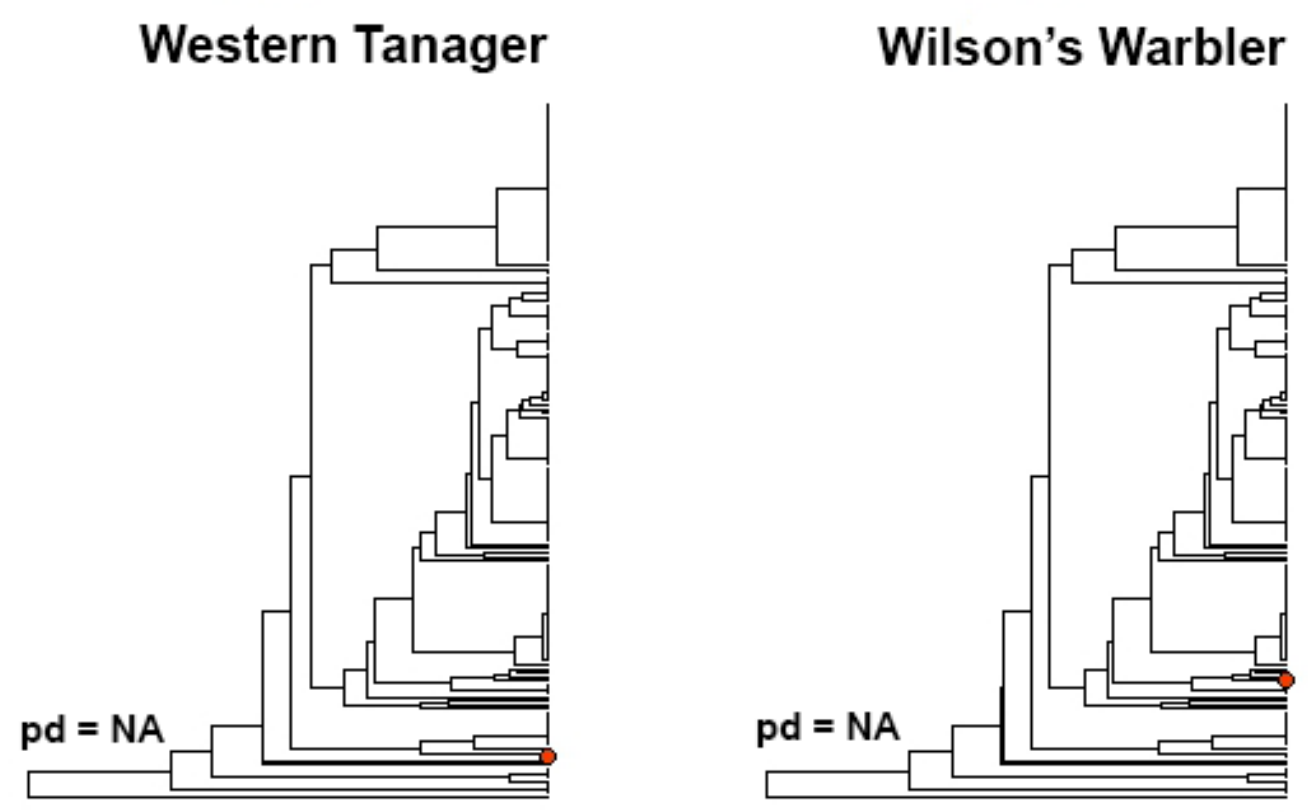


\section{Appendix D: Supplemental Figures in Support of Chapter 4}

D1: Map of all the patches sampled across the park.

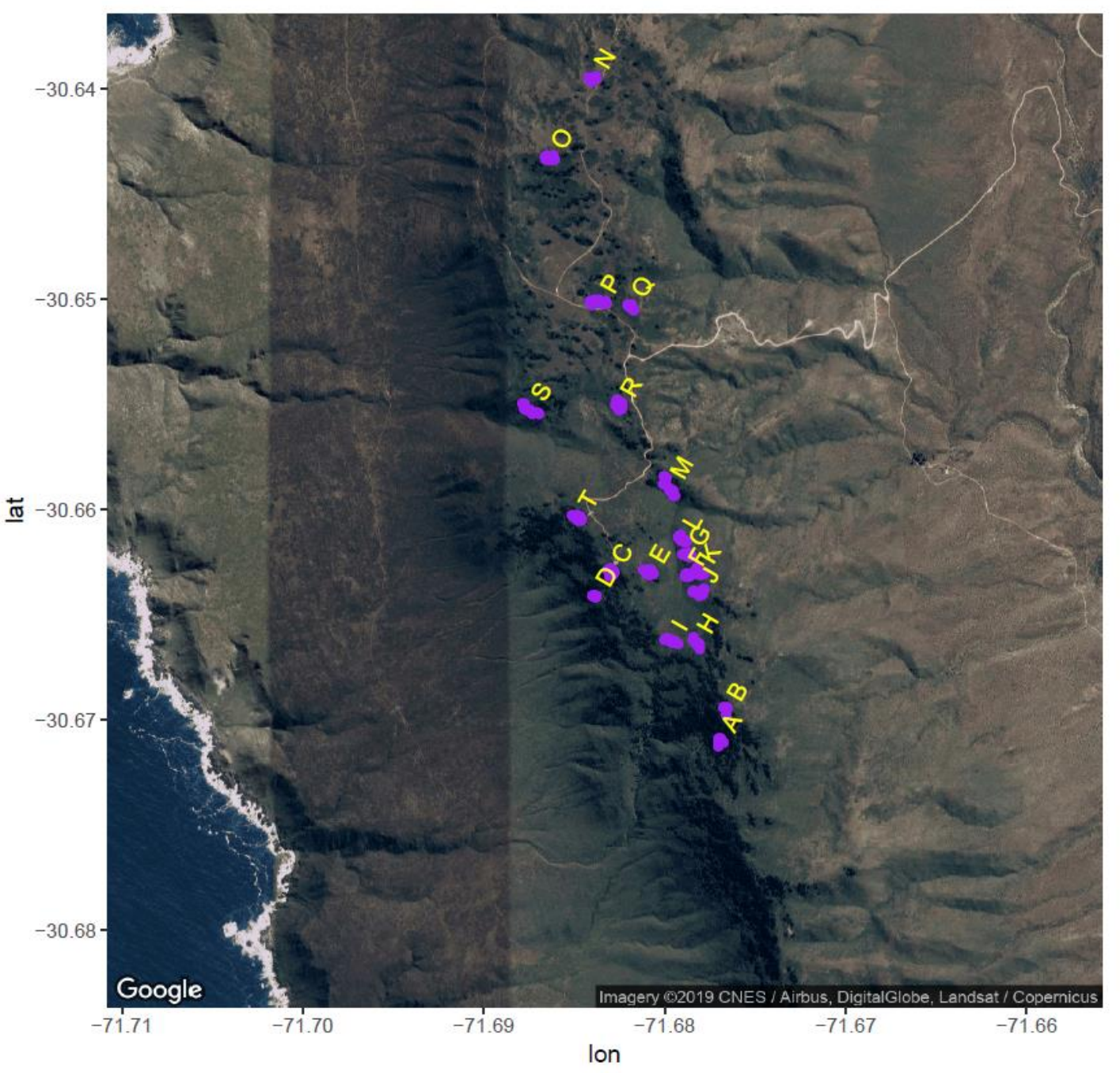


D2: Ordinated matrices used to determine metacommunity structure for the whole park, the high and low compartments, and individual plots A-T.

Total Park

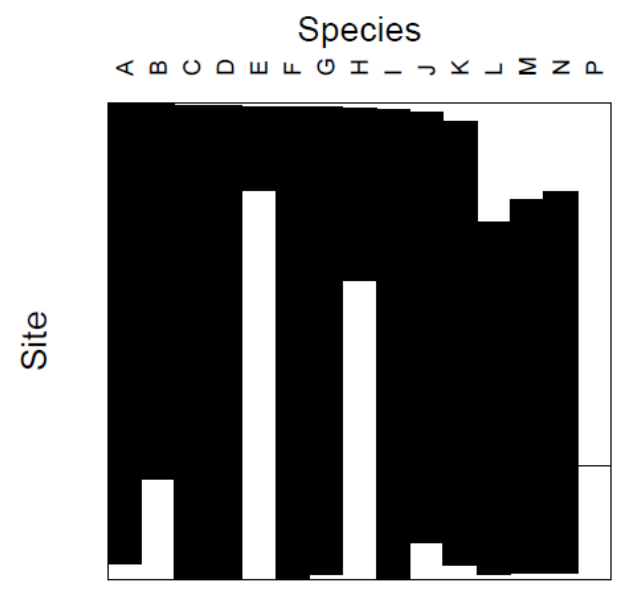

High Plots

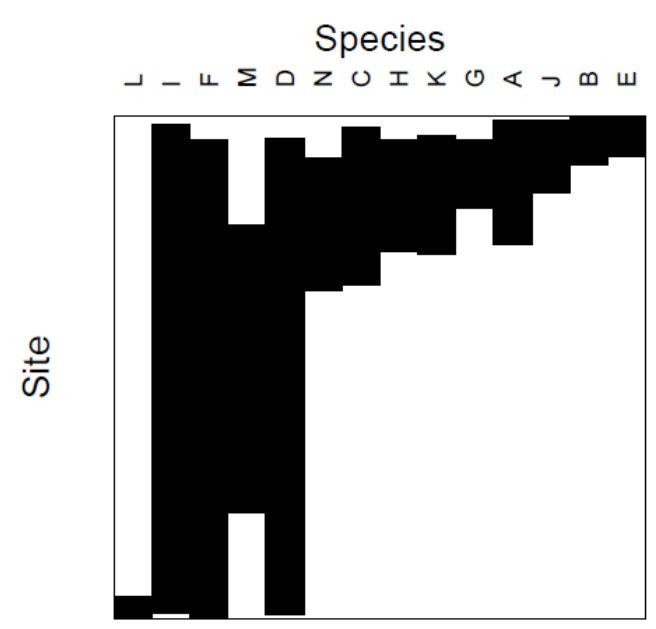

\section{Low Plots}

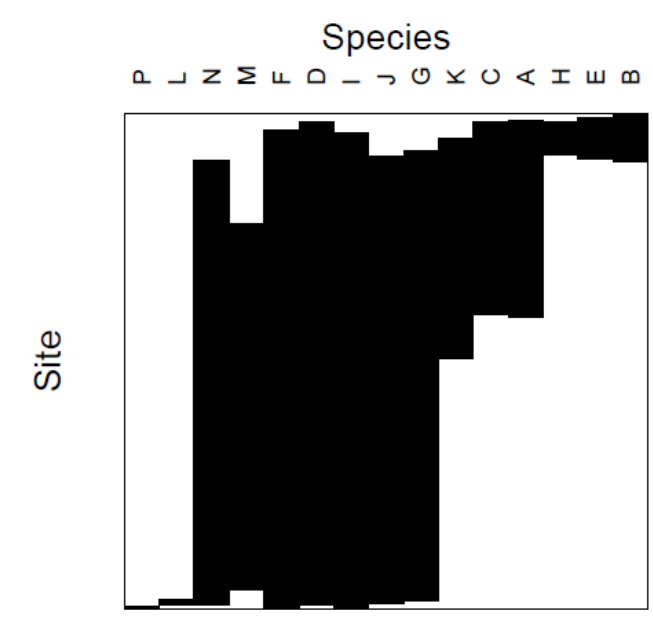

Plot A

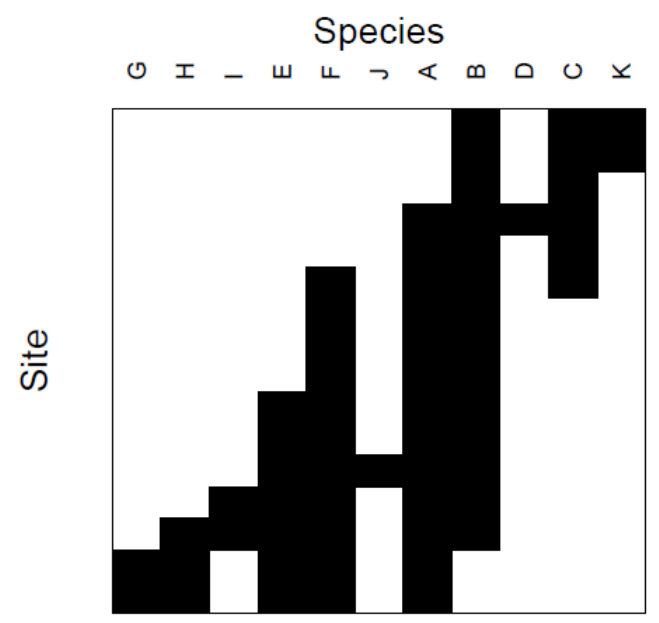


Plot B

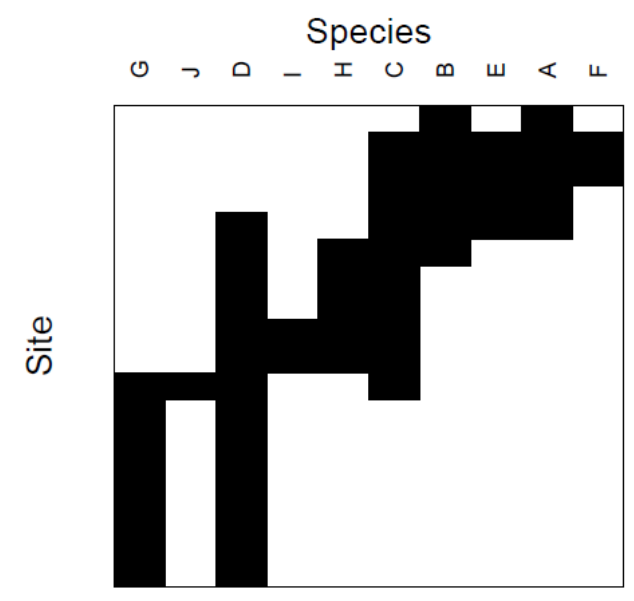

Plot C

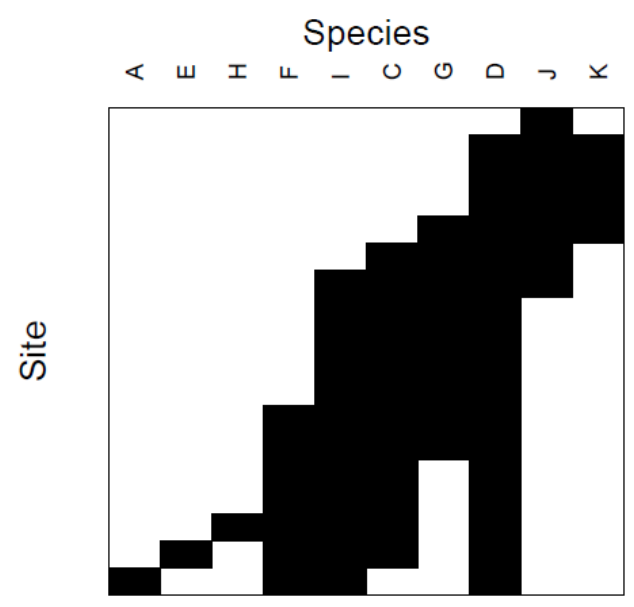

Plot D

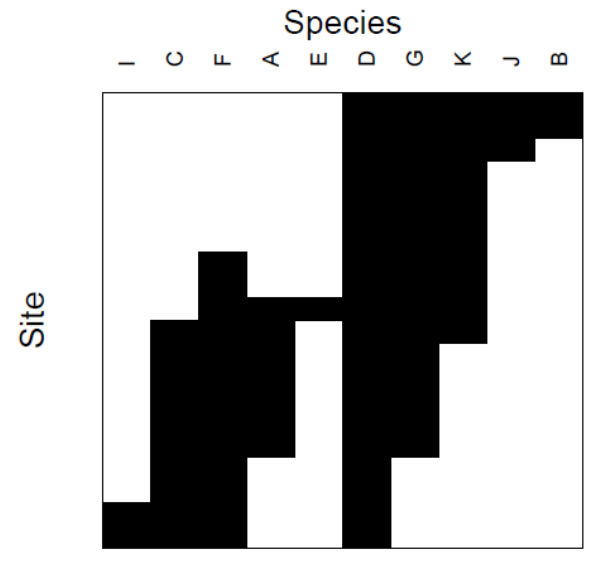

Plot E

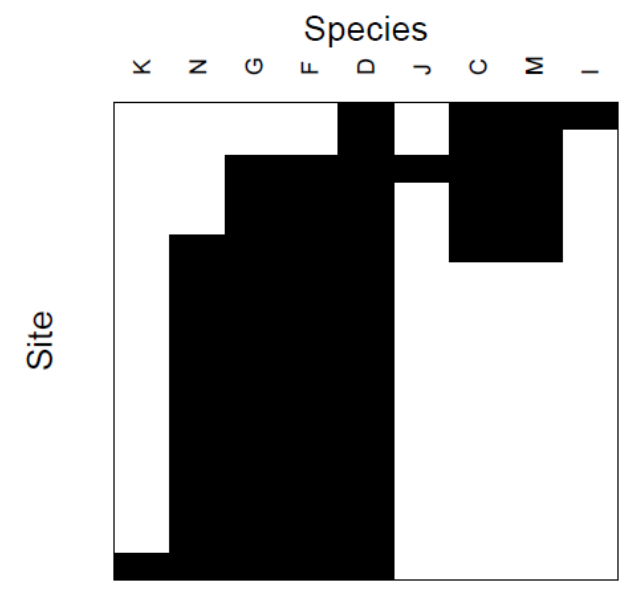


Plot F

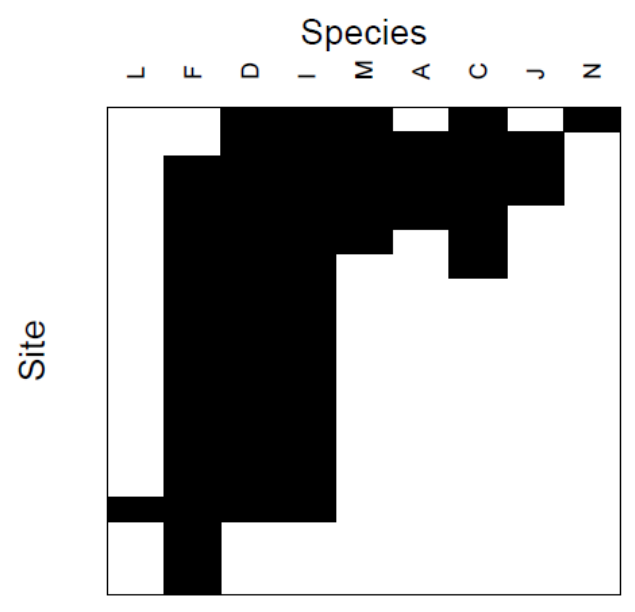

Plot G

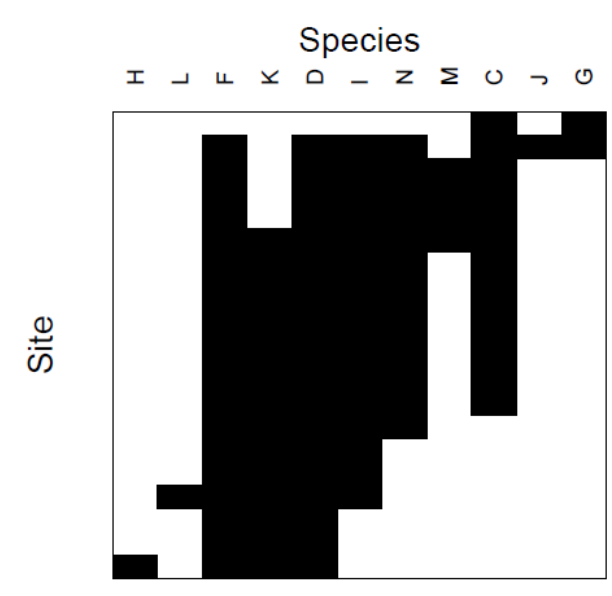

Plot $\mathrm{H}$

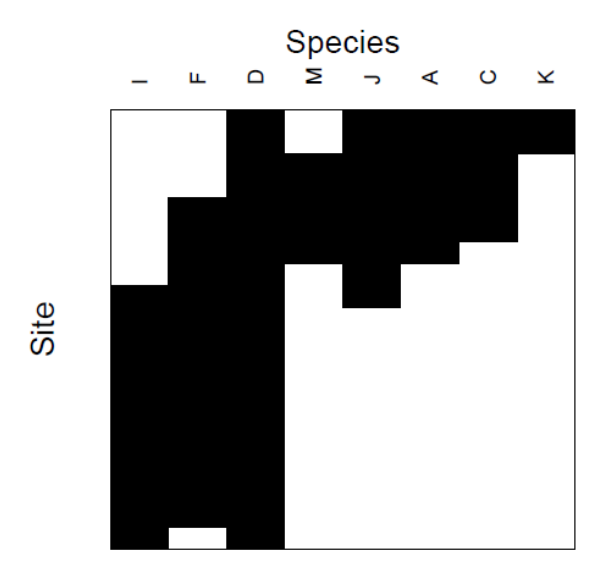

Plot I

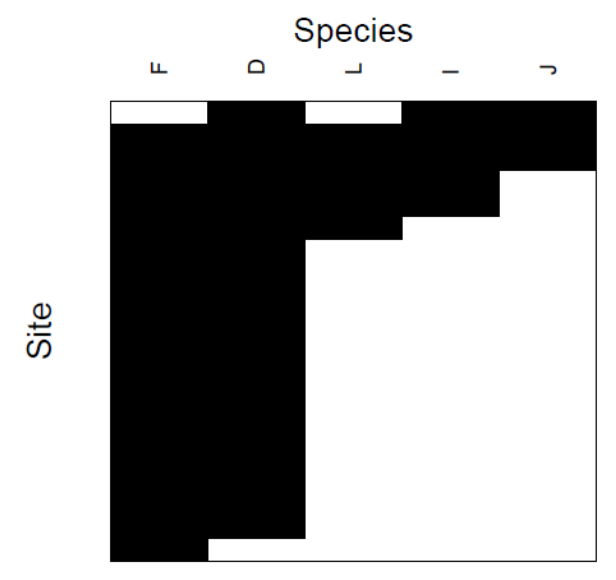


Plot J

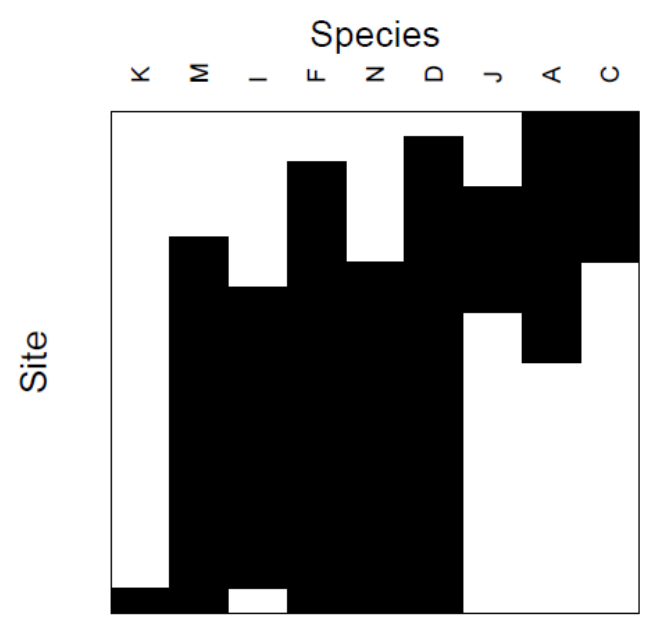

Plot K

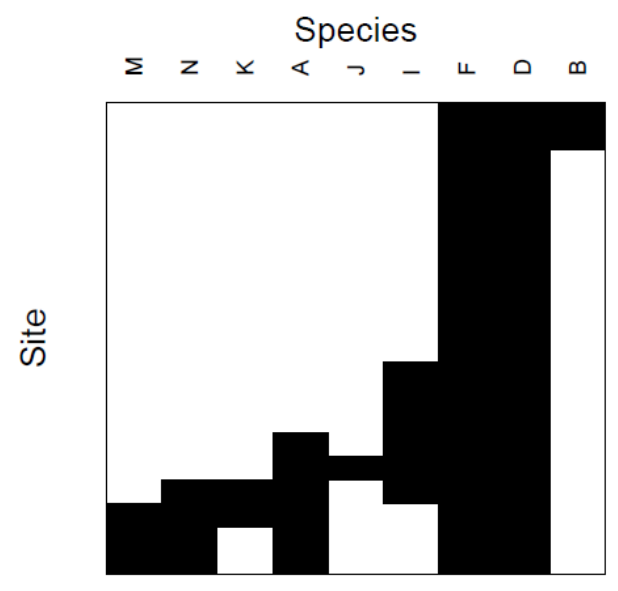

Plot L

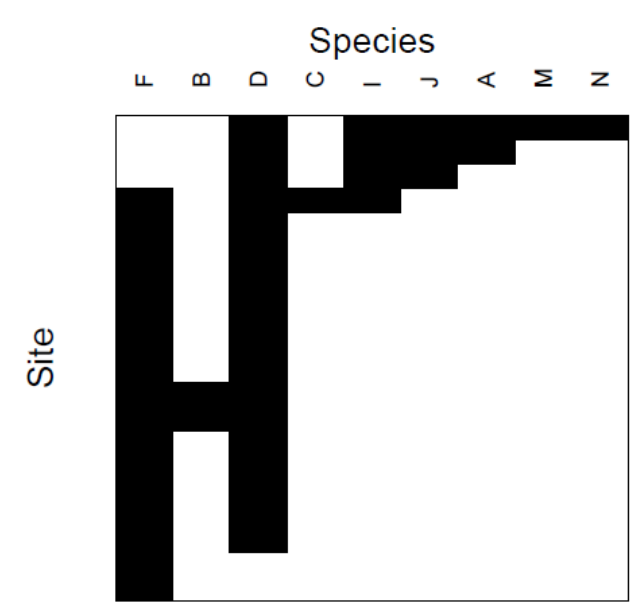

Plot M

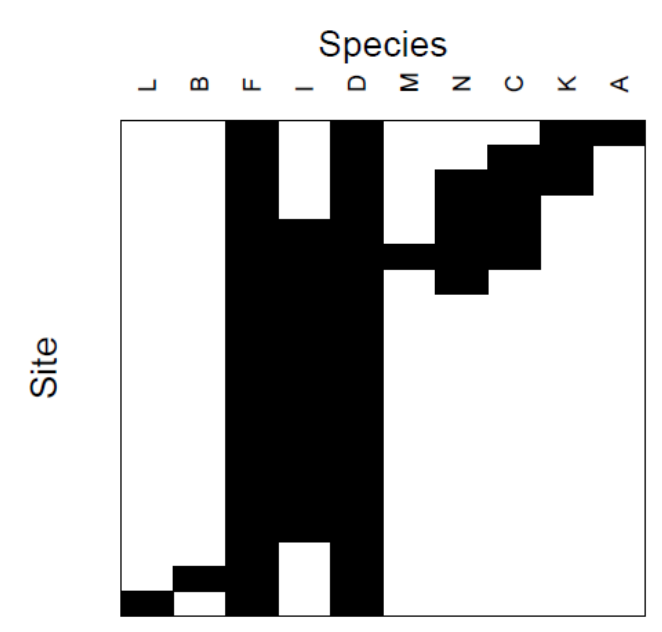


Plot N

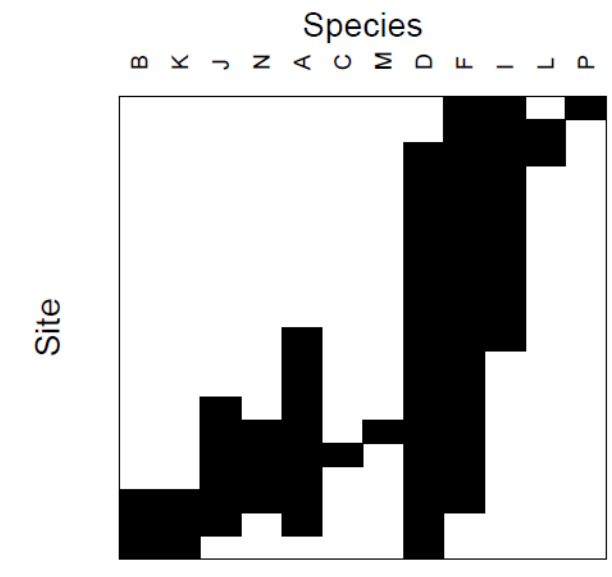

Plot

$\mathrm{O}$

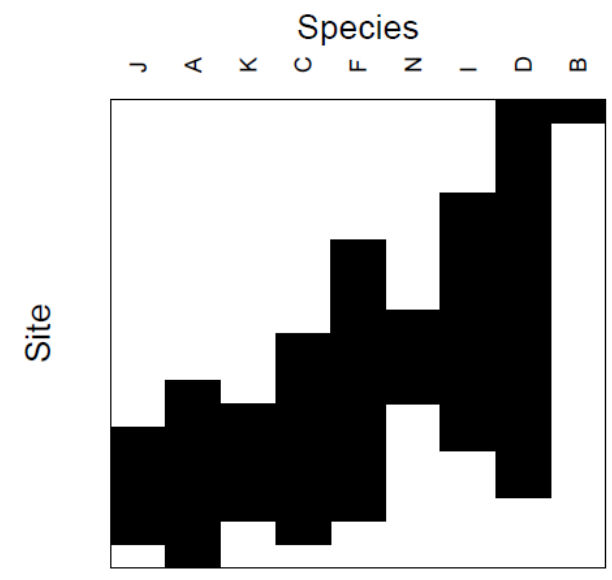

Plot P

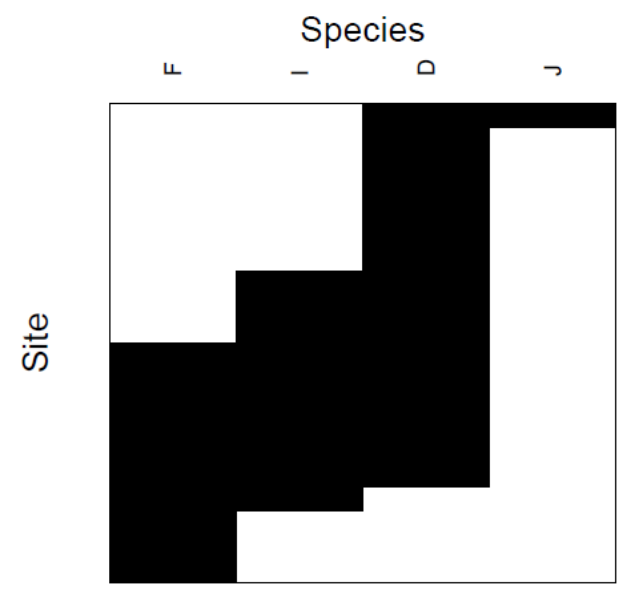

Plot Q

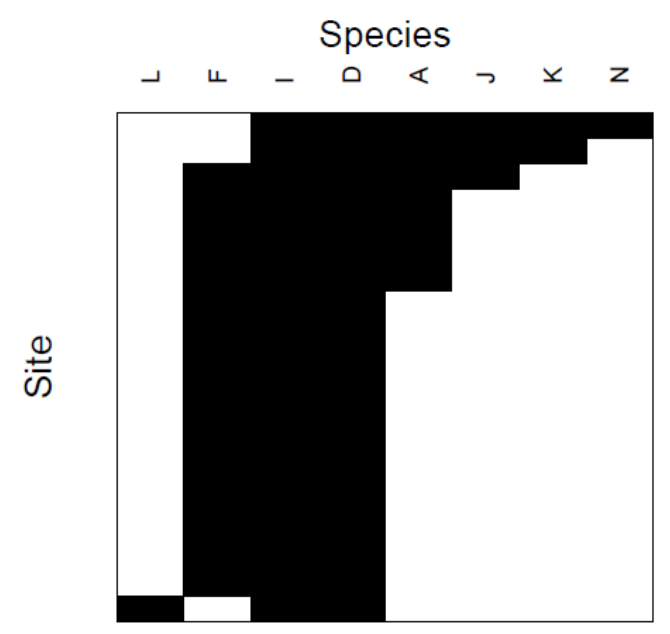


Plot R

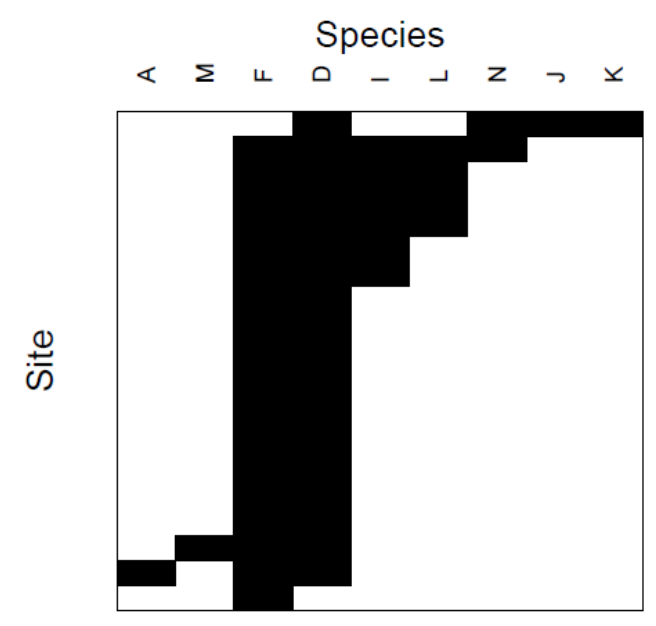

Plot T

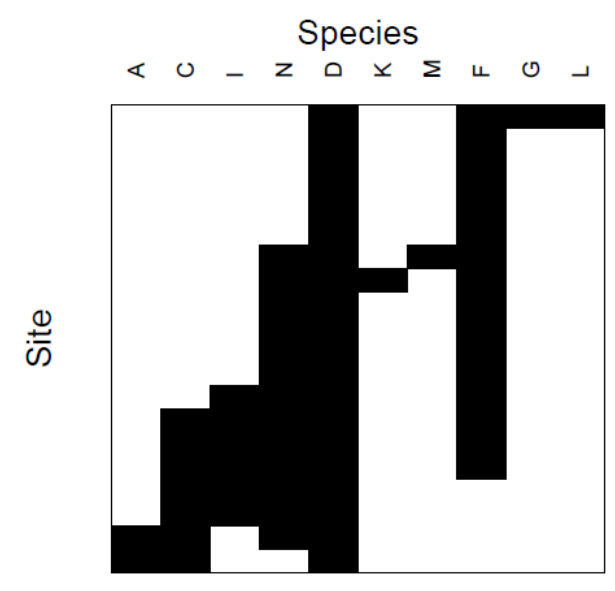

Plot S

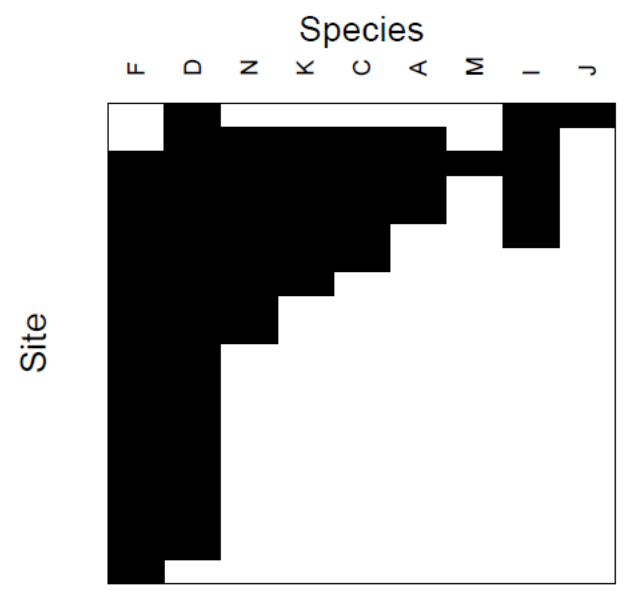


D3: Bryophytes found growing on the trunks of olivillo (Aextoxicon punctatum) trees in Parque Nacional Bosque Fray Jorge during our survey of metacommunity structure.

\begin{tabular}{|c|c|}
\hline \multirow[t]{8}{*}{ Liverworts } & Chiloscyphus aequifolius (Nees \& Mont.) Hässel (Lophocoleaceae) \\
\hline & $\begin{array}{l}\text { Chiloscyphus subbidentatus (Herzog) J.J. Engel \& R.M. Schust. } \\
\text { (Lophocoleaceae) }\end{array}$ \\
\hline & Metzgeria cf. decrescens Steph. (Metzgeriaceae) \\
\hline & Plagiochila subpectinata Besch. \& C. Massal. (Plagiochilaceae) \\
\hline & Frullania stipatiloba Steph. (Frullaniaceae) \\
\hline & Frullania reicheana Steph. (Frullaniaceae) \\
\hline & Radula decora Gottsche ex Steph. (Radulaceae) \\
\hline & Porella recurva (Taylor) Kuhnem. (Porellaceae) \\
\hline \multirow[t]{7}{*}{ Mosses } & \\
\hline & Pleurorthotrichum chilense Broth. (Orthotrichaceae) \\
\hline & Rigodium toxarion (Schwägr.) A. Jaeger (Rigodiaceae) \\
\hline & Brachythecium sp. (Brachytheciaceae) \\
\hline & Rhaphidorrhynchium callidum (Mont.) Broth. (Sematophyllaceae) \\
\hline & Weymouthia mollis (Hedw.) Broth. (Meteoriaceae) \\
\hline & Campylopus introflexus (Hedw.) Brid. (Leucobryaceae) \\
\hline
\end{tabular}


D4: Shannon's Diversity Index by latitude in the high compartment of sampled trees.

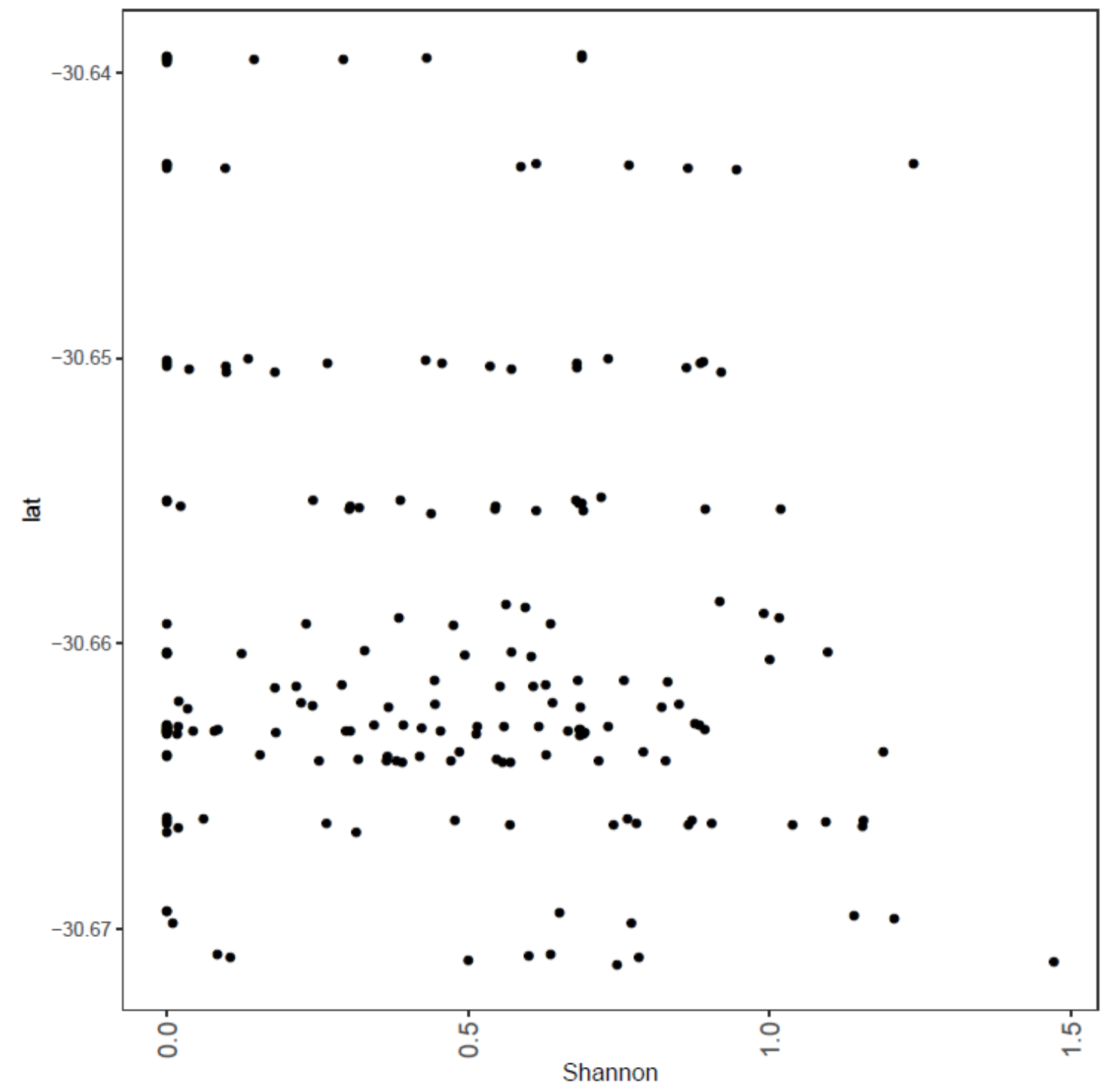


D5: Shannon's Diversity Index by longitude in the high compartment of sampled trees.

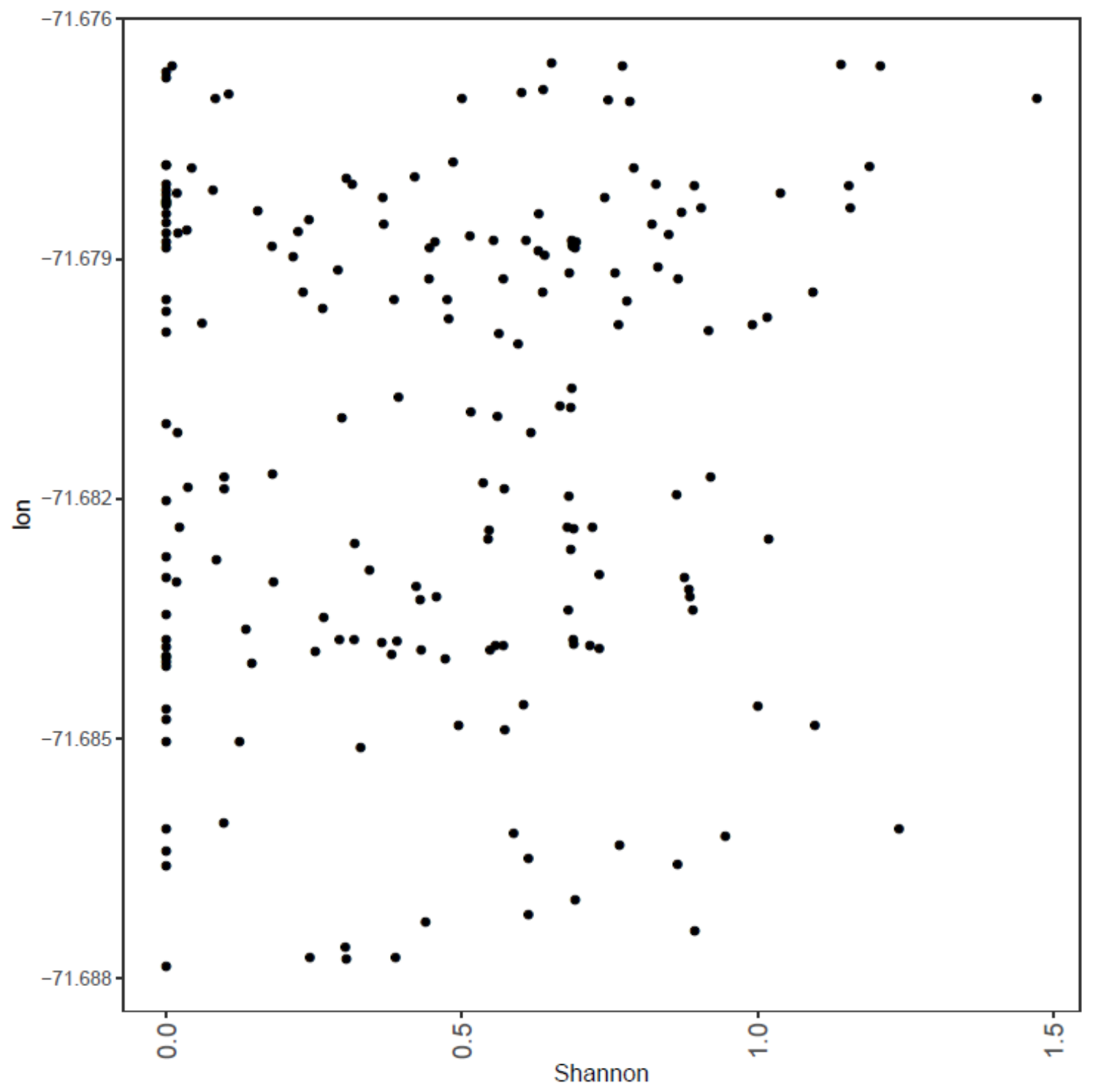


D6: Shannon's Diversity Index by latitude in the low compartment of sampled trees.

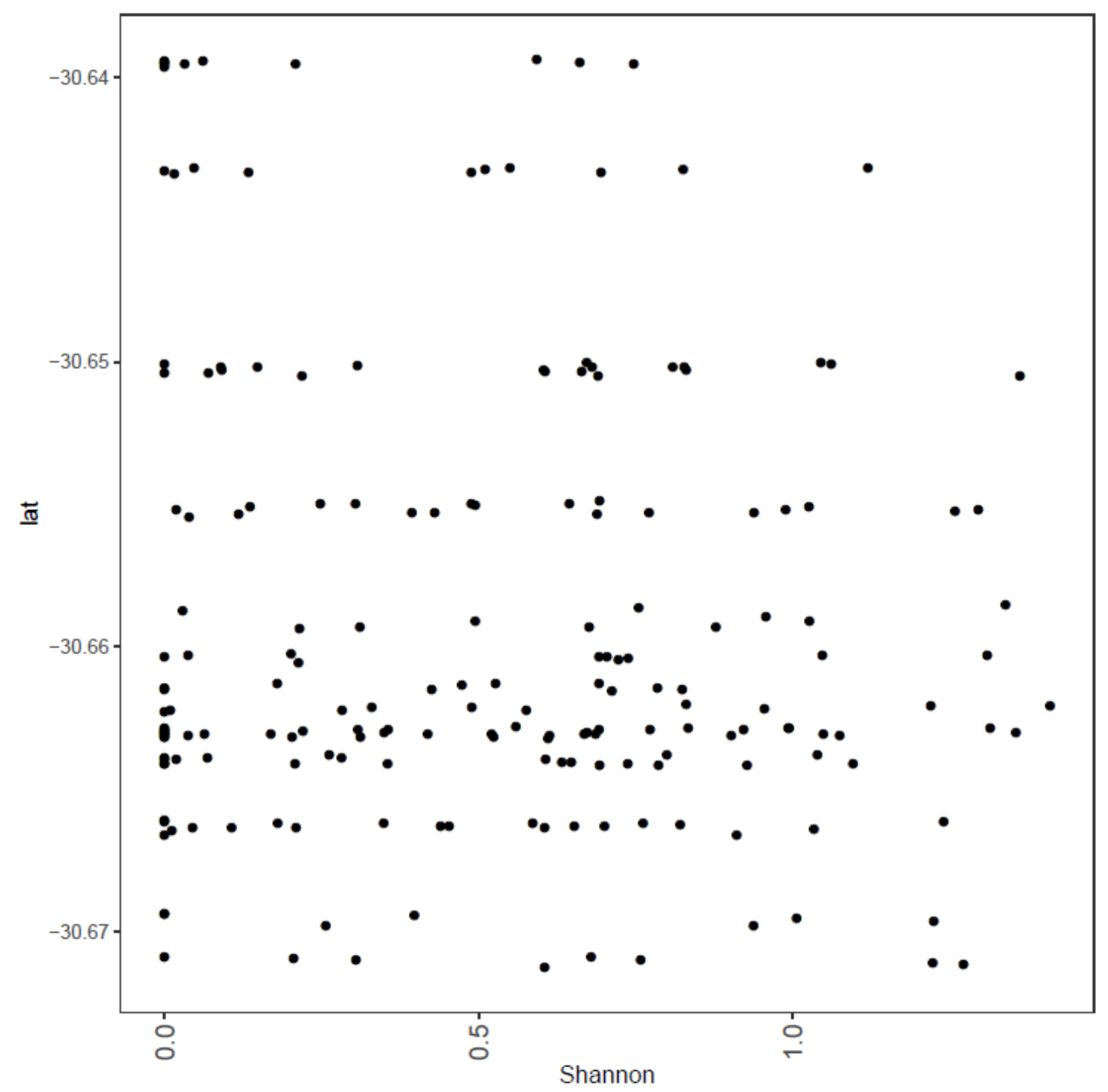


D7: Shannon's Diversity Index by longitude in the low compartment of sampled trees.

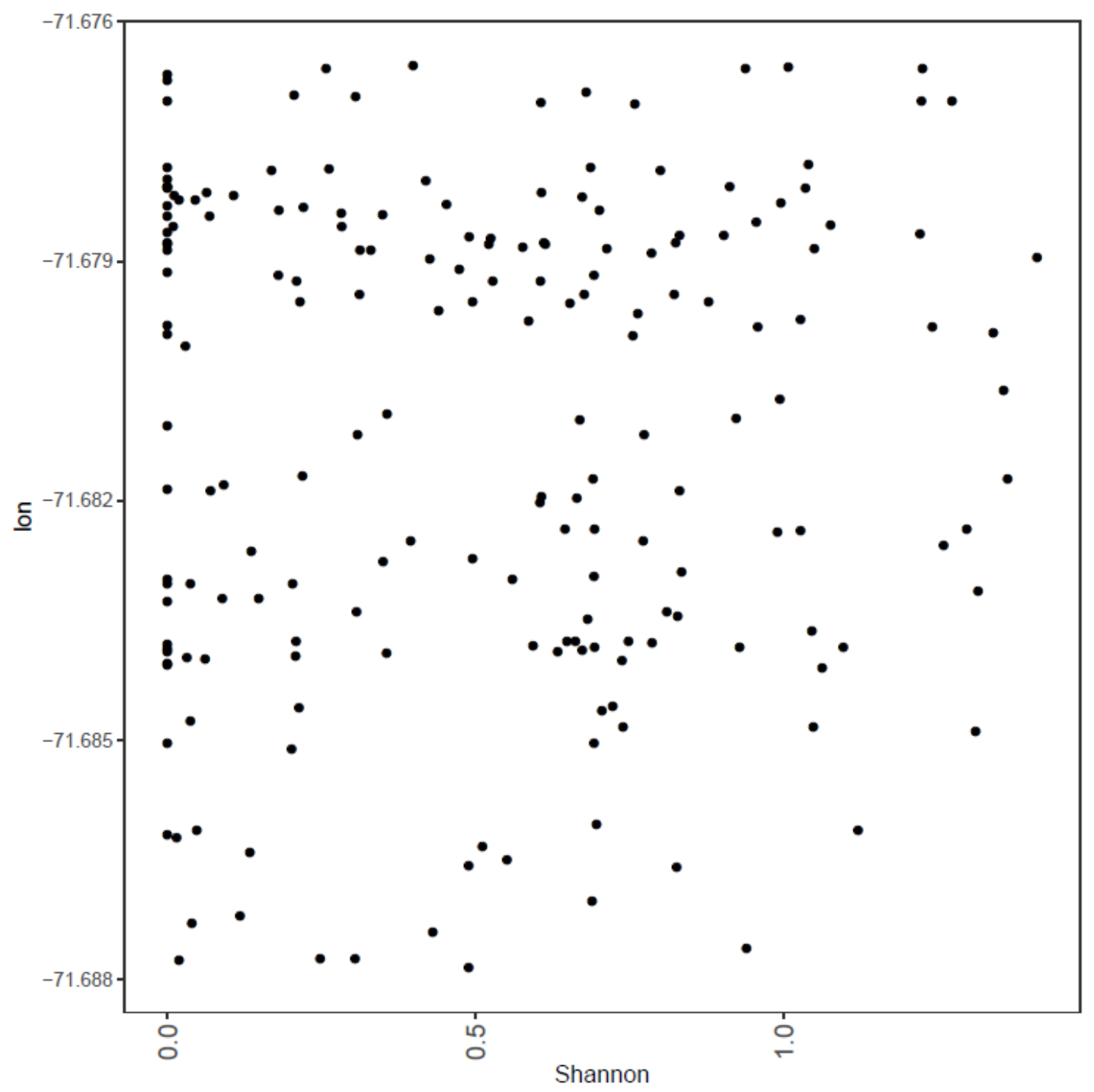


D8: Shannon's Diversity Index by height compartment. Low and high compartments did not differ significantly in diversity $(\mathrm{F}=2.27, \mathrm{p}=0.13)$.

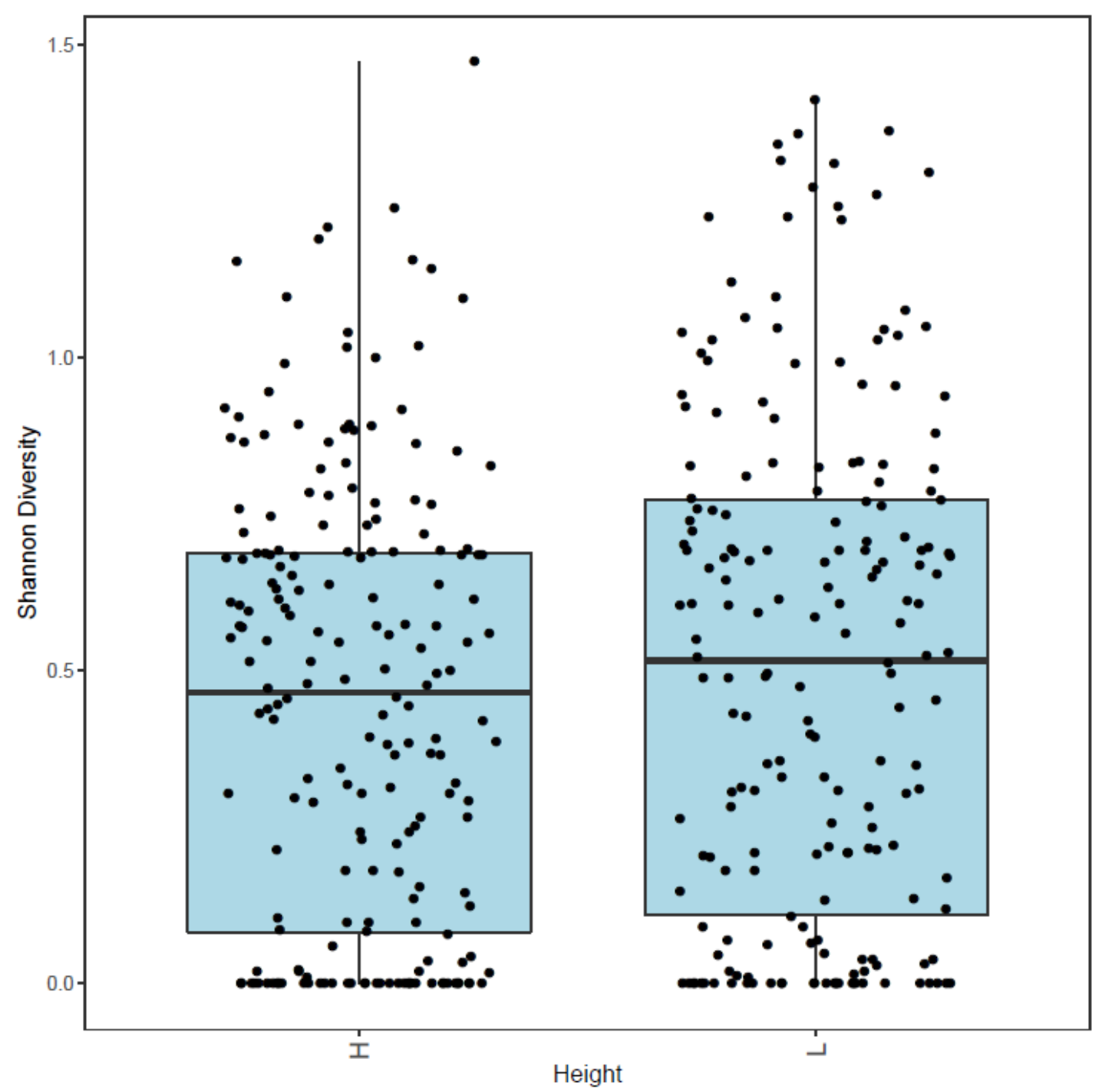

